\title{
Materials' Methods: NMR in Battery Research
}

\author{
Oliver Pecher,* Javier Carretero-González, Kent J. Griffith, and Clare P. Grey* \\ Department of Chemistry, University of Cambridge, Lensfield Road, Cambridge CB2 1EW, United Kingdom
}

\section{Supporting Information}

\begin{abstract}
Improving electrochemical energy storage is one of the major issues of our time. The search for new battery materials together with the drive to improve performance and lower cost of existing and new batteries is not without its challenges. Success in these matters is undoubtedly based on first understanding the underlying chemistries of the materials and the relations between the components involved. A combined application of experimental and theoretical techniques has proven to be a powerful strategy to gain insights into many of the questions that arise from the "how do batteries work and why do they fail” challenge. In this Review, we

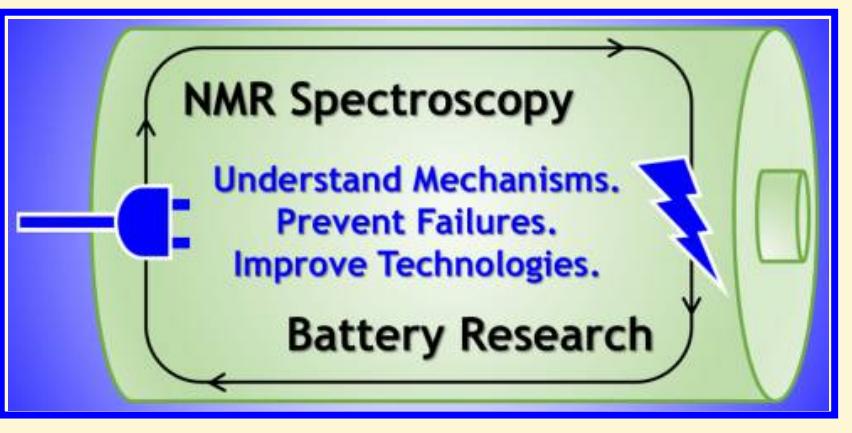
highlight the application of solid-state nuclear magnetic resonance (NMR) spectroscopy in battery research: a technique that can be extremely powerful in characterizing local structures in battery materials, even in highly disordered systems. An introduction on electrochemical energy storage illustrates the research aims and prospective approaches to reach these. We particularly address "NMR in battery research" by giving a brief introduction to electrochemical techniques and applications as well as background information on both in and ex situ solid-state NMR spectroscopy. We will try to answer the question "Is NMR suitable and how can it help me to solve my problem?" by shortly reviewing some of our recent research on electrodes, microstructure formation, electrolytes and interfaces, in which the application of NMR was helpful. Finally, we share hands-on experience directly from the lab bench to answer the fundamental question "Where and how should I start?" to help guide a researcher's way through the manifold possible approaches.
\end{abstract}

\section{INTRODUCTION}

At the Paris climate summit in December 2015, 195 countries agreed to set out a global action plan to put the world on track to avoid dangerous climate change by limiting global warming to well below $2{ }^{\circ} \mathrm{C}$. ${ }^{1}$ To achieve this goal, the launch of research programs based on the development of innovative and more efficient carbon-free technologies for the electrification of the grid and the automotive transportation in cities will be needed. Energy storage in secondary or rechargeable batteries is a versatile and lower-emission option to achieve the aforementioned goals. ${ }^{2}$ In the past decades, the research in secondary Liion batteries (LIBs) has been driven by the increasing demands of portable electronic devices. ${ }^{3,4}$ However, some disadvantages such as the loss of performance of the current battery materials during use ${ }^{5}$ as well as the presence of scarce and expensive metals (e.g., Co and $\mathrm{Ni}$ ) in the electrodes, flammable solvents, toxic and hazardous Li salts ${ }^{6}$ in the liquid electrolyte of the LIBs inside our laptops and mobile phones need to be solved. Moreover, the necessary increase of the gravimetric and volumetric energy density of next-generation batteries will be facilitated by using the correct chemical strategies to raise both the operation cell voltage and the capacity of the electrode materials. ${ }^{7,8}$ Therefore, alternative chemistries to Li-ion, the use of earth abundant precursors and the application of synthetic routes that are environmentally friendly during the preparation of the different battery components such as electrodes and electrolyte materials will be needed. ${ }^{9-11}$ Improving electro- chemical energy storage is one of the major sought-after issues of our time. The search for new battery materials together with the drive to improve performance and lower the cost of existing and new, more sustainable batteries is not without its challenges. Success in these matters requires first understanding the underlying chemistries of the materials and components involved by applying novel in situ testing and visualization techniques on functioning batteries. A combined application of experimental and theoretical techniques has shown high propensity to gain insights into many of the questions that arise from the "how do batteries work and why do they fail" challenge.

1.1. How do Batteries Work? A battery (Figure 1a) fundamentally consists of an anode and cathode (mixed ionic/ electronic conductors), electrolyte (ionic conductor), and external circuit (electronic conductor). As the battery is discharged, the anode (potential $\mu_{\mathrm{a}}$ ) is oxidized as electrons flow through the external circuit to reduce the cathode (potential $\mu_{\mathrm{c}}$ ). This redox reaction is enabled by the change of free energy $\Delta G$ expressed as the difference of the (electro)chemical potential of the two materials (redox pair);

Special Issue: Methods and Protocols in Materials Chemistry

Received: August 1, 2016

Revised: October 27, 2016

Published: October 27, 2016 


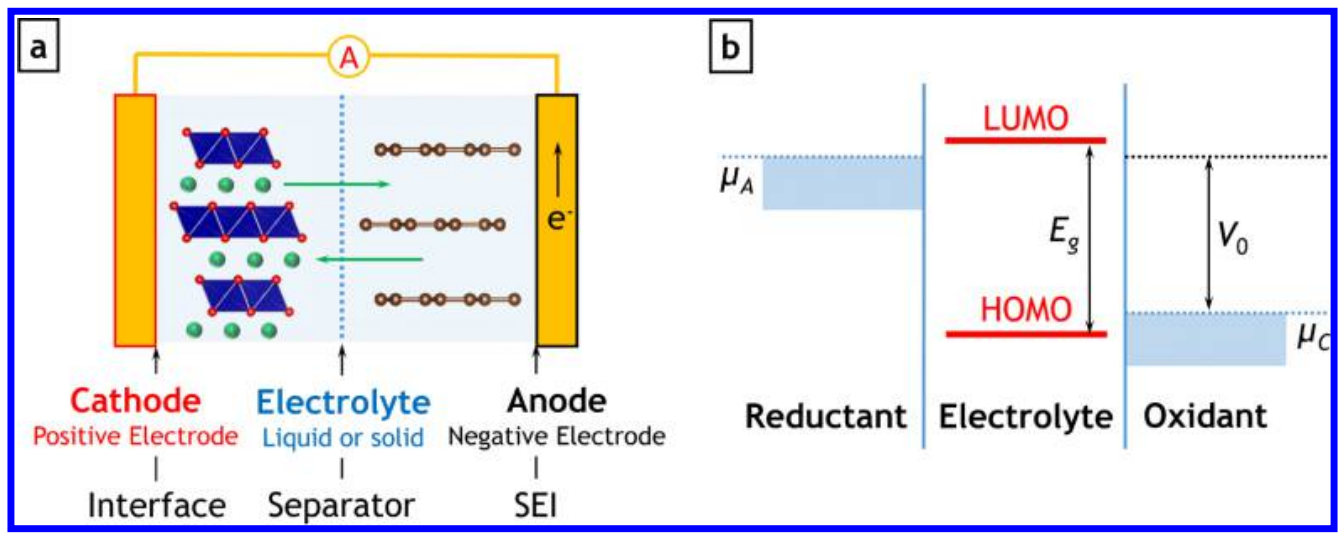

Figure 1. Complex systems. (a) A battery is a multicomponent device, which generally comprises a cathode, an anode, electrolyte, and the respective interfaces between the components. Upon discharge, cations are extracted from the anode (e.g., graphite), transported throughout the electrolyte, and intercalated into the cathode (e.g., a layered transition metal compound). While the ions move through the electrolyte, electrons flow through an external circuit from the anode to the cathode. This process is reversed on charge. (Note that in the Ni-Cd (NiCad) battery, anions (hydroxide ions) are extracted from the anode on charging, the hydroxide ions reacting with $\mathrm{Ni}(\mathrm{OH})_{2}$ at the cathode), (b) Relative energies of the electrolyte window $E_{\mathrm{g}}$ and the anode and cathode electrochemical potentials $\mu_{\mathrm{A}}$ and $\mu_{\mathrm{C}}$, respectively, representing electrode stability with respect to the electrolyte electronic energy levels.

thus the energy from each electron is $\mu_{\mathrm{a}}-\mu_{\mathrm{c}}=V_{0}$ (Figure $1 \mathrm{~b}$ ). To retain charge neutrality, the electron transfer is accompanied by a flow of cations from the anode to the cathode. In the absence of an applied voltage, the chemical potential $(\mu)$ and electrochemical potential $(\bar{\mu})$ are equivalent; however, to reverse the reaction, a potential is applied and the relevant thermodynamic quantity becomes $\bar{\mu}=\mu+z \mathrm{~F} \phi$ where $z$ is the ionic charge, $F$ is Faraday's constant, and $\phi$ is the applied potential.

The phenomenon of reversible electrochemical intercalation of alkali ions into host crystal structures (e.g., bronzes, graphite) was introduced in the 1970 s. $^{12,13}$ This generally involves the participation of a single ionic species that goes back and forth between the host structures of the electrodes, in principle with no significant structural rearrangement of the host materials during charge and discharge. Furthermore, it established a basis with which to develop the first generation of rechargeable or secondary batteries such as those presently commercialized based on Li-ion or "rocking chair" technology (Figure 1a). ${ }^{14}$

The scientific community has expended an enormous effort in the search for new electrode and electrolyte materials toward the goal of enhancing the amount of energy stored in electrochemical cells. The energy density of a battery is determined by the product of the equilibrium voltage $\left(V_{0}\right)$ of the electrochemical cell and the capacity $(Q)$ of reversible charge transfer between the anode and the cathode per unit weight $\left(\mathrm{A} \cdot \mathrm{h} \cdot \mathrm{g}^{-1}\right.$, gravimetric energy density) or unit volume (A. $\mathrm{h} \cdot \mathrm{cm}^{-3}$, volumetric energy density) (Section 2). Hence, maximization of $Q$ and $V_{0}$ by choosing chemical redox couples of lightweight elements with dense particle morphologies and large electronegativity differences, respectively, is pursued. The resulting secondary batteries are complex systems with anodes, cathodes, and electrolytes (Figure 1a) that are constantly undergoing structural and chemical changes during operation. Finding the best-performing combination of these three components can only be achieved through the selective use of existing and new electrode materials and of the right electrolyte combination so as to minimize detrimental reactions associated with the electrode-electrolyte interface, a critical component of any electrochemical system. ${ }^{3}$
1.1.1. Anodes. Lithium is the most desired anode (i.e., negative electrode) material for high energy density batteries because it has the most negative available electrode potential $(-3.04 \mathrm{~V} \text { vs the standard hydrogen electrode, SHE })^{15}$ and is the lightest metal of the periodic table (theoretical gravimetric and volumetric capacities of $\mathrm{Li}$ metal: $3.86 \mathrm{~A} \cdot \mathrm{h} \cdot \mathrm{g}^{-1}$ and $2.12 \mathrm{~A}$. $\left.\mathrm{h} \cdot \mathrm{cm}^{-3}\right)$. Moreover, $\mathrm{Li}$ can act as its own current collector, without the need for heavy, expensive $\mathrm{Cu}$. However, upon replating during charge, the metal has a proclivity to form dendrites with consequent risk of short circuit and thermal runaway. Moreover, alkali metals are unstable toward essentially all electrolytes, reacting with both organic solvents and inorganic salts used as electrolyte in the battery. This reaction is associated with the formation of a solid-electrolyte interphase (SEI): a protective and nanostructured, ionconductive, thin, inorganic/organic (polymeric) composite layer, with a variable composition and disordered structure that forms on the anode materials. Long-term operation of the battery relies on the formation of a stable SEI during the first few conditioning cycles, which prevents the electrolyte from further breakdown, concomitant consumption of $\mathrm{Li}$ (to form $\mathrm{Li}$ salts in the SEI), and continued increase in cell resistance (see Section 1.1.3). It has not, to date, been possible to identify a failure-proof electrolyte that prevents dendrite formation and allows for the formation of a stable SEI.

Because of the safety issues with lithium metal, most commercial lithium-ion batteries use a highly graphitic carbon as the anode material. Graphite reversibly intercalates $\mathrm{Li}$ to form $\mathrm{LiC}_{6}$; most of the theoretical capacity of $372 \mathrm{~mA} \cdot \mathrm{h} \cdot \mathrm{g}^{-1}$ is achieved from approximately $250-50 \mathrm{mV}$ vs $\mathrm{Li}^{14}{ }^{14}$ Considerable work has been undertaken to identify anode materials with higher theoretical capacities, prospective candidates including $\mathrm{Si}$ (theoretical gravimetric capacity: $3.572 \mathrm{~A} \cdot \mathrm{h} \cdot \mathrm{g}^{-1}$ ), ${ }^{16,17} \mathrm{P}$ (theoretical gravimetric capacity: $2.596 \mathrm{~A} \cdot \mathrm{h} \cdot \mathrm{g}^{-1}$ ), ${ }^{18,19}$ and metal phosphides, ${ }^{20} \mathrm{Sn}$ and $\mathrm{Sn}-\mathrm{O}$ composites, ${ }^{21} \mathrm{Sb}$ and intermetallic compounds such as $\mathrm{Cu}_{6} \mathrm{Sn}_{5}$ and $\mathrm{Cu}_{2} \mathrm{Sb}$ that form metal alloys. ${ }^{22,23}$ Problems associated with these metal alloys include the large volume changes ( $2300 \%$ for $\mathrm{Si})$ during discharge and charge. These volumetric changes result in particle fracture (pulverization) causing continuous electrolyte decomposition (due to the exposure of fresh surfaces and 
destruction and subsequent reformation of the SEI due to expansion/contraction); the formation of dead, nonelectrically connected particles; and delamination from the current collector. The net effect of these factors is poor long-term cyclability and large irreversible capacity loss during the first cycle. Structural and chemical investigations of these anodes during electrochemical cycling seek a better understanding of those parameters limiting capacity as well as other failure mechanisms. With this knowledge, scientists will design new materials and electrode engineering strategies to improve the performance and also mitigate the degradation processes of these high-capacity anode materials.

Concerns with possible $\mathrm{Li}$-deposition on graphite, particularly at high rates, have motivated studies to investigate safer anode materials that operate at higher voltages (especially for high-power applications). SEI formation is also generally thought to be significantly decreased (though not eliminated) for these "high-voltage anodes", which typically operate with lower limits of $1.0 \mathrm{~V}$ vs $\mathrm{Li}^{+} / \mathrm{Li}$. This material class has been dominated by research into spinel $\mathrm{Li}_{4} \mathrm{Ti}_{5} \mathrm{O}_{12}$, which reversibly intercalates about $150 \mathrm{~mA} \cdot \mathrm{h} \cdot \mathrm{g}^{-1}$ at $1.55 \mathrm{~V}$ at high rates for thousands of cycles, ${ }^{24}$ but novel materials with improved capacity, stability, and/or ease-of-synthesis are under investigation, including materials such as $\mathrm{TiO}_{2}-\mathrm{B},{ }^{25} \mathrm{~T}-\mathrm{Nb}_{2} \mathrm{O}_{5},{ }^{26}$ and $\mathrm{TiNb}_{2} \mathrm{O}_{7}{ }^{27}$ based on the $\mathrm{Ti}^{4+/ 3+}$ and $\mathrm{Nb}^{5+/ 4+}$ redox couples.

1.1.2. Cathodes. The "rules" determining the electrochemical potential of high-voltage cathode (i.e., positive electrode) materials are the same as their negative counterparts. Prior and present positive electrode materials contain cations of transition metals such as $\mathrm{Ti}, \mathrm{Co}, \mathrm{Ni}, \mathrm{V}, \mathrm{Mn}$, and $\mathrm{Fe}$, among others. The tailoring of the redox potential will depend on the formal valence of the cation and the covalent component of its neighboring bonding atoms, commonly sulfur or oxygen. This latter component is also influenced by the presence and nature of any countercation as well as by the crystal structure (ionic component). ${ }^{8}$ The first Li-ion intercalation cathodes were layered structures based on chalcogenide-group elements, e.g., $\mathrm{TiS}_{2}\left(2.3 \mathrm{~V} \mathrm{vs}^{+} / \mathrm{Li}\right)$. In the $1980 \mathrm{~s}$, metal oxides with twodimensional (2D) structures such as $\mathrm{Li}_{x} \mathrm{MO}_{2}$ (where $\mathrm{M}$ is Co, $\mathrm{Ni}$ or $\mathrm{Mn}$ ) exhibiting higher intercalation voltages (ca. $4.0 \mathrm{~V}$ vs $\mathrm{Li}^{+} / \mathrm{Li} ; \mathrm{M}-\mathrm{O}$ bonds possess higher ionic character than $\mathrm{M}-\mathrm{S}$ bonds) gained interest and led to the commercialization of a $\mathrm{LiCoO}_{2}$-carbon cell $\left(3.6 \mathrm{~V}_{\text {vs }} \mathrm{Li}^{+} / \mathrm{Li}\right)$ by Sony in $1991 .{ }^{14}$ In the search for new cathodes, three-dimensional (3D) spinel structures with interstitial spaces for Li-ion insertion were also developed. ${ }^{28}$ In general, cathodes based on the spinel structure such as $\mathrm{LiMn}_{2} \mathrm{O}_{4}$ exhibit moderately high-voltages $(\geq 4 \mathrm{~V}$ vs $\mathrm{Li}^{+} / \mathrm{Li}$ ), high $\mathrm{Li}^{+}$mobility (leading to high-power batteries) and low volumetric changes during charge and discharge cycles. In practice, compositions closer to $\mathrm{Li}_{1.05} \mathrm{Mn}_{1.95} \mathrm{O}_{4}$ are used, so as to prevent the Jahn-Teller distortion that occurs in stoichiometric $\mathrm{LiMn}_{2} \mathrm{O}_{4}$ when additional $\mathrm{Li}$ is inserted into the structure. One mode of battery failure of these $\mathrm{LiMn}_{2} \mathrm{O}_{4}$-based cathodes involves dissolution of $\mathrm{Mn}$ from the cathode/electrolyte interface due to the disproportionation reaction of $\mathrm{Mn}^{3+}$ and the subsequent deposition of $\mathrm{Mn}^{2+}$ and $\mathrm{Mn}$ on the anode. Strategies to suppress $\mathrm{Mn}$ dissolution include chemical doping $^{29}$ and the coating of the surface of the spinel cathode material. ${ }^{30}$ In the late $1990 \mathrm{~s}$, the discovery of one-dimensional (1D) Li-ion conductivity in olivine-type $\mathrm{LiFePO}_{4}$ initiated a revolution in the battery field. $\mathrm{LiFePO}_{4}$ is low cost, nontoxic and it is synthesized from abundant material sources. ${ }^{31}$ Moreover, $\mathrm{LiFePO}_{4}$ has a moderate operation voltage $(3.4 \mathrm{~V}$ vs $\mathrm{Li}^{+} / \mathrm{Li}$ ) in the electrolyte stability window, a capacity of approximately $170 \mathrm{~mA} \cdot \mathrm{h} \cdot \mathrm{g}^{-1}$ and high-rate capabilities when combined with carbon additives. Polyoxyanionic-type structures with $\mathrm{XO}_{4}{ }^{n-}$ entities are interesting because a significant increase in the potential of the metal redox couple can be achieved by changing the nature of the countercation in the polyanion (i.e., $\mathrm{SO}_{4}{ }^{2-}$ instead of $\mathrm{PO}_{4}{ }^{3-}$ ) and by introducing electron withdrawing halogen atoms in the crystal structure (inductive effect). ${ }^{32,33}$

Increasing the energy in cathode materials is extremely challenging. Among the different ways to activate (i.e., allow reversible reaction with $\mathrm{Li}$ ) a wider range of electrode materials in the pursuit of higher energy densities, we highlight three approaches. The first one involves the use of higher voltage cathode materials, for example, (i) using the spinel $\mathrm{LiNi}_{0.5} \mathrm{Mn}_{1.5} \mathrm{O}_{4}$ in place of $\mathrm{LiMn}_{2} \mathrm{O}_{4}$, raising the operating voltage to ca. $4.7 \mathrm{~V}$ vs $\mathrm{Li}^{+} / \mathrm{Li}^{34}$ or (ii) operating presently used materials $\left(\mathrm{LiCoO}_{2}, \mathrm{Li}\left(\mathrm{Ni}_{1 / 3} \mathrm{Mn}_{1 / 3} \mathrm{Co}_{1 / 3}\right) \mathrm{O}_{2}\right.$ (NMC)) over larger voltage windows (i.e., removing more lithium). This has two major problems, namely electrolyte decomposition and possible oxygen loss from the highly oxidized (metastable) phases and consequent safety concerns. The second approach we will discuss involves the design of electrodes in which the oxidation state of the transition metal reversibly changes by more than one unit during charge-discharge. One example of this is the reversible electrochemical reaction of $\mathrm{Li}$ with transition metal oxides, sulfides and fluorides forming nanoparticles of the metal $\left(\mathrm{M}_{a} \mathrm{X}_{b}+(b \cdot n) \cdot \mathrm{Li} \leftrightarrow a \cdot \mathrm{M}+b \cdot \mathrm{Li}_{n} \mathrm{X}\right)$, a class of reactions that are associated with very high capacities. These are known as conversion reactions as the original host materials completely transform on lithiation. Reversibility of these reactions is enabled by the formation of high-surface area electrically connected metal nanoparticles, which coat the insulating metal salts. ${ }^{35}$ Considerable work has been performed to understand the underlying reaction mechanisms during operation, aiming to reduce the large voltage hysteresis and often large Coulombic inefficiency associated with SEI/salt formation. $^{36,37}$ The large voltage hysteresis is at least in part caused by the differential mobilities of the various components involved in the reaction (e.g., $\mathrm{Fe}, \mathrm{Fe}^{2+}, \mathrm{Fe}^{3+}$, and $\mathrm{F}^{-}$in $\mathrm{FeF}_{2}$ ), and the most promising results have been obtained for materials with either polarizing anions or materials that are capable of both conversion and intercalation. Another example of a multi redox state cathode is $\mathrm{Li}_{x} \mathrm{VOPO}_{4} \cdot{ }^{38}$ Because of the stability of several redox states for vanadium, cycling is possible

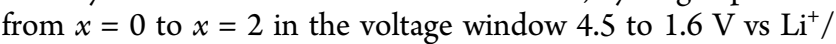
Li. A third approach is to use high surface area (nanostructured) electroactive materials, often coated or mixed intimately with carbon, activating materials that might not otherwise be sufficiently ionically and electronically conducting to react with $\mathrm{Li}$. Furthermore, the shorter particle dimensions usually increase rate performance and, in some materials, suppress the structural transformations that can be detrimental to both rate and capacity. However, the presence of high surface area also has some disadvantages because there is a higher likelihood of side reactions with the electrolyte. Another disadvantage of nanoparticles is the significantly reduced volumetric energy density of the total electrode (due to low packing density), which is particularly relevant to spatially confined applications such as portable electronics and compact electric vehicles.

1.1.3. Electrolyte. Among the properties that the electrolyte must ideally have are the following: large electrolyte/electro- 
Table 1. Selection of Experimental Techniques and Their Commonly Used Acronyms (italics) along with Some Information That Can Be Derived by Applying These Techniques to Battery Materials

\begin{tabular}{|c|c|}
\hline Technique & Acronyms and information \\
\hline \multirow{6}{*}{$\begin{array}{l}\text { X-ray and neutron } \\
\text { diffraction and total } \\
\text { scattering }\end{array}$} & single crystal $7^{73}$ and powder X-ray diffraction $(X R D)^{74,75}$ and neutron diffraction $(N D)^{76}$ \\
\hline & $\begin{array}{l}\text { qualitative and quantitative phase analysis, atomic coordinates, lattice parameters, interatomic distances, occupancy of atomic positons; } \\
\text { suitable for crystalline materials }\end{array}$ \\
\hline & pair distribution function $(P D F)^{22}$ \\
\hline & interatomic distances, crystal structure; suitable for crystalline and amorphous materials \\
\hline & small-angle X-ray scattering (SAXS), ${ }^{77,78}$ small angle neutron scattering $(S A N S)^{79}$ \\
\hline & mesoscopic structure, particle size and distribution; suitable for crystalline and amorphous materials \\
\hline \multirow{2}{*}{$\begin{array}{l}\text { Thermoanalytical } \\
\text { investigations }\end{array}$} & differential thermal analysis (DTA), ${ }^{80}$ differential scanning calorimetry (DSC), thermogravimetric analysis (TGA) \\
\hline & $\begin{array}{l}\text { characteristic temperatures (phase transformation, melting, decomposition), caloric information (reaction enthalpies, specific heat } \\
\text { capacities) }\end{array}$ \\
\hline \multirow[t]{2}{*}{ Chemical analysis } & $\begin{array}{l}\text { inductively coupled plasma optical emission spectrometry (ICP-OES), inductively coupled plasma mass spectrometry (ICP-MS), laser ablation } \\
\text { inductively coupled plasma mass spectrometry (LA-ICP-MS), energy/wavelength-dispersive X-ray spectroscopy (EDX/WDX) }\end{array}$ \\
\hline & quantitative elemental analysis, a check for impurities, spatially resolved determination of chemical compositions \\
\hline \multirow[t]{2}{*}{ Microscopy } & $\begin{array}{l}\text { atomic force microscopy }(\mathrm{AFM}),{ }^{81} \text { scanning electron microscopy (SEM), [scanning] transmission electron microscopy }\left([S] \text { TEM) }{ }^{82-84} \text { scanning }\right. \\
\text { tunneling microscopy }(\mathrm{STM}){ }^{85}\end{array}$ \\
\hline & $\begin{array}{l}\text { high-resolution and imaging techniques for particles sizes and distributions, structure analysis, superstructure formation, order-disorder } \\
\text { phenomena, crystal structure refinements from precision electron scattering }\end{array}$ \\
\hline \multirow{2}{*}{$\begin{array}{l}\text { X-ray and neutron } \\
\text { tomography }\end{array}$} & X-ray computed tomography $(X C T),{ }^{86}$ neutron computed tomography $(\mathrm{NCT})^{87}$ \\
\hline & microstructure, porosity, phase separation, particle fracture, delamination, thermal runaway processes ${ }^{88}$ \\
\hline $\begin{array}{l}\text { Neutron and muon } \\
\text { spectroscopy }\end{array}$ & $\begin{array}{l}\text { Inelastic neutron scattering (INS), }{ }^{89} \text { quasielastic neutron scattering (QENS), }{ }^{90} \text { muon spin relaxation spectroscopy }\left(\mu^{+}-S R\right)^{91,92} \\
\text { solid-state dynamics on a macroscopic scale }\end{array}$ \\
\hline \multirow{2}{*}{$\begin{array}{l}\text { X-ray absorption } \\
\text { spectroscopy }\end{array}$} & $X$-ray absorption near-edge structure (XANES) $)^{93,94}$ and extended X-ray absorption fine structure (EXAFS) ${ }^{95}$ \\
\hline & $\begin{array}{l}\text { compound identification and quantification, electronic structure, oxidation states, symmetry, and solid-solution vs biphasic mechanisms } \\
\text { (XANES); local environments of the absorbing elements (EXAFS) }\end{array}$ \\
\hline \multirow[t]{2}{*}{ Surface techniques } & $\begin{array}{l}\text { X-ray photoelectron spectroscopy (XPS), }{ }^{96} \text { total electron yield X-ray absorption spectroscopy (TEY-XAS), time-of-flight secondary ion mass } \\
\text { spectrometry }\left(\text { TOF-SIMS), }{ }^{97} \text { low-energy ion scattering (LEIS), }{ }^{98} \text { medium-energy ion scattering }(M E I S),{ }^{99} \text { electron energy loss spectroscopy }\right. \\
(E E L S)^{100-12}\end{array}$ \\
\hline & $\begin{array}{l}\text { surface properties: composition and oxidation states, bonding environment, (spatially resolved) quantitative surface analysis, single atomic } \\
\text { layer selectivity (LEIS), surface structure, ion distributions and phase identification }\end{array}$ \\
\hline \multirow{2}{*}{$\begin{array}{l}\text { Mössbauer and EPR } \\
\text { spectroscopy }\end{array}$} & Mössbauer, ${ }^{103}$ electron paramagnetic resonance $(E P R)^{104}$ \\
\hline & oxidation states, local symmetry, bonding characteristics, magnetic interactions \\
\hline \multirow{2}{*}{$\begin{array}{l}\text { NMR and NQR } \\
\text { spectroscopy, MRI }\end{array}$} & nuclear magnetic resonance (NMR), nuclear quadrupole resonance (NQR), magnetic resonance imaging $(M R I)^{105}$ \\
\hline & quantitative species identification, atomic connectivity, local symmetry, electric field gradients, interatomic distances, dynamics \\
\hline \multirow[t]{4}{*}{ Other } & $\begin{array}{l}\text { electrochemical quartz crystal microbalance (EQCM) })^{106,107} \text { electrical conductivity measurements, }{ }^{108} \text { Raman }{ }^{109} \text { and Fourier transform infrared } \\
\quad(\text { FTIR })^{110} \text { spectroscopy, Rutherford backscattering }(R B S)^{111}\end{array}$ \\
\hline & high-precision electrode mass changes; electrical conductivity; coordination and bonding, species identification; composition and structure \\
\hline & superconducting quantum interference device (SQUID) magnetometry \\
\hline & magnetization, magnetic susceptibility, physical properties (heat capacity; electrical, magneto-electrical, and thermal transport properties) \\
\hline
\end{tabular}

chemical stability window (Figure 1b), good ionic conductivity, chemical stability with the electrode materials, low cost and low toxicity. To achieve thermodynamic stability during cell operation, the electrochemical potential of the anode and cathode must be within the lowest unoccupied and highest occupied molecular orbitals (LUMO and HOMO, respectively) of the electrolyte (Figure 1b). Otherwise, the anode and cathode will reduce or oxidize the electrolyte, respectively, causing electrolyte depletion in the cell and a progressive degradation until failure. ${ }^{8}$ For anode materials with operating voltages close to $\mathrm{Li}$, the controlled partial reduction of the electrolyte and the formation of an ion-conducting SEI thinlayer $(\ll 1 \mu \mathrm{m})$ provides kinetic stability during the reversible ion insertion in the electrode preventing further electrolyte decomposition as well as maintaining long-term capacity retention. ${ }^{17}$ Considerable effort has been expended to optimize the electrolyte composition via the use of different solvent molecules and additives that help increase the stability of the SEI. A rational strategy toward SEI optimization has been hindered by the inherent difficulty of studying this phase because of its nanoscale thickness, amorphous composite structure, and air and moisture sensitivity. NMR has, however, played and will continue to play an important role. To reach the desired ion conductivities in the electrolyte $\left(\sim 10^{-4} \mathrm{~S} \cdot \mathrm{cm}^{-1}\right.$ at ambient/room temperature, RT), formulations contain dissolved fluorinated salts in highly flammable solvents with 


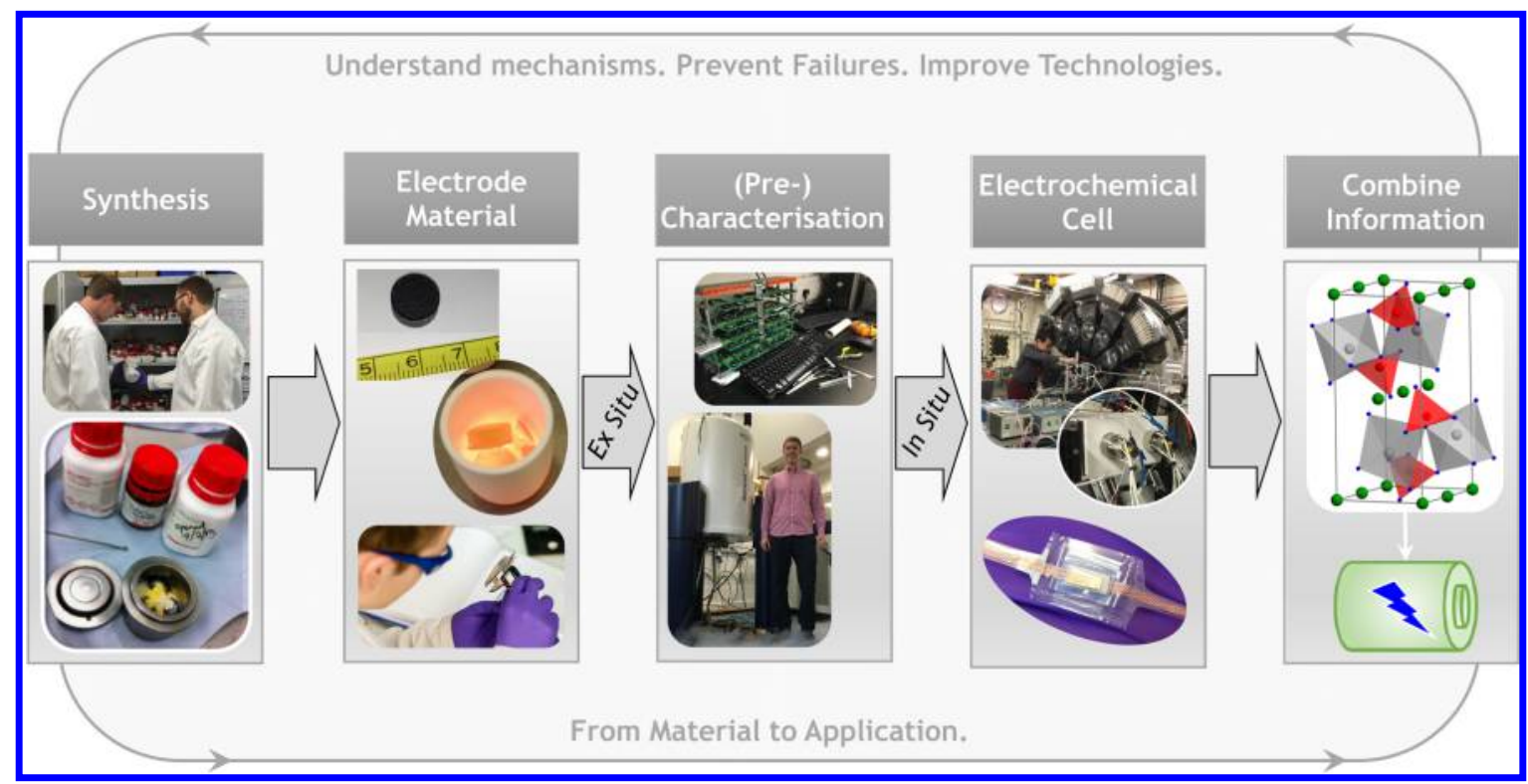

Figure 2. From material to application. Pictorial flowchart of a systematic approach to help understand reaction mechanisms, prevent cell failures, and improve battery technologies. Synthesized materials and electrodes are first characterized by various ex situ techniques (e.g., electrochemical tests, diffraction, NMR) to gain information on phase purity, structure, and physical properties. Advanced characterization such as in situ methods provides a further level of detail regarding device behavior. This is a cyclical process with correlations between structure and function feeding back into material optimization, which ultimately leads to a better understanding from the atomic to device scale.

flash points near RT. A short-circuit might cause the temperature in the electrolyte to rise rapidly to above $250{ }^{\circ} \mathrm{C}$; the separator (which physically separates the cathode and anode) melts causing very rapid short-circuiting and "thermal runaway". A high risk of fire or explosion results along with the release of toxic fluoro-organic compounds, i.e., bis(2fluoroethyl)-ether ${ }^{6}$ and even hydrogen fluoride. ${ }^{39}$ A move away from organic, liquid electrolytes therefore represents an important strategy to increase safety. Both organic (polymeric) and inorganic (ceramic) materials are well positioned. Although some ceramic electrolytes possess higher Li-ion conductivities at RT $\left(10^{-4} \mathrm{~S} \cdot \mathrm{cm}^{-1}\right)$ in comparison to polymer electrolytes, ${ }^{40}$ the latter, due to their flexible nature, allow improved electrolyte/electrode contacts resulting in lower interfacial resistances and can help reduce the mechanical strain associated with the volumetric changes of the electrodes during chargedischarge cycles. Indeed, Li metal/polymer batteries have even been commercialized and are currently being used in electric vehicles. $^{41,42}$

1.1.4. Beyond Li-lon Technologies? Na-based batteries are candidates for large-scale stationary energy storage applications. $^{43,44}$ The main motivations for $\mathrm{Na}$ include (a) energy densities that are closest to those of lithium, (b) decreased cost and increased abundance, and (c) no alloying with $\mathrm{Al}$ at low voltage; hence, no requirement for expensive, heavy, and less abundant copper as the current collector material in negative electrodes. ${ }^{10,44}$ The development of new technologies with energy densities approaching the internal combustion engine, such as batteries based on $\mathrm{Li}-\mathrm{O}_{2}{ }^{45-47}$ and $\mathrm{Li}-\mathrm{S},{ }^{48-51}$ are also under investigation. ${ }^{52}$ Other systems such as $\mathrm{Mg}$-ion ${ }^{53-58}$ and Ca-ion ${ }^{59}$ chemistries as well as redox-flow systems, ${ }^{60}$ among others, in combination with sustainable materials, are being pursued. $^{61}$ Pushing forward the development of present and future battery technologies requires a deeper understanding of the structural and electronic changes of the different materials and components that comprise the electrochemical cell.
1.2. Complex Systems Require Complementary Techniques. An electrochemical cell is a complex system involving a fascinating interplay of various components and multiple concurrent processes. The electrode materials and the nature of their phase transitions on cycling strongly influence the performance of the functioning battery. Key to the understanding of the multiple processes and underlying chemistries is the combined application of experiment and theory to investigate the various sources and scales of information available.

Combine Experiment and Theory. Experimental techniques offer insights into the crystal structure, phase analysis, particle sizes, surfaces, oxidation states of the elements, physical properties, and electrochemical performance of both crystalline and amorphous materials (Table 1, Section 2). However, no single technique is a panacea to cure all battery issues and a combination of complementary experimental techniques, e.g., diffraction and nuclear magnetic resonance (NMR), as well as theoretical methods is crucial. ${ }^{62}$

The huge field of molecular and periodic simulations can be applied to probe various structural or dynamical properties. ${ }^{63}$ $A b$ initio methods, such as density functional theory (DFT) and (post) Hartree-Fock (HF) methods, provide a quantum mechanical description of the electronic structure of materials, without the need for experimental input. These calculations can therefore reliably be used to predict the structural and spectroscopic properties of battery materials and screen for new structures and phases ${ }^{63,64}$ that might form during charge and discharge of a cell. Furthermore, these electronic structure calculations enable the calculation of spectroscopic properties such as NMR parameters, e.g., chemical and hyperfine shifts and quadrupole coupling constants, which are crucial for the assignment and interpretation of experimental NMR spectra. ${ }^{65-68}$ Although $a b$ initio calculations have primarily been used to study the static properties of materials at $0 \mathrm{~K}$, in recent years there has been a growing interest in the use of these methods to study the dynamical processes in battery materials 
at finite temperature through techniques such as $a b$ initio molecular dynamics. ${ }^{69}$ However, the large computational cost of these calculations means that only diffusional processes over short time scales and in small system sizes can reasonably be investigated. Classical molecular simulations, which use a force field representation of the interactions between ions, are well suited to the longer time scales required to capture accurately phenomena such as diffusion and the effects of some parameters, e.g., pressure and temperature. However, they do not adequately capture the changes in electronic structure of, for example, transition metals (and accompanying properties such as electronic conductivity, magnetism) that accompany the redox processes inherent to battery electrode materials.

Go in Situ and Operando?! Because thermodynamic and kinetic pathways are influenced by the presence of an applied potential, the analysis of materials derived from cycled batteries can result in misleading data due to relaxation effects. To probe the multiple processes in real time, many ex situ investigations can be complemented by in situ characterization and operando measurements. Ex situ investigations involve cycling a cell, stopping it at a certain state of charge, extracting the electrode, and performing a measurement. During in situ measurements, the data collection is performed without disassembling the cell-with the components in their appropriate positions within the battery-hence, the connection to the Latin expression in situ meaning "in position". ${ }^{70}$ Note that in some in situ experiments, where the measurement is performed on the intact cell but after charging to a specific state of charge, reactions (such as self-discharge mechanisms and relaxation processes) ${ }^{16}$ can continue to occur after the electrochemistry stops. On the other hand, for operando measurements, ${ }^{70}$ where data collection is done during electrochemical cycling, there is generally less time for side-reactions to occur. Both in situ and operando measurements, where the latter may be considered a special case of in situ, allow insights into fundamental chemical and structural properties under working conditions including dynamics and metastable/intermediate phases to be obtained, which are often not detectable in ex situ characterization approaches. $^{70-72}$ For the sake of simplicity, we primarily refer to the terms $e x$ and in situ measurements throughout this text. Nevertheless, we will-where appropriate-distinguish between in situ and operando experiments, in particular, where we describe NMR methods for obtaining insights into structure and dynamics (Section 4).

Focusing on the major aim of understanding mechanisms of underlying chemistries, preventing battery failures, and improving materials and technologies for electrochemical energy storage, the application of in situ techniques is without a doubt important but not generally the first step within the strategy (Figure 2). The synthesis of new materials should be followed by detailed ex situ characterization to optimize the purity and collect the relevant information on crystal and electronic structure as well as electrochemical performance (Table 1, Section 2). Once the equilibrium conditions of a material are appropriately understood, in situ characterization may offer further insights into the complex processes that occur in an operational device. The correlation between structure and function feeds back into materials synthesis and optimization to improve energy storage technology (Figure 2).

In the context of this work, it is particularly important to begin with ex situ NMR methods. Generally, this involves packing powdered samples into rotors and performing fast magic angle spinning (MAS) NMR spectroscopy (Section 3.3.1 and 5.1). These experiments are easier to optimize for the specific material under investigation in terms of choice of pulse sequence, choice of magnetic field, etc. and result in highresolution spectra that are often easier to interpret than the in situ analogues described below. In particular, the inability to perform sample spinning during in situ NMR experiments limits the information that can be extracted. The assembly of electrochemical cells and selection of NMR parameters based on well-characterized materials streamlines the in situ experiments (Section 3).

1.3. What Should I Expect from This Review? In this contribution, we highlight the application of solid-state NMR spectroscopy in battery research. We will give a brief introduction to electrochemical techniques and applications (Section 2) as well as selected background information on NMR spectroscopy in the context of researching battery materials (Section 3). In discussing the sources of information, e.g., signal shift and line shape, and addressing benefits of ex and in situ solid-state NMR experiments we will lay the foundation necessary to understand the NMR approaches and results of the following section. Afterward, we will try to answer the question "Is NMR suitable and how can it help me to solve my problem?" by shortly reviewing some of our research on electrodes, microstructure formation, electrolytes, and interfaces, in which the application of ex and/or in situ NMR was helpful (Section 4). Finally, we share hands-on experience on battery materials and NMR sample preparation to answer the fundamental questions "Where and how should I start?", aiming to guide a researcher's way through the process (Section 5).

\section{ELECTROCHEMICAL TECHNIQUES AND APPLICATIONS}

The most common approach to study the electrochemical properties of an electrode material during the reversible charge and discharge processes in laboratory cells is the galvanostatic/ chronopotentiometric method, i.e., electrochemical cycling at a constant current applied per gram of active material or with respect to the total surface area of the electrode. In general, the resulting galvanostatic profile displays the evolution of the cell voltage as a function of the chemical composition (and structural phase transformations) of the electrode material enabled by the electric field (Figure 3).

By cycling the electrode at constant current, one can quantify the fraction of exchangeable ions and electrons within the host structure in the electrochemical reaction (state of charge) and from this value deduce the experimental capacity $\left(\mathrm{mA} \cdot \mathrm{h} \cdot \mathrm{g}^{-1}\right)$ of the electroactive material (Section 5) under the selected cycling conditions, i.e., temperature, current density, and voltage range. The cell voltage and capacity are critical parameters in the battery design process because their values are proportional to the total amount of energy that can be stored and delivered in the electrochemical cell. ${ }^{112}$

Before current is applied, the electrochemical cell has an equilibrium voltage known as the open circuit voltage ( $\mathrm{OCV}$, $V_{\text {oc }}$ ) that often differs from the theoretical or equilibrium voltage of the cell $\left(V_{0}\right)$, (Figure 3a). ${ }^{113}$ The difference between $V_{\text {oc }}$ and $V_{0}$ values can be due to the presence of surface species that could yield an apparent voltage, which is not representative of the potential of the bulk structure of the electrode material. This phenomenon may be observed ${ }^{114,115}$ in oxides such as $\mathrm{TiO}_{2}$ and $\mathrm{Nb}_{2} \mathrm{O}_{5}$ where the initial OCV measures ca. $+3.0 \mathrm{~V}$ vs $\mathrm{Li}^{+} / \mathrm{Li}$ but drops immediately by $1 \mathrm{~V}$ as intercalation begins. Furthermore, during the electrochemical measurement the 


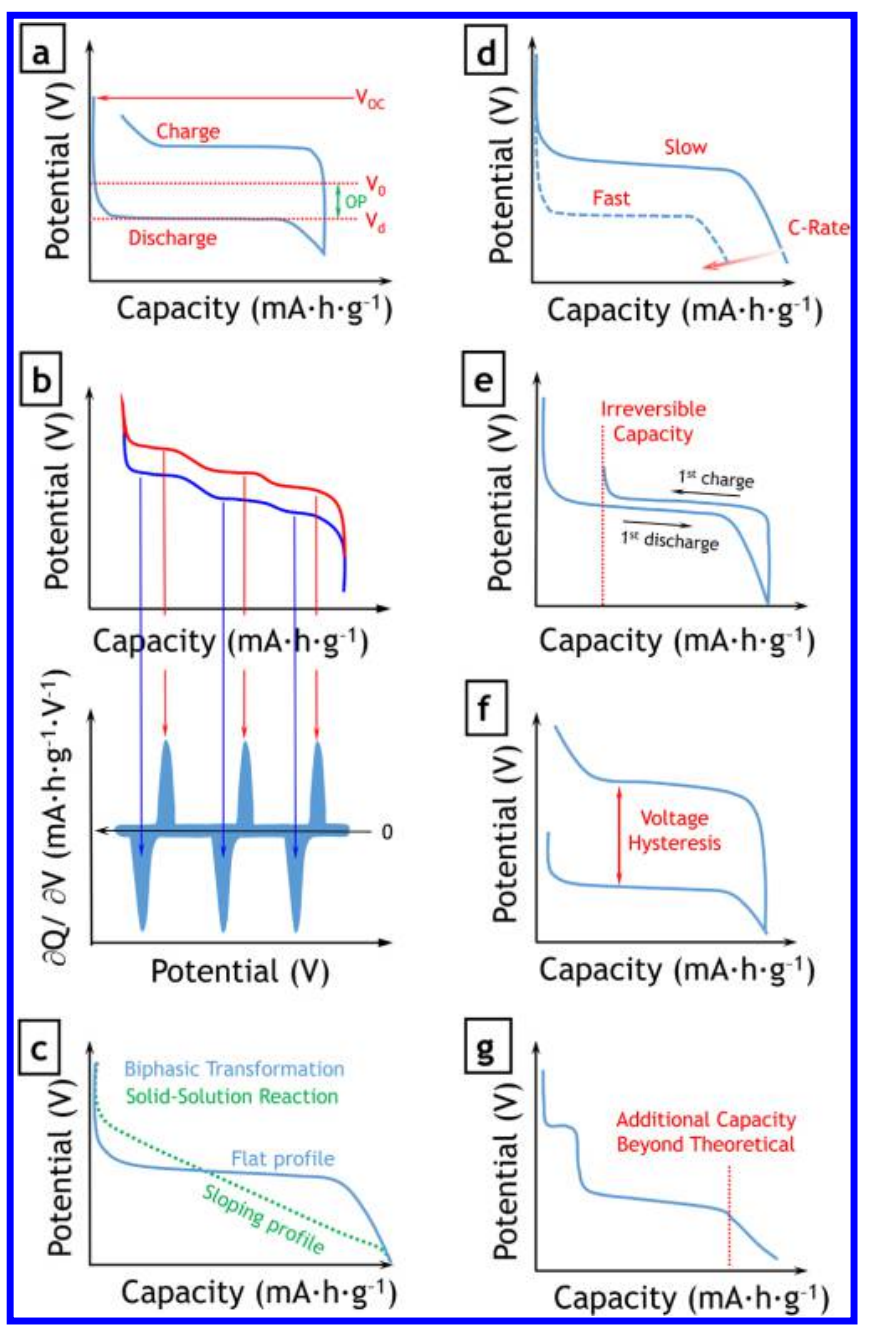

Figure 3. Schematic diagrams of several features and phenomena encountered in galvanostatic profiles during electrochemical cycling: (a) identification of some components of a typical cycle including open circuit voltage $\left(V_{\text {oc }}\right)$, overpotential $(\mathrm{OP})$, equilibrium voltage $\left(V_{0}\right)$, and discharge voltage $\left(V_{\mathrm{d}}\right) ;(\mathrm{b})$ multistage discharge (blue) and charge (red) processes and corresponding $\mathrm{d} Q / \mathrm{d} V$ plot; (c) two-phase vs solid solution reaction mechanisms; (d) effect of C-rate on voltage and capacity; (e) irreversible capacity (e.g., electrolyte decomposition); (f) voltage hysteresis between discharge/charge; (g) additional capacity beyond the theoretical value (e.g., metastable phases or displacement reactions).

voltage profile will generally drop below $V_{0}$ on discharge and rise above $V_{0}$ on charge due to polarization and resistances from the electrode material, electrolyte, separator, and interfacial regions. This difference between $V_{0}$ and discharge $\left(V_{\mathrm{d}}\right)$ or charge $\left(V_{\mathrm{c}}\right)$ is known as the overpotential (OP) (Figure $3 a)$. In general, when the reaction is only controlled by the rate of the electron transfer, the OP is a measure of the additional voltage required to force the current to pass through the cell.

The appearance of one or more equilibrium voltagecomposition plateaus during the galvanostatic cycling may be indicative of the formation of a series of distinct phases, (Figure $3 \mathrm{~b}$, upper) though the distinction between processes that involve solid solutions and two-phase transformations (between structurally distinct phases) usually requires more careful electrochemical measurements often coupled with structural characterization and crystallographic insight. ${ }^{75,116-119}$ To visualize more clearly the number of distinct plateaus and the voltage at which each of these processes occur, we can apply the derivative operator $(\partial / \partial V)$ to both the galvanostatic charge and discharges curves over the applied voltage window and then plot them against the voltage (Figure $3 b$, lower). The integral corresponding to the different $\partial Q / \partial V$ curves will also provide quantitative values for the fraction of ions/electrons (capacity) involved in the electrochemical process at each voltage.

The kinetics and thermodynamics of the electrochemical phase transformation enabled by the electric field will depend on several factors such as current density $\left(\mathrm{A} \cdot \mathrm{g}^{-1}\right)$, particle size of the electrode material, cycling temperature, and crystal structure transformations, e.g., crystalline to amorphous. ${ }^{120}$ All of these factors may induce different chemical reactivity paths between the exchangeable ions and the redox active material during cycling, which will influence the shape of the galvanostatic curve (Figure 3c). For example, a solid solution generally exhibits a sloping-type voltage curve during the galvanostatic cycling, instead of the classical flat voltage profile (plateau) associated with a two phase reaction. However, it has been observed that the size of the particle in $\mathrm{LiFePO}_{4}$ electrodes strongly affects the chemical pathway, favoring a metastable solid solution pathway at the nanoparticle level instead of the two-phase transformation as in bulk particles; ${ }^{75,116,117}$ operando X-ray diffraction studies performed at high rates were required to capture this process. In general the rapid insertion-extraction of $\mathrm{Li}$ ions (i.e., high $\mathrm{C}$ rates) into the host electrode structure will diminish the capacity and potential due to mass-transport limitations and electronic resistance (Figure 3d).

Electrochemical and chemical reactions between the electrolyte and the electrode during cycling will foster the formation of the SEI layer, among others processes, causing an irreversible fraction of the capacity to be lost in the first cycle (Figure 3e). A pronounced overpotential between charge and discharge processes is also observed in some systems and exacerbated under certain conditions (e.g., high current density). This voltage hysteresis (Figure 3f) might be minimized by using a suitable electrolyte, catalyst or soluble redox mediator. Additional charge storage beyond theoretical capacity (Figure $3 \mathrm{~g}$ ) is possible via formation of metastable phases (e.g., the formation of $\mathrm{Li}_{15+x} \mathrm{Si}_{4}$ in $\mathrm{Si}$ anodes $)^{16}$ and reversible chemical reactions (such as $\mathrm{LiOH}$ and $\mathrm{LiH}$ formation in the $\mathrm{RuO}_{2}$ conversion reaction); ${ }^{121}$ such reactions are difficult to observe and in some cases only detected by applying in situ characterization techniques.

\section{SOLID-STATE NMR SPECTROSCOPY}

Atoms with a nuclear spin $I \neq 0$ possess a magnetic moment and are, in principle, accessible by NMR spectroscopy. ${ }^{122-124}$ This technique is based on the interactions of the nuclear magnetic moment with an electromagnetic field in the radio frequency (RF) range while a strong magnetic field $B_{0}$ is applied. The local magnetic fields of surrounding nuclei and electrons influence these interactions, which are basically differentiated as external and internal interactions of NMR spectroscopy. The external interactions comprise the interactions of the nuclear spins with the magnetic field (Zeeman effect; with the difference between the energy levels corresponding to the so-called Larmor frequency $\omega_{0}$ ) and the manipulation of the nuclear spins due to RF fields (Section 3.1). The NMR signal shift and line shape are determined by the internal interactions, e.g., chemical, Knight, and Fermi contact shifts, as well as dipolar and quadrupole coupling, 


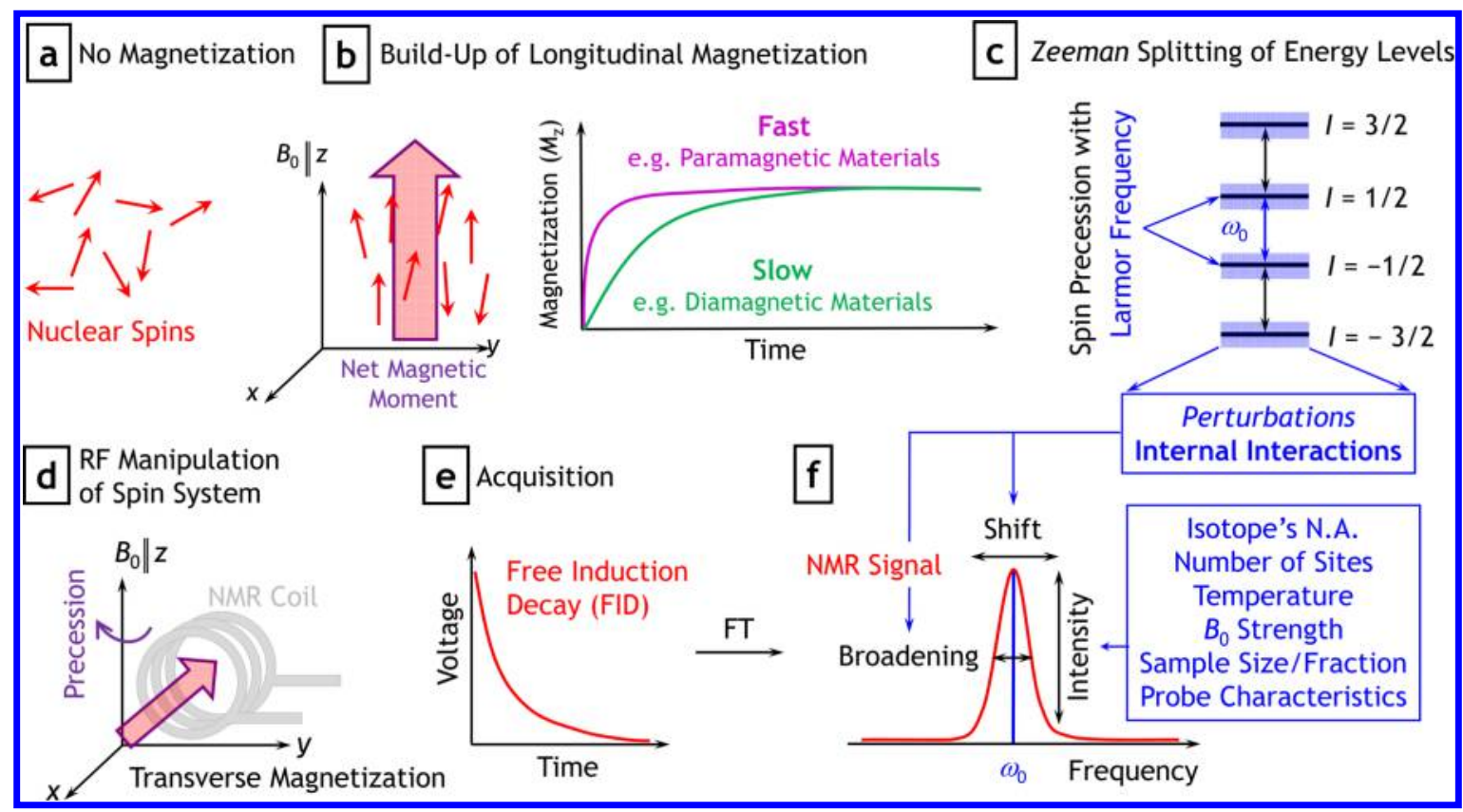

Figure 4. What is behind the NMR signal? (a) No magnetization is present for the randomly orientated nuclear spins of the sample. (b) Longitudinal magnetization along the $z$-axis builds up as soon as a magnetic field $B_{0}$ is applied. A net magnetic moment results. Spin-lattice relaxation ( $T_{1}$ processes) determines whether there is fast (e.g., paramagnetic materials) or slow (e.g., diamagnetic materials) magnetization build-up. (c) Under the influence of $B_{0}$, the spins precess with the Larmor frequency which is related to the Zeeman splitting of the energy levels. (d) The spin system is manipulated by RF pulses and the resulting transverse magnetization acts as a moving magnetic moment inside a coil, which induces a voltage. Because of relaxation processes and internal NMR interactions, the induced voltage decays, which is detected as (e) the free induction decay (FID). (f) Fourier transformation (FT) of this voltage-time signal results in the NMR signal of frequency vs intensity. Figure in part adapted from and inspired by M. Levitt's Spin Dynamics - Basics of Nuclear Magnetic Resonance (John Wiley \& Sons, Ltd.; ref 125). Free download of all figures of this book's 1st edition (2000) from the Levitt webpage (http://www.southampton.ac.uk/ mhl/publications/books/SpinDynamics/SD1/index. html).

which will be discussed in Section 3.2. Afterward, we describe basic approaches and strategies of NMR in battery research (Section 3.3 and Section 3.4). Finally, benefits and challenges of in situ NMR on battery materials are summarized (Section 3.5).

3.1. What is behind the NMR Signal? In a simple picture, the nuclear spins are tiny compass needles that, under the influence of the external magnetic field, are aligned causing a net magnetic moment to build up along the $B_{0}$ direction, which is commonly defined to be the $z$ direction (Figure $4 \mathrm{a}, \mathrm{b}$ ). The magnetization build-up is driven by so-called spin-lattice relaxation processes ( $T_{1}$ relaxation) and is generally very fast for paramagnetic materials and slow for diamagnetic materials (Figure $4 \mathrm{~b}$ ). Once the maximum of this longitudinal magnetization is reached the spin system is in its thermal equilibrium. In a semiclassical picture of NMR, the (very simplified) description of the nuclear spins as compass needles has to be enhanced by describing them as spinning tops, which precess under the influence of a gravitational field (here, the magnetic field). The frequency of this precession movement is the socalled Larmor frequency $\omega_{0}$ which is characteristic for every nuclei with respect to $B_{0}$ (Figure $4 c$ ). This frequency is related to the energy difference between the nuclear spin states, e.g., $-1 / 2 \leftrightarrow+1 / 2$, where, in the classical quantum mechanical description of NMR, the population of the energy states determines the magnetization (Figure 4c). Internal NMR interactions cause perturbations to these distinct energy levels and, therefore, to a distribution of frequencies (Section 3.2). The thermal equilibrium of longitudinal magnetization is now manipulated by RF pulses, which are applied on the sample through an RF coil used for both manipulation of the spin system and signal detection. The net magnetization is thereby transferred into the $x-y$ plane (transverse magnetization), where it rotates around the $z$ axis (Figure $4 d$ ). This rotation of the magnetic moment inside the coil induces a voltage. Because of internal NMR interactions and so-called spin-spin relaxation processes $\left(T_{2}\right.$ relaxation), a relatively quick loss of this coherency (transverse magnetization) occurs as well as a slow recovery to the longitudinal magnetization (back to equilibrium). This causes a decay of the induced voltage, which is measured as the free induction decay (FID) (Figure 4e). Via Fourier transformation (FT), the voltage-time signal is translated into an intensity-frequency signal (Figure 4f). Here, the shift and signal broadening (line shape) are determined by the internal interactions and can become rather complex. The intensity of an NMR signal is furthermore determined by the natural abundance (N.A.) of the isotope under investigation (Table 2) as well as the number of sites/ chemical species within the sample, the temperature, magnetic field strength, sample size/fraction and the probe characteristics (Figure $4 \mathrm{f}$ ). Species in locally different chemical environments, e.g., due to structural defects, atomic disorder, dynamical processes, etc., generally possess different NMR signals. Hence, NMR spectroscopy allows these species to be distinguished on a local atomic level.

3.2. In a Nutshell: NMR Interactions and Shift Ranges for Battery Materials. The key for NMR experiments on battery materials is to gain information about the signal shifts of the different chemical species of the material as well as the interfaces of an electrochemical cell. Because NMR spectros- 
Table 2. Short Guide to Accessible Nuclei for Different Types of Energy Storage Materials ${ }^{a}$

\begin{tabular}{|c|c|c|c|c|c|c|}
\hline Isotope & Spin & N.A. (\%) & $Q\left(\mathrm{fm}^{2}\right)$ & $\begin{array}{l}\text { F.R. } \\
(\%)\end{array}$ & Major challenges & Information and materials' applications \\
\hline${ }^{1} \mathrm{H}$ & $1 / 2$ & 99.99 & & 100.00 & Signal background & Electrolytes, supercapacitors, surface chemistry \\
\hline${ }^{13} \mathrm{C}$ & $1 / 2$ & 1.07 & & 25.25 & $\begin{array}{l}\text { Low N.A. (enrichment); partial } \\
\text { enrichment allows detection of } \\
\text { specific functional groups }\end{array}$ & Electrolytes, supercapacitors, carbon anodes, SEI \\
\hline${ }^{19} \mathrm{~F}$ & $1 / 2$ & 100 & & 94.09 & Signal background & Electrolytes, supercapacitors, cathode coatings, SEI \\
\hline${ }^{29} \mathrm{Si}$ & $1 / 2$ & 4.68 & & 19.87 & Low N.A. (enrichment) & Si anodes \\
\hline${ }^{31} \mathrm{P}$ & $1 / 2$ & 100 & & 40.48 & $\begin{array}{l}\text { Slow relaxation can cause long } \\
\text { experiment times }\end{array}$ & Phosphide and phosphate electrodes, electrolytes, SEI \\
\hline${ }^{119} \mathrm{Sn}$ & $1 / 2$ & 8.59 & & 37.29 & Comparably low N.A. & Sn metal anodes \\
\hline${ }^{2} \mathrm{H}$ & 1 & 0.01 & 0.29 & 15.35 & Low N.A. (enrichment) & See ${ }^{1} \mathrm{H}$ for applications; better suited to study dynamics \\
\hline${ }^{6} \mathrm{Li}$ & 1 & 7.59 & -0.08 & 14.72 & Low N.A. (enrichment) & $\begin{array}{l}\text { See }{ }^{7} \mathrm{Li} \text { for applications; improved resolution vs }{ }^{7} \mathrm{Li} \text { (smaller } \\
\text { quadrupolar and dipolar broadening); provides some complementary } \\
\text { information when combined with }{ }^{7} \mathrm{Li}\end{array}$ \\
\hline${ }^{7} \mathrm{Li}$ & $3 / 2$ & 92.41 & -4.01 & 38.86 & $\begin{array}{l}\text { Comparably small diamagnetic shift } \\
\text { range }\end{array}$ & Electrolytes, electrodes, dynamics, SEI \\
\hline${ }^{17} \mathrm{O}$ & $5 / 2$ & 0.04 & -2.56 & 13.56 & $\begin{array}{l}\text { Low N.A. (enrichment); enrichment } \\
\text { readily available but expensive }\end{array}$ & Metal-air batteries, oxygen dynamics in oxide materials \\
\hline${ }^{23} \mathrm{Na}$ & $3 / 2$ & 100 & 10.4 & 26.45 & None & Electrolytes, electrodes, dynamics, SEI \\
\hline${ }^{25} \mathrm{Mg}$ & $5 / 2$ & 10.00 & 19.94 & 6.12 & $\begin{array}{l}\text { Low FR, low N.A., large quadrupole } \\
\text { moment; low sensitivity without } \\
\text { expensive enrichment }\end{array}$ & Beyond $\mathrm{Li}$-ion technologies: divalent $\mathrm{Mg}^{2+}$ \\
\hline${ }^{27} \mathrm{Al}$ & $5 / 2$ & 100 & 14.66 & 26.06 & Large quadrupole moment & $\begin{array}{l}\text { Beyond } \mathrm{Li} \text {-ion technologies: trivalent } \mathrm{Al}^{3+} \text {; cathode coatings, solid } \\
\text { electrolytes }\end{array}$ \\
\hline${ }^{33} \mathrm{~S}$ & $3 / 2$ & 0.76 & -6.78 & 7.68 & $\begin{array}{l}\text { Low N.A. (enrichment); expensive } \\
\text { enrichment; very broad signals }\end{array}$ & $\mathrm{Li}-\mathrm{S}$, all-solid-state batteries \\
\hline${ }^{39} \mathrm{~K}$ & $3 / 2$ & 93.26 & 5.85 & 4.67 & $\begin{array}{l}\text { Low sensitivity and long relaxation } \\
\text { times }\end{array}$ & Beyond Li-ion technologies: $\mathrm{K}^{+}$ \\
\hline${ }^{43} \mathrm{Ca}$ & $7 / 2$ & 0.135 & -4.08 & 6.73 & Requires very expensive enrichment & Beyond Li-ion technologies: divalent $\mathrm{Ca}^{2+}$ \\
\hline${ }^{51} \mathrm{~V}$ & $7 / 2$ & 99.75 & -5.2 & 26.30 & Large quadrupole moment & Electrodes; redox flow batteries \\
\hline${ }^{67} \mathrm{Zn}$ & $5 / 2$ & 4.10 & 15.9 & 6.26 & $\begin{array}{l}\text { Very large quadrupole moment; } \\
\text { expensive enrichment }\end{array}$ & Zn-air batteries, redox flow batteries \\
\hline
\end{tabular}

${ }^{a}$ Isotopes, nuclear spin $(I)$, natural abundance (N.A.), quadrupole moment $(Q)$, and frequency ratio (F.R., relative to $\left.{ }^{1} \mathrm{H}\right)$ are given and some major experimental challenges as well as selected applications summarized.

copy is usually not phase sensitive, this can be challenging since all components possessing the NMR active isotope under investigation give a signal. This can be overcome to some extent by the range of shifts and various influences on line shape originating from different interactions. NMR signal line shape analysis is then used to extract the NMR coupling parameters allowing a quantification of the various internal interactions (Figure 5).

3.2.1. Shift Interactions (Nuclear Spin-Electron Spin). The spins of the valence, conduction, and/or unpaired electrons cause different local magnetic fields and therefore a shift of the NMR signal from its Larmor frequency (Figure 5a). The (de)shielding of the nucleus by its surrounding valence electrons is named chemical shift. For some commonly used nuclei such as ${ }^{6 ; 7} \mathrm{Li}$, this shift has only a minor influence for battery materials, which can make NMR signal line shape analysis challenging. While the chemical shift is due to the orbital angular momentum of the paired electrons, there are two additional shift interactions due to spin magnetic moment of unpaired electrons, namely Knight and Fermi contact shift (Figure 5a). The interaction with conduction electrons for metals or metallically conductive samples causes the so-called Knight shift, which is generally outside the range of shifts of diamagnetic materials. Because it is related to the conduction electrons, the Knight shift is a measure of the density of states at the Fermi level. ${ }^{126,127}$ Furthermore, localized interactions with unpaired electrons for paramagnetic compounds, e.g., mixed valent $\mathrm{LiMn}_{2} \mathrm{O}_{4}$ containing $\mathrm{Mn}^{3+}\left(\mathrm{d}^{4}\right)$ and $\mathrm{Mn}^{4+}\left(\mathrm{d}^{3}\right)$ ions, can occur, providing information on local crystal and electronic structure (Figure 5a). ${ }^{128}$ When present, these hyperfine couplings are usually the strongest interaction for battery materials and are quantified via the hyperfine coupling constant. The through-bond interaction of nuclear spins with time-averaged magnetic moments causes a Fermi contact shift, which is a measure of unpaired electron spin density that is transferred from the paramagnet to the nucleus under investigation (Figure 5a). ${ }^{128}$

3.2.2. Dipolar Coupling (Nuclear Spin-Nuclear Spin). Magnetic dipole-dipole interactions provide a direct spectroscopic route to determine interatomic/internuclear distances and, hence, to investigate crystal structures (Figure 5b). This can be beneficial if none of the other NMR couplings dominate the signal line shape. Dipolar couplings may occur between two of the same nuclei (homonuclear) or two different NMR active nuclei (heteronuclear). This interaction also enables many multidimensional NMR experiments (Sections 4.3.1 and 4.3.3).

3.2.3. Quadrupolar Coupling. The interaction of the nuclear quadrupole moment $Q$ (nonzero for nuclei with $I>1 / 2$ ) with the electric field gradient (EFG) at the nucleus is known as quadrupole coupling (Figure 5c). ${ }^{129-131}$ This coupling only occurs for atoms/ions in noncubic symmetry. Hence, structural information on local distortions is accessible.

3.2.4. Anisotropy of NMR Interactions (Signal Broadening). The aforementioned NMR interactions are all referred to as "anisotropic", because different orientations of the materials' crystallites cause different local magnetic fields and 


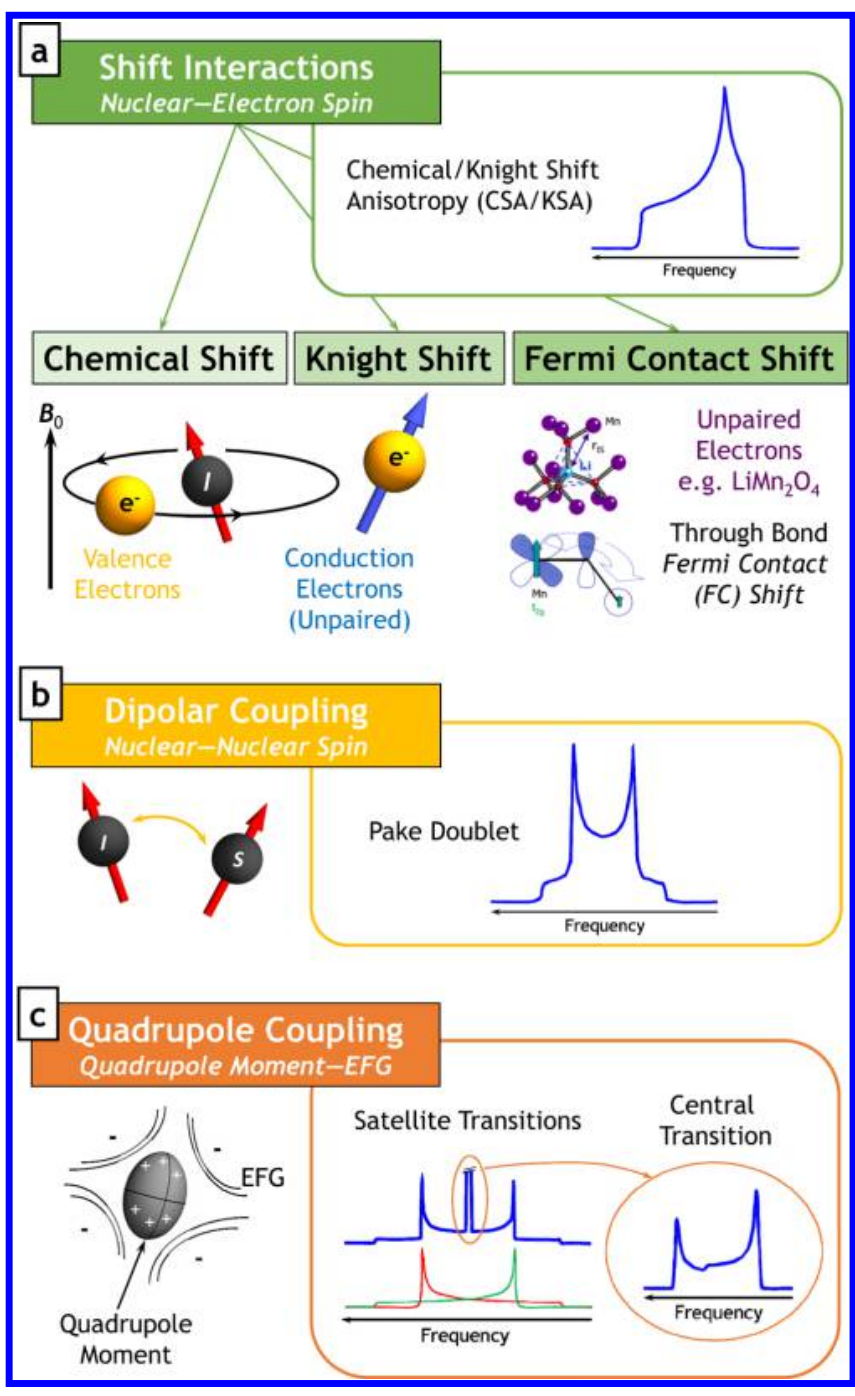

Figure 5. Internal NMR couplings that are relevant for battery materials. Here, we differentiate between (a) shift interactions (chemical, Knight, and Fermi contact shift), (b) dipolar and (c) quadrupole coupling. The (very simplified) sketches underneath illustrate the respective interaction. Characteristic NMR signal lineshapes (of static, powder samples) due to the anisotropy of the interactions are depicted in the rounded boxes. Figure in part (Fermi contact shift) reprinted and adapted with permission from C. P. Grey and N. Dupré, Chem. Rev. 2004, 104, 4493 (ref 128). Copyright 2004 American Chemical Society. Chemical and Knight shift as well as quadrupole coupling scheme adapted from M. Levitt's Spin Dynamics - Basics of Nuclear Magnetic Resonance (John Wiley \& Sons, Ltd.; ref 125). Free download of all figures of this book's 1st edition (2000) from the Levitt webpage (http://www.southampton.ac.uk/ mhl/ publications/books/SpinDynamics/SD1/index.html).

thus different shifts. In solid-state NMR measurements of powders, this results in characteristic "powder patterns" (Figure 5 , shown in rounded boxes). For chemical and Knight shift, these are caused by chemical shift anisotropy (CSA) and Knight shift anisotropy (KSA), respectively (Figure 5, top right). Dipolar coupling can lead to so-called Pake doublets (Figure 5, middle right). The multiple energy transitions possible for $I>1 / 2$ are affected differently by the quadrupolar coupling, resulting in characteristic line shapes for the central transition $(-1 / 2 \leftrightarrow+1 / 2)$ and satellite transition (e.g., $-3 / 2$ $\leftrightarrow-1 / 2$ and $+1 / 2 \leftrightarrow+3 / 2$, etc.) NMR signals (Figure $4 c$ Figure 5, bottom right). ${ }^{132}$ The characteristic line shapes due to the various NMR interactions are a significant source of information as long as the underlying coupling parameters can be extracted and signal contributions resolved.

3.3. "Playgrounds". The major aim of the NMR investigations is to collect as much information as possible about signal shifts, line shapes, and quantitative data (e.g., spin-lattice relaxation times) to gain insights into phase chemistry, local structure, and ion dynamics. In many cases, a high experimental resolution is therefore crucial. Solid-state NMR spectroscopy, especially when investigating battery materials, offers a huge "playground" in which to gather this information. We will highlight some of the approaches in the following subsections.

3.3.1. Static vs Magic Angle Spinning NMR. Magic angle spinning (MAS) is a technique to gain high experimental resolution in ex situ solid-state NMR experiments on powder samples. Here, the sample is packed inside a cylindrical ceramic rotor and spun at an angle of $54.7^{\circ}$ relative to the orientation of the external magnetic field during the NMR measurement (Section 5.1 for details). The sample rotation at this angle (the body diagonal through a cube) averages out many of the anisotropic internal interactions and can lead to very sharp signals with corresponding MAS sidebands (Figure 6a). These sidebands, characteristic of MAS NMR, are separated by the rotational frequency (typically 5-60 kHz). Furthermore, the application of pulse sequences containing adiabatic pulses similar to those used in wide-line quadrupolar NMR, ${ }^{133,134}$ and broadband paramagnetic NMR, ${ }^{135}$ e.g., adiabatic magic angle turning (aMAT), ${ }^{136}$ can be used to detect extremely wide frequency ranges and remove the overlap between sideband manifolds for broad spectra of paramagnetic samples. However, MAS NMR is not always the best strategy or even possible, e.g., for in situ NMR experiments. Here, the broadening and characteristic features of static NMR resonances are a valuable source of information.

3.3.2. Orientation Effects in Static NMR. An additional complication is introduced by bulk magnetic susceptibility (BMS) effects, due to the inherent variations in local magnetic fields caused by the very different magnetic susceptibilities of the (diamagnetic, paramagnetic, insulating and metallic) components that make up the batteries. ${ }^{137-139}$ Sample shape, packing of the material (particles), and sample orientation with respect to $B_{0}$ give rise to variable BMS effects. Even for a single Li metal (anode) strip, this results in a systematic change in shift and slight influences on the signal width as the metal strip is rotated within the NMR coil (Figure 6b-i). The theory underlying this effect is relatively straightforward to understand, ${ }^{139,140}$ and the variation in local magnetic field can be modeled by computing the variation in dipolar fields of (in the case of Li metal strip) a two-dimensional object as a function of orientation. The underlying physics is similar to that used to describe the MAS of solids, and perhaps surprisingly BMS shifts can be removed by simply orienting the electrochemical cell (such as bag cells, containing a uniform distribution of materials; Sections 3.5, 5.2, 5.3 and Figure 20a) so that the normal to the cell is oriented at the magic angle (Figure $6 \mathrm{~b}$ ). However, this trick does not remove the broadening and care must be taken because components at different locations within the bag cell with respect to the materials giving rise to the largest local fields may not show the same orientation dependence; the problem will be particularly severe for electrodes with large inhomogeneities. Although adding complexity, the BMS effects can be exploited to distinguish 


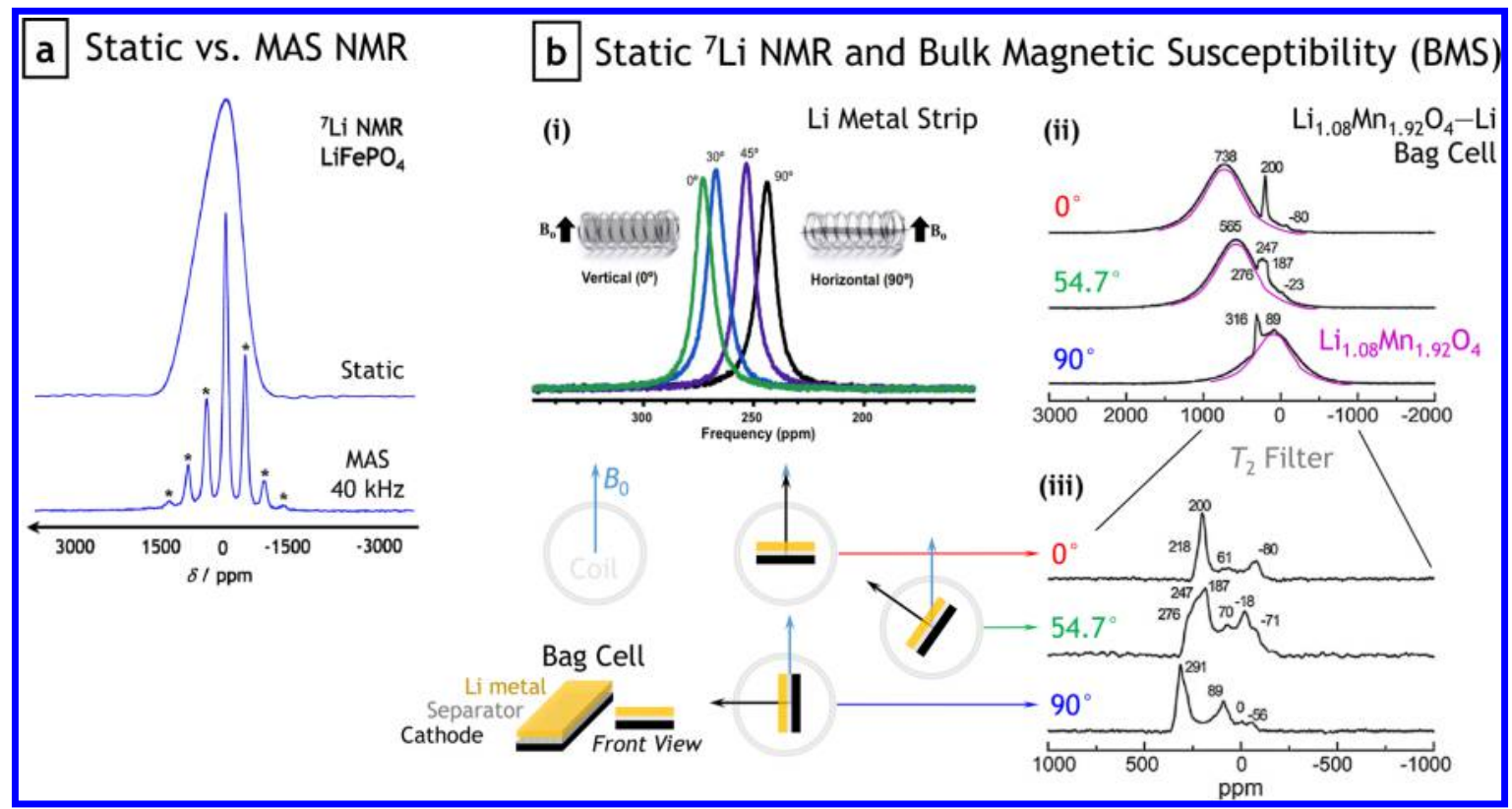

Figure 6. "Playgrounds" of NMR in battery research. (a) Increase of experimental resolution during a ${ }^{7} \mathrm{Li}$ MAS vs static NMR measurement on $\mathrm{LiFePO}_{4}$ powder samples. Rotational sidebands are indicated by asterisks. (b-i) ${ }^{7} \mathrm{Li} \mathrm{BMS}$ effects (static NMR) for Li metal strips with respect to their orientation to the external magnetic field. Reprinted with permission from N. M. Trease et al. Solid State Nuclear Magnetic Resonance 2012, 42, 62 (ref 138). Copyright 2012 Elsevier. (b-ii) Static ${ }^{7} \mathrm{Li}$ NMR signals for a $\mathrm{Li}_{1.08} \mathrm{Mn}_{1.92} \mathrm{O}_{4} / \mathrm{PTFE} /$ Carbon cathode film vs $\mathrm{Li}$ metal anode bag cell in parallel and perpendicular orientation with respect to $B_{0}$ as well as at the magic angle. In addition to the ${ }^{7} \mathrm{Li}$ NMR signals from the other phases, a broad $\mathrm{Li}_{1.08} \mathrm{Mn}_{1.92} \mathrm{O}_{4}$ cathode signal is observed, whose center of mass is strongly dependent on the orientation of the bag cell; this broad signal is highlighted by a purple line. Recycle and Hahn echo delays of $0.05 \mathrm{~s}$ and $20 \mu$ s were used, respectively. (b-iii) A $T_{2}$ filter is applied to remove the broad signal, the Hahn echo delay being increased to $500 \mu \mathrm{s}$, significantly influencing the line shape. Reprinted with permission from L. Zhou et al. J. Magn. Reson. 2013, 234, 44 (ref 139). Copyright 2013 Elsevier.

between different $\mathrm{Li}$ morphologies, e.g., Li dendrites experience a different local field than the bulk Li metal anode from which they grow (in a Li metal cell; Figure 20a) and can often be resolved as a distinct resonance. Furthermore, orientations other than the magic angle sometimes allow improved resolution of different signals.

BMS shifts are much more significant for cells containing paramagnetic materials, as was recently illustrated for ${ }^{7} \mathrm{Li} \mathrm{NMR}$ signals of paramagnetic $\mathrm{Li}_{1.08} \mathrm{Mn}_{1.92} \mathrm{O}_{4}$ spinels as cathodes in a LIB (Figure 6b-ii/iii). ${ }^{139}$ The broad cathode signal, in addition to the ${ }^{7} \mathrm{Li}$ signals from the other phases, are strongly influenced by the orientation of the cell; the $\mathrm{Li}_{1.08} \mathrm{Mn}_{1.92} \mathrm{O}_{4}$ and $\mathrm{Li}$ metal resonance vary from approximately 740 and $200 \mathrm{ppm}$ to 90 and 290 ppm, respectively, on changing the orientation of the bag cell from 0 to $90^{\circ}$, with respect to $B_{0}$. The measurements of the cell in parallel and perpendicular orientation as well as at the magic angle with respect to $B_{0}$ can additionally be combined with a $T_{2}$ filter experiment (Figure 6b-iii). A significantly longer waiting time between the RF pulses used for signal detection is applied to remove the faster relaxing signal contributions (e.g., the paramagnetic cathode) revealing the signals from the $\mathrm{Li}$ metal, electrolyte, and SEI. The resulting increase in experimental resolution can now be combined with measurements in different orientations to collect additional and complementary NMR data sets for analysis and interpretation.

3.3.3. Different Magnetic Field Strengths. The anisotropic NMR interactions and resulting frequency distributions scale differently with the magnetic field strength; e.g., paramagnetic broadening is proportional to $B_{0}$ whereas quadrupole coupling is inversely proportional. Hence, it can be useful to measure a sample at different magnetic fields since, e.g., at very low field the quadrupole interaction (if present) may dominate the line shape and paramagnetic broadening will be reduced. On the other hand, it can be beneficial to measure samples that are strongly influenced by quadrupole coupling at high fields. A rule of thumb for starting, in particular ${ }^{6 ; 7} \mathrm{Li}$ and ${ }^{23} \mathrm{Na}$, NMR experiments on a paramagnetic battery material might be "go low, spin fast" (e.g., $4.7 \mathrm{~T}$ with MAS of $60 \mathrm{kHz}$ ) because this will give the highest resolution possible.

3.3.4. Variable Temperature NMR. Variable temperature (VT) NMR is beneficial to differentiate between shift contributions because chemical and Fermi contact shifts are temperature-dependent, whereas the Knight shift is generally temperature-independent. Furthermore, temperature-dependent changes of the NMR signal line shape offer insights into ion dynamics and can be used to derive intrinsic properties, e.g., VT $T_{1}$ measurements can be used to calculate activation energies, diffusion coefficients, and ion hopping rates based on this data. ${ }^{141-144}$

3.3.5. Complementary Isotopes. Another approach is to collect complementary information by measurements of different isotopes of the same nucleus, e.g., in the case of lithium, ${ }^{6} \mathrm{Li}$ generally offers higher resolution and ${ }^{7} \mathrm{Li}$ offers very good sensitivity (Table 2, Section 4.1.4 and Section 4.3.2). ${ }^{140,141}$ Furthermore, measurements of ${ }^{7} \mathrm{Li}$ in ${ }^{6} \mathrm{Li}$-enriched samples are useful because the dilution will suppress ${ }^{7} \mathrm{Li}-{ }^{7} \mathrm{Li}$ dipolar couplings, which could result in even higher resolution. ${ }^{144}$

3.4. Why is NMR Useful for Studying Battery Materials? Chemical and electrochemical processes depend on redox reactions. Ions such as $\mathrm{Li}^{+}$and $\mathrm{Na}^{+}$are often directly involved in these processes and corresponding ${ }^{6 ; 7} \mathrm{Li}$ and ${ }^{23} \mathrm{Na}$ NMR spectra, respectively, are influenced by the electronic structure of the materials under investigation. Hence, it is often 
possible to distinguish between insulators and conductors as well as diamagnetic and paramagnetic contributions. Furthermore, the range of nuclei that can be used to gain insights into electronic and structural changes of the material (direct or indirect) is not by any means limited to ${ }^{6 ; 7} \mathrm{Li}$ and ${ }^{23} \mathrm{Na}$ only. Many other nuclei, e.g., $I=1 / 2$ isotopes like ${ }^{1} \mathrm{H},{ }^{13} \mathrm{C},{ }^{19} \mathrm{~F},{ }^{29} \mathrm{Si}$, ${ }^{31} \mathrm{P}$, and ${ }^{119} \mathrm{Sn}$ as well as quadrupolar nuclei with $I>1 / 2$ like ${ }^{2} \mathrm{H},{ }^{17} \mathrm{O},{ }^{25} \mathrm{Mg},{ }^{27} \mathrm{Al},{ }^{33} \mathrm{~S},{ }^{39} \mathrm{~K},{ }^{43} \mathrm{Ca},{ }^{51} \mathrm{~V}$, and ${ }^{67} \mathrm{Zn}$, can provide useful insights (Table 2). However, NMR measurements using some of these isotopes can be challenging due to large quadrupolar coupling, low natural abundance and/or low frequency (gyromagnetic ratio) affecting the NMR sensitivity and detectability (Table 2). ${ }^{145,146}$ Generally, NMR experiments applied to these nuclei, which might be found in different parts of the electrochemical cell, i.e., anode, cathode, electrolyte, and interfaces, tremendously expands the application of this technique to gain insights into short-range, local structure information. In combination with diffraction methods (providing long-range information), complementary information on both crystal and electronic structure is accessible. Furthermore, NMR can be used to derive information on ion dynamics, e.g., activation energies, which can be correlated with data from theoretical calculations as well as other experimental techniques such as impedance spectroscopy (Table 1, Section 1.2).

3.5. In situ...Everything? In situ NMR experiments are of considerable interest because they enable monitoring of structural and electronic changes of the materials while the electrochemical processes are happening. The real-time investigations are highly beneficial since they minimize selfrelaxation processes, offer a high chemical specificity to both crystalline and amorphous species, and enable the monitoring of dynamic processes and the tracking of metastable and shortlived phases. ${ }^{137,138}$ A major difference to the commonly applied ex situ NMR measurements is that in situ NMR is performed under static conditions, i.e., no sample spinning. Hence, additional experimental challenges are present for both the detection and analysis as well as cell design and hardware setup.

Within the past 2 decades, two major approaches regarding the NMR probe and/or cell design have been established: ${ }^{71,138}$ toroid probeheads ${ }^{147-149}$ and the use of static NMR probes in which either Bellcore-type bag cells ${ }^{150-156}$ or Swagelok-type plastic inserts ${ }^{157}$ were used (Section 5). In its final setup, the toroid was designed as a "battery imager" and is both part of the electrochemical cell and NMR detector. ${ }^{147-149}$ A drawback of this design is an inherently low signal-to-noise and complicated analysis of the spectra due to nonlinear RF excitation/ detection. Higher sensitivity and flexibility were achieved by placing the electrochemical cell inside the coil of a static NMR probe and connecting it to an external potentiostat (electrochemical cycler, EC). Afterward, the spectra were acquired as a function of charge. ${ }^{71,137}$ Depending on the battery materials and their sensitivity to moisture and air, various designs exist for the bag cells, e.g., using $\mathrm{Cu}$ or $\mathrm{Al}$ mesh or foil as the current collector, polyester or $\mathrm{Al}$ bags as the container and contact heat sealers or lamination for the cell assembly. ${ }^{150-156}$ Swageloktype cylindrical plastic inserts instead of flat bag cells improve the pressure on the cell, which can be beneficial for the electrochemical performance, but introduce a poor filling factor and issues with the signal intensity. We recently developed a new in situ cell setup that combines the layout of the bag cells with some aspects of the Swagelok-type cylinder design, which is explained in detail later in the text (Section 5.3 and Section 5.4). Despite in situ NMR being a very beneficial tool in battery research, it comes with challenges. Significantly different resonance frequencies, changing sample conditions, signal broadening, and interferences of the NMR and EC circuit can impair the experiments.

3.5.1. NMR Resonance Frequency Shift Ranges. The different components of an electrochemical cell (e.g., solid anode and cathode as well as liquid electrolyte) cover large shift ranges that are determined by the internal NMR interactions (Figure 5, Figure 7). ${ }^{128}$ The electrolyte and SEI ${ }^{6,7} \mathrm{Li}$ signals

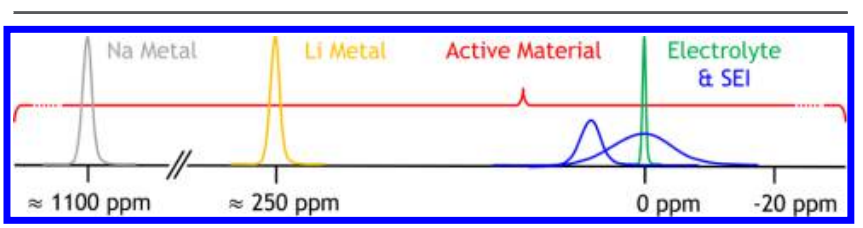

Figure 7. Schematic and simplified presentation of typical ${ }^{6 ; 7} \mathrm{Li},{ }^{23} \mathrm{Na}$ NMR shift ranges for components and chemical species of electrochemical cells. Signals of electrolyte (green) and SEI (blue) generally occur in the diamagnetic range around $0 \mathrm{ppm}$. Shifts of $\mathrm{Li}$ (yellow) and $\mathrm{Na}$ (gray) metal are Knight shifted to approximately 250 and $1100 \mathrm{ppm}$. NMR signals of the active material (red) can be influenced by chemical, Knight, as well as Fermi contact shift and cover huge frequency ranges that strongly depend on the material under investigation.

normally appear in the diamagnetic range of -10 to $10 \mathrm{ppm}$; the range for ${ }^{23} \mathrm{Na}$ is only slightly larger. Often, $\mathrm{Li}$ or $\mathrm{Na}$ metal strips are used as anodes with Knight shifted resonances at 242 and 1126 ppm, respectively. ${ }^{138,158}$ Furthermore, these shifts are orientation dependent due to BMS effects resulting in $272 \mathrm{ppm}$ (Li; Figure 6b-i, Figure 7) and $1131 \mathrm{ppm}(\mathrm{Na})$ for a vertical orientation of the metal strip to the magnetic field. ${ }^{128,137,138,158}$ Finally, the resonance frequency(ies) of the active material of the cathode can range over thousands of ppm (Figure 7). ${ }^{128,138,158}$ Simultaneous detection of the signals can be challenging and often requires varying carrier frequencies during the NMR experiment. ${ }^{137}$

3.5.2. Changing Sample Conditions. The properties of the cell's materials can change during electrochemical cycling, e.g., nonmetallic materials can become metallic or semiconducting, or a new microstructure may form that influences the magnetic susceptibility of the electrodes. The changes can affect the optimal NMR measurement conditions that have been set up for the pristine cell. Therefore, signal detectability and line shape measurement can be influenced and recalibration of the NMR circuit may be needed.

3.5.3. NMR Signal Broadening. In addition to the shift interactions (chemical/Knight shift), the signal line shape of the battery materials can be influenced by quadrupole coupling and paramagnetic broadening (Section 3.2, Figure 5). ${ }^{128}$ In particular, the hyperfine interaction with unpaired electrons in paramagnetic materials often gives rise to very broad resonances since many battery components are paramagnetic. Furthermore, BMS effects influence the resonance shift and line width (Section 3.3.1 and Figure 6b); ${ }^{128,138,139}$ sample shape, packing of the material (particles) and sample orientation with respect to the static magnetic field give rise to BMS effects.

3.5.4. NMR-EC Circuit Interferences. The implementation of an electrochemical cell connected to an EC inside of a NMR coil can cause interferences between the alternating current of the NMR and direct current of the EC circuits. In worst-case scenarios, this influences both the electrochemical performance and NMR detectability. Hence, the EC circuit needs filtering, 


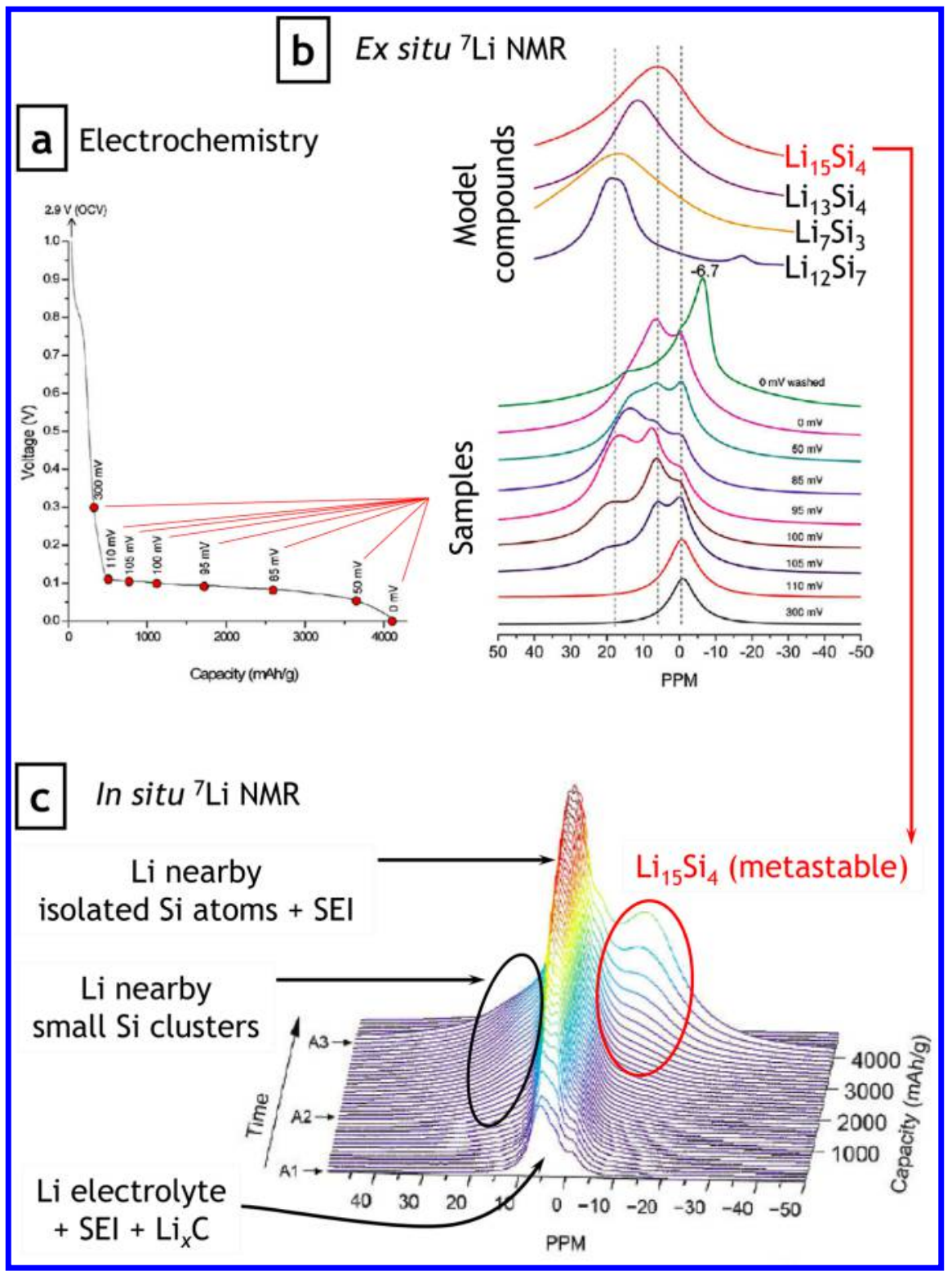

Figure 8. (a) Electrochemical profile of the first discharge of crystalline $\mathrm{Si}$ vs $\mathrm{Li} / \mathrm{Li}^{+}$. (b) Ex situ ${ }^{7} \mathrm{Li}$ MAS NMR spectra of battery samples stopped at different potentials during first discharge of crystalline $\mathrm{Si}$ vs $\mathrm{Li} / \mathrm{Li}^{+}$. (c) ${ }^{7} \mathrm{Li}$ in situ static NMR signals of $\mathrm{Li}$ insertion into crystalline $\mathrm{Si}$. Reprinted and adapted with permission from B. Key et al. J. Am. Chem. Soc. 2009, 131, 9239 (ref 16). Copyright 2009 American Chemical Society.

e.g., by using low pass filters, to prevent it from acting as an antenna that brings all the RF noise of the environment into the NMR circuit. We recently reported on a new in situ NMR approach by applying the Automatic Tuning Matching Cycler (ATMC) in situ NMR system to overcome some of these challenges. ${ }^{137}$ We will discuss some hands-on experience on how to use this in Section 5.5.

\section{OBTAINING INSIGHTS INTO STRUCTURE AND DYNAMICS}

This section reviews recent representative publications of our research group, which used solid-state NMR (primarily or in addition with other experimental techniques) to investigate structure-property relationships in battery materials. We will highlight some recent studies on electrodes (Section 4.1), microstructure formation (Section 4.2), as well as electrolytes and interfaces (Section 4.3). The objective of this section is to give selected insights into the wide range of applications and strategies so as to guide the way to ask the right questions with respect to "what is possible, how is it done and where to start?" We hope that these case studies demonstrate how the NMR principles and interactions described in Section 3 can provide insight into real-world battery applications.

4.1. Electrodes. For many systems, NMR can be used to reveal structural details (including electronic structure), phase identification of intermediates, and dynamics in battery materials. NMR is especially useful for the two former applications when there is an interest in local details and noncrystalline materials. Calculations or measurements of model compounds often add further insight into unidentified intermediates. The latter aspect-dynamics - is a particularly crucial aspect for battery materials with respect to motion of the alkali ion and one that NMR is well-suited to investigate with experiments covering subnanosecond to second time domains.

4.1.1. Alloying Electrodes. Ex.: Real-Time NMR Investigations of Structural Changes in Si Electrodes for LIBs. ${ }^{16} \mathrm{Si}$ 


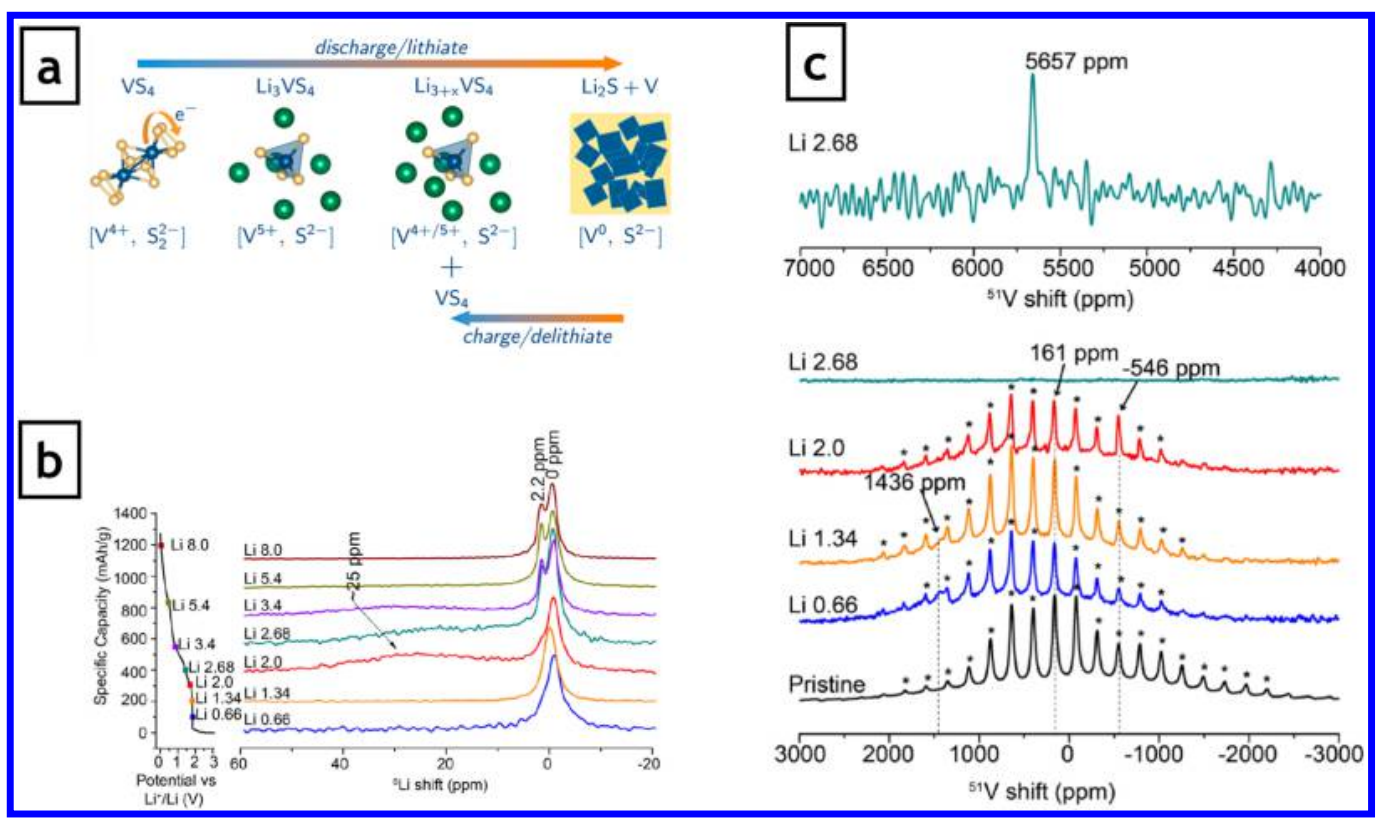

Figure 9. (a) Reaction mechanism of $\mathrm{VS}_{4}$ as a function of (de)lithiation. (b) ${ }^{6} \mathrm{Li}$ MAS NMR spectra and (c) ${ }^{51} \mathrm{~V}$ MAS NMR spectra of $e x$ situ battery samples during first discharge. Reprinted with permission from S. Britto et al. J. Am. Chem. Soc. 2015, 137, 8499 (ref 93 ). Copyright 2015 American Chemical Society.

electrodes offer the highest theoretical capacity for LIB anodes, alloying with $\mathrm{Li}$ to form $\mathrm{Li}_{15} \mathrm{Si}_{4}$ giving a theoretical capacity of $3572 \mathrm{~mA} \cdot \mathrm{h} \cdot \mathrm{g}^{-1}$. During the first lithiation, crystalline $\mathrm{Si}$ undergoes a crystalline-to-amorphous phase transition. In situ and ex situ XRD provided evidence for the loss of crystalline Si but no other phases were observed until the crystalline phase $\mathrm{Li}_{15} \mathrm{Si}_{4}$ was formed at the end of discharge. A combination of $e x$ situ ${ }^{7} \mathrm{Li}$ NMR on both lithium silicide model compounds and discharged samples (Figure 8a,b) enabled signal assignments. Distinct resonances were observed for $\mathrm{Li}$ in the carbon/ electrolyte/SEI above $110 \mathrm{mV}$; below this potential, additional resonances were observed from $\mathrm{Li}$ ions nearby isolated $\mathrm{Si}$ and 2-5 atom $\mathrm{Si}$ clusters. As the $\mathrm{Li}$ content increased, the resonance for $\mathrm{Li}$ near isolated $\mathrm{Si}$ increased, indicating $\mathrm{Si}-\mathrm{Si}$ bond breaking within the clusters and the final formation of the $\mathrm{Li}_{15} \mathrm{Si}_{4}$ phase. Further insights into metastable intermediates were obtained through in situ (here: operando) ${ }^{7} \mathrm{Li} \mathrm{NMR}$ (Figure 8c). The observation of a new, negatively shifted resonance revealed that, upon deep discharge, a reactive $\mathrm{Li}_{15+\delta} \mathrm{Si}_{4}$ phase was formed, which relaxed back to the more stable $\mathrm{Li}_{15} \mathrm{Si}_{4}$ when the cell was left to rest, a process that is likely accompanied by electrolyte reduction. This negative resonance had not previously been observed in the ex situ studies because the reaction occurred before the cells were disassembled for the ex situ measurements. This nonstoichiometry and reactivity revealed by NMR clearly highlighted one of the challenges associated with the practical use of $\mathrm{Si}$ in a commercial cell and motivated studies to explore the effect of binders on the self-discharge processes. The use of a carboxymethyl cellulose (CMC) binder slowed down this process but did not completely suppress it.

4.1.2. Conversion Electrodes. Ex.: Multiple Redox Modes in the Reversible Lithiation of High-Capacity, Peierls-Distorted Vanadium Sulfide. ${ }^{93}$ The transition metal sulfide compound $\mathrm{VS}_{4}$ is a member of an interesting class of materials that achieve high capacity by undergoing anion-mediated conversion reactions (Figure 9a). Initial lithiation gave rise to NMR resonances at 0 and $161 \mathrm{ppm}$ for ${ }^{6} \mathrm{Li}$ and ${ }^{51} \mathrm{~V}$ NMR, respectively
(Figure $9 \mathrm{~b}, \mathrm{c}$ ), proving $\mathrm{VS}_{4}$ to be diamagnetic due to a Peierls distortion of the linear chains. Upon further lithiation, the appearance of a ${ }^{51} \mathrm{~V}$ shift at $+1436 \mathrm{ppm}$, similar to the reference compound $\mathrm{K}_{3} \mathrm{VS}_{4}$, suggested the unexpected phenomenon of vanadium oxidation on discharge. In combination with sulfur Xray absorption spectroscopy, it was determined that $\mathrm{V}^{4+}$ is oxidized to $\mathrm{V}^{5+}$ with a concurrent anion reduction from $\mathrm{S}_{2}{ }^{2-}$ to $\mathrm{S}^{2-}$ during discharge. At lower potentials, the ${ }^{51} \mathrm{~V}$ NMR positively shifted resonance was followed by a negatively shifted resonance as the $\mathrm{V}^{5+}$ was reduced back to $\mathrm{V}^{4+}$, this time in the paramagnetic state, causing a hyperfine shift. Finally, the observation of a ${ }^{51} \mathrm{~V}$ resonance from vanadium metal and a ${ }^{6} \mathrm{Li}$ resonance for $\mathrm{Li}_{2} \mathrm{~S}$ at the end of discharge confirmed the existence of the full conversion mechanism. NMR proved to be powerful for the detection of amorphous intermediates as well as the conversion products because conversion electrodes are known to yield (metallic) nanoparticles, which may not be readily observed in diffraction data.

4.1.3. Intercalation Cathodes. Ex.: Local Structure and Dynamics in $\mathrm{Na}_{3} \mathrm{~V}_{2}\left(\mathrm{PO}_{4}\right)_{2} \mathrm{~F}_{3}$ as a Cathode for Sodium-Ion Batteries. ${ }^{137,159} \mathrm{Na}_{3} \mathrm{~V}_{2}\left(\mathrm{PO}_{4}\right)_{2} \mathrm{~F}_{3}$ is a potential cathode material for Na-ion batteries, with rapid $\mathrm{Na}$ motion being at least partially responsible for its high rate performance. The longrange crystal structure and symmetry is dependent on the Naion content, dynamics, and disorder. Recent ex situ ${ }^{31} \mathrm{P}$ NMR investigations on $\mathrm{Na}_{3-x} \mathrm{~V}_{2}\left(\mathrm{PO}_{4}\right)_{2} \mathrm{~F}_{3}(0 \leq x \leq 1)^{137,159}$ and $\mathrm{Na}_{3} \mathrm{~V}_{2}\left(\mathrm{PO}_{4}\right)_{2} \mathrm{~F}_{3-y} \mathrm{O}_{y}(0 \leq y \leq 0.5)^{160}$ indicate complex local $\mathrm{P}$ environments and different ${ }^{31} \mathrm{P}$ NMR signals that depend strongly on $\mathrm{O} / \mathrm{F}$ ratio and oxidation state. $\mathrm{Na}_{3-x} \mathrm{~V}_{2}\left(\mathrm{PO}_{4}\right)_{2} \mathrm{~F}_{3}$ with $x=0$ was first published in the space group $\mathrm{P}_{2} / \mathrm{mnm}$, comprising $\mathrm{F}-\mathrm{V}\left(\mathrm{O}_{4}\right) \mathrm{FV}\left(\mathrm{O}_{4}\right)-\mathrm{F}$ dimers and $\mathrm{PO}_{4}$ tetrahedra with two crystallographic $\mathrm{Na}$ as well as $\mathrm{P}$ sites in the framework. For $x=0$ (derived by solid-state synthesis route), two intense ${ }^{31} \mathrm{P}$ signals (P1 and P2 at 6096 and 4600 ppm, respectively) were observed which were assigned to the two crystallographic sites; signals due to minor structural defects $\mathrm{P}($ def $)$ and a signal of highly oxidized impurities $\mathrm{P}(\mathrm{ox})$ were also found (Figure 


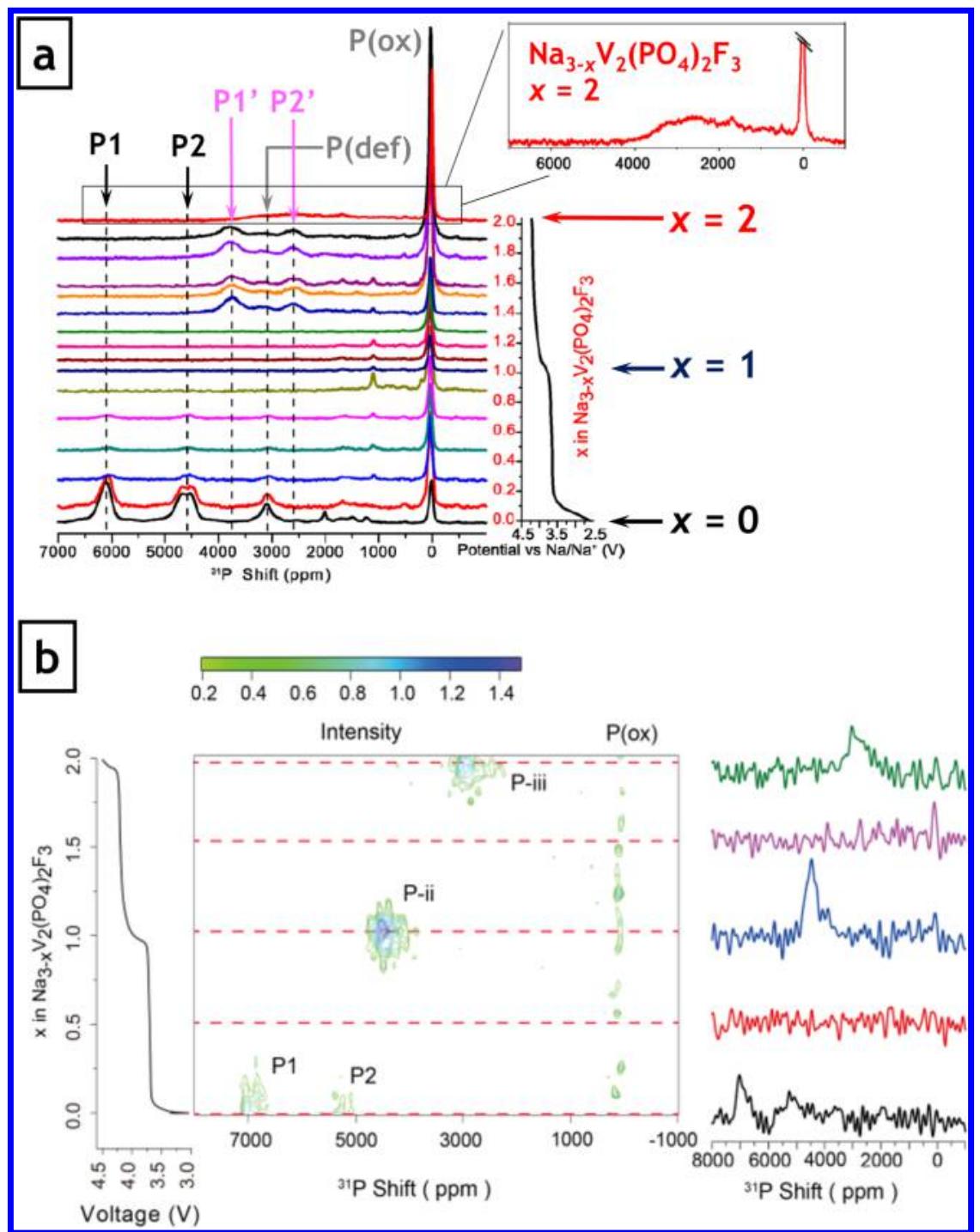

Figure 10. (a) Ex situ ${ }^{31} \mathrm{P}$ MAS NMR spectra of $\mathrm{Na}_{3-x} \mathrm{~V}_{2}\left(\mathrm{PO}_{4}\right)_{2} \mathrm{~F}_{3}(4.7 \mathrm{~T}$, MAS $40 \mathrm{kHz})$ at different states of charge. For $x=0$, two stronger ${ }^{31} \mathrm{P}$ signals (P1 and $\mathrm{P} 2$ ) are observed which are assigned to the $\mathrm{P}$ environments containing all $\mathrm{V}^{3+}(\mathrm{P} 1)$ and one $\mathrm{V}^{4+}$ in the $\mathrm{P}$ local coordination shell; further signals due to other defects in the structure are labeled as $\mathrm{P}\left(\mathrm{def}\right.$; two $\left.\mathrm{V}^{4+}\right)$ as well as an intense signal of highly oxidized impurities $\mathrm{P}($ ox $)$. The inset shows the spectrum of the sample at the end of charge for $x=2$ with the spectral region above $0 \mathrm{ppm}$ scaled up to show the broadening of the former P1' and P2' signals. Adapted and reprinted with permission from Z. Liu et al. Chem. Mater. 2014, 26, 2513 (ref 159). Copyright 2014 American Chemical Society. (b) Charge curve (left), ${ }^{31} \mathrm{P}$ in situ NMR spectra of a $\mathrm{Na}_{3} \mathrm{~V}_{2}\left(\mathrm{PO}_{4}\right)_{2} \mathrm{~F}_{3} / \mathrm{Na}$ cell (middle), and slices of the $2 \mathrm{D}$ NMR contour plot at the horizontally marked (red dashed lines) states of charge at the right. Different phosphorus signals are labeled as P1, P2, P-ii, P-iii, and $\mathrm{P}(\mathrm{ox})$ indicating varying chemical environments due to the crystal structure of the pristine (P1, P2) and desodiated (P-ii, P-iii) material as well as highly oxidized impurities $\mathrm{P}(\mathrm{ox})$, respectively. Reprinted with permission from O. Pecher et al. J. Magn. Reson. 2016, 265, 200 (ref 137). Copyright 2016 Elsevier.

10a). ${ }^{137,159}$ More recent investigations by Broux et al. report $\mathrm{Na}_{3} \mathrm{~V}_{2}\left(\mathrm{PO}_{4}\right)_{2} \mathrm{~F}_{3-y} \mathrm{O}_{y}$ (derived from solid-state synthesis) in space group Amam for $0 \leq y \leq 0.5$ with only one $\mathrm{P}$ and three Na sites. ${ }^{160}$ Here, they (re)assign the up to five ${ }^{31} \mathrm{P}$ NMR signals (for $\mathrm{Na}_{3} \mathrm{~V}_{2}\left(\mathrm{PO}_{4}\right)_{2} \mathrm{~F}_{3-y} \mathrm{O}_{y}$ with $y=0.5$ at 6097, 4583, 3058,1565 , and $0 \mathrm{ppm}$, respectively) to different local $\mathrm{P}$ environments that arise due to varying $\mathrm{V}^{3+} / \mathrm{V}^{4+}$ ratios with respect to the $\mathrm{Na}_{3} \mathrm{~V}_{2}\left(\mathrm{PO}_{4}\right)_{2} \mathrm{~F}_{3-y} \mathrm{O}_{y}$ sample composition and $\mathrm{F} /$ $\mathrm{O}$ ratio, respectively. The $\mathrm{O}$ for $\mathrm{F}$ substitution in the $\mathrm{V}$ local environment causes $\mathrm{V}^{3+}$ to $\mathrm{V}^{4+}$ oxidation and a discrete shift to lower frequencies. ${ }^{160}$ This indicates a significant influence of the synthesis route on the number of defects and distortions of the crystal structure.

Our recent $e x$ situ ${ }^{31} \mathrm{P}$ MAS NMR spectra also show a high sensitivity to local $\mathrm{Na}$ and $\mathrm{P}$ ordering and enabled a study of the mechanisms associated with the structural changes in $\mathrm{Na}_{3-x} \mathrm{~V}_{2}\left(\mathrm{PO}_{4}\right)_{2} \mathrm{~F}_{3}$ during electrochemical cycling (Figure 10a). ${ }^{137,159}$ The $\mathrm{P} 1$ and $\mathrm{P} 2$ signals decrease very quickly upon desodiation and disappear for $x=1$. Moreover, two new $\mathrm{P}$ environments ( $\mathrm{P} 1^{\prime}$ and $\mathrm{P} 2$ ' at 3749 and $2605 \mathrm{ppm}$, respectively) are found for $\mathrm{Na}_{3-x} \mathrm{~V}_{2}\left(\mathrm{PO}_{4}\right)_{2} \mathrm{~F}_{3}$ with $1.4 \leq x<$ 2 (Figure 10a). The $\mathrm{P} 1^{\prime}$ and $\mathrm{P}^{\prime}$ signals are significantly broadened and (overall) shifted to approximately $2800 \mathrm{ppm}$ at the top of charge for $x=2$ (Figure 10a, inset). To gain insights into the structural changes and unravel possible influences of nuclear spin relaxation and $\mathrm{Na}$ dynamics, we recently applied ${ }^{31} \mathrm{P}$ ATMC in situ (here: operando) NMR with an automatic recalibration of the carrier frequency to cover the huge frequency range of the measurement. ${ }^{137}$ While the number and shift of signals is identical for $x=0$, in situ ${ }^{31} \mathrm{P}$ NMR reveals 


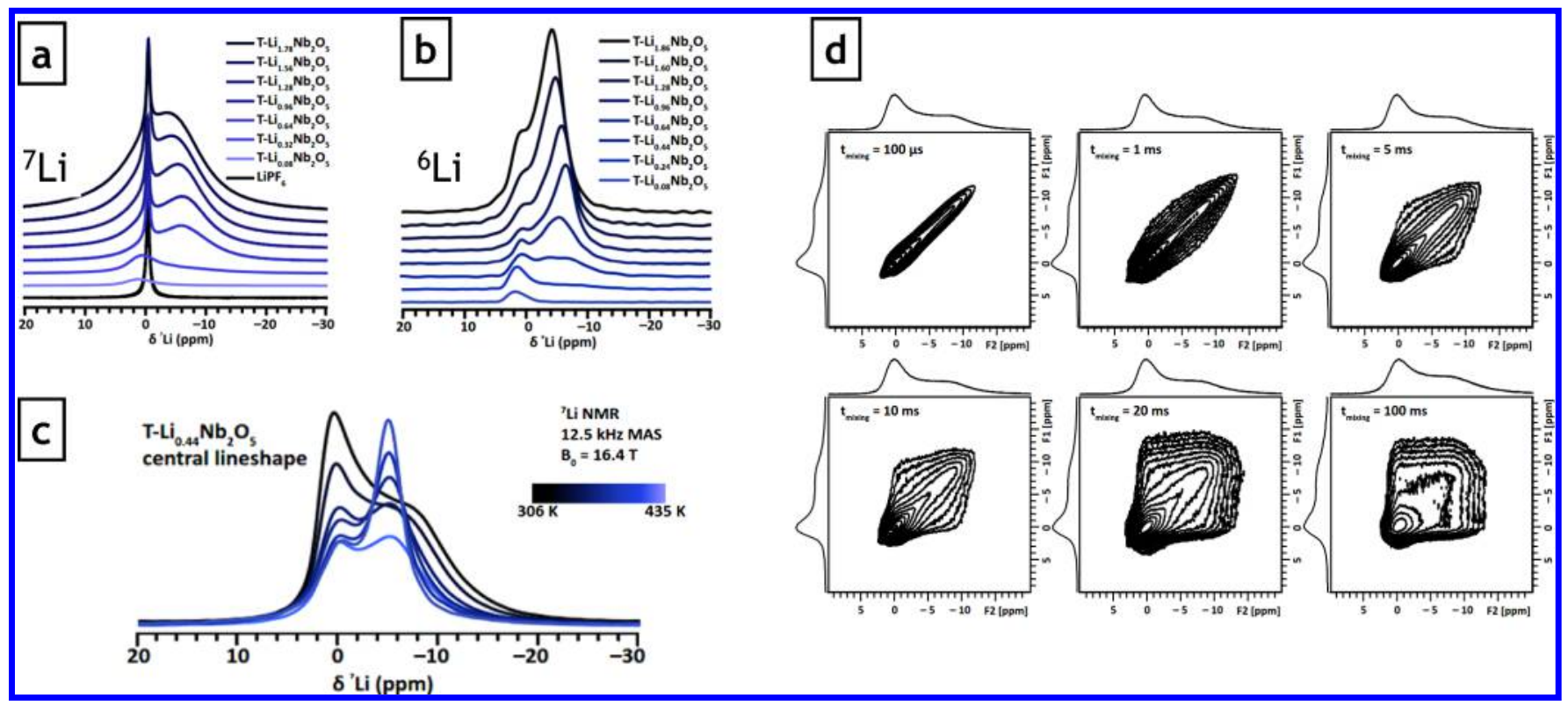

Figure 11. (a) Low magnetic field strength $(4.7 \mathrm{~T}){ }^{7} \mathrm{Li}$ MAS NMR spectra of $\mathrm{T}-\mathrm{Li}_{x} \mathrm{Nb}_{2} \mathrm{O}_{5}$ from $0<x<2$. (b) High magnetic field strength (16.4 T) ${ }^{6} \mathrm{Li}$ MAS NMR spectra of $\mathrm{T}-\mathrm{Li}_{x} \mathrm{Nb}_{2} \mathrm{O}_{5}$ from $0<x<2$. (c) Variable temperature ${ }^{7} \mathrm{Li}$ MAS NMR spectra of $\mathrm{T}_{-}-\mathrm{Li}_{0.44} \mathrm{Nb}_{2} \mathrm{O}_{5}$, and $(\mathrm{d}){ }^{7} \mathrm{Li}$ exchange spectroscopy plots for $\mathrm{T}-\mathrm{Li}_{0.44} \mathrm{Nb}_{2} \mathrm{O}_{5}$ as a function of exchange (mixing) time. Reprinted with permission from K. Griffith et al. J. Am. Chem. Soc. 2016, 138, 8888 (ref 26). Copyright 2016 American Chemical Society.

a new P-ii signal with approximately the sum of the P1+P2 signal intensities for $x=1$ (Figure 10b). Upon further desodiation to $x=2$, an additional shift to lower frequencies for a P-iii signal (as seen by ex situ NMR, Figure 10a, inset) is found. The number and shifts of the signals measured in situ are reversible upon sodiation (Figure 10b).

The ex situ detection of two P signals ( $\mathrm{P} 1^{\prime}$ and $\left.\mathrm{P} 2^{\prime}\right)$ vs the sequential detection of P-ii and the P-iii (in situ) may be related to $\mathrm{Na}$ ordering that may occur for samples that have been allowed to relax before data collection. In contrast, the samples measured in situ are likely to contain a higher $\mathrm{Na}$ disorder, which might be associated with the increased $\mathrm{Na}$ mobility resulting in collapse of ${ }^{31} \mathrm{P}$ signals and possibly loss of some ${ }^{31} \mathrm{P}$ NMR signal intensity. The study reveals the potential of in situ NMR to gain insights beyond the scope of ex situ techniques, in particular by applying new ATMC in situ NMR approaches allowing an automated recalibration of the RF circuit during the experiment.

4.1.4. Intercalation Anodes. Ex.: High-Rate Intercalation without Nanostructuring in Metastable $\mathrm{Nb}_{2} \mathrm{O}_{5}$ Bronze Phases. ${ }^{26} \mathrm{~T}_{-} \mathrm{Nb}_{2} \mathrm{O}_{5}$ - the low temperature polymorph of niobia-exhibits high-rate electrochemical behavior even when the particles have micrometer-sized morphologies. This is unusual compared to other high-rate electrode materials, e.g., $\mathrm{LiFePO}_{4}, \mathrm{Li}_{4} \mathrm{Ti}_{5} \mathrm{O}_{12}, \mathrm{TiO}_{2}$, that must be nanoscaled to suppress phase transitions and decrease ionic and electronic diffusion distances in order for them to perform well. Complementary ${ }^{6 ; 7} \mathrm{Li}$ NMR studies revealed two distinct lithium resonances and thus lithium populations in $\mathrm{T}-\mathrm{Nb}_{2} \mathrm{O}_{5}$; a small, rigid population that is occupied at low lithiation levels and a distribution of mobile lithium sites that represents the majority species (Figure $11 \mathrm{a}, \mathrm{b})$. Note that the electrolyte peak from residual $\mathrm{LiPF}_{6}$ can generally be removed by rinsing the electrode with a solvent such as dimethyl carbonate. Although ${ }^{7} \mathrm{Li}$ offers higher signal (higher N.A., higher gyromagnetic ratio), ${ }^{6} \mathrm{Li}$ may offer substantially higher resolution. The lighter isotope experiences smaller dipolar and quadrupolar broadenings due to a lower gyromagnetic ratio and nuclear quadrupole moment, respectively (Section 3.3.5, Table 2). ${ }^{7} \mathrm{Li}$ VT NMR spectroscopy (Figure 11c), relaxometry, and two-dimensional exchange spectroscopy (EXSY, Figure 11d) revealed that the mobile lithium exchange rapidly and are characterized by activation energies for lithium hopping of $<100 \mathrm{meV}\left(\mathrm{a}\right.$ few $\left.k_{\mathrm{B}} \mathrm{T}\right)$.

4.2. Microstructure Formation. Dendrite formation occurs upon cycling in both lithium and sodium cells with metallic anodes and can lead to short circuiting, which causes cell failure and presents a serious fire/explosion risk. This is particularly unfortunate as metal anodes have no wasted mass or volume and thus represent the highest theoretical capacity. To design strategies to suppress dendrite formation, it is beneficial to identify first the microstructural characteristics, growth mechanisms, and key factors that contribute to dendrite formation (e.g., current density, electrolyte salt, solvents, additives).

4.2.1. Li Microstructures. Ex.: In Situ NMR Observation of the Formation of Metallic Li Microstructures in $\mathrm{Li}$ Batteries. ${ }^{161}$ Mossy, dendritic growth occurs on lithium metal anodes during cycling, as observed via microscopy methods. To gain quantitative, time-resolved insight into this phenomenon, in situ (here, operando) ${ }^{7} \mathrm{Li} \mathrm{NMR}$ was performed on $\mathrm{Li} / \mathrm{LiCoO}_{2}$ cells and symmetric $\mathrm{Li} / \mathrm{Li}$ cells. Because of the aforementioned Knight shift (Section 3.2), the ${ }^{7} \mathrm{Li}$ resonance corresponding to $\mathrm{Li}$ metal appears at $+260 \mathrm{ppm}$, which is well separated from electrolyte or SEI signals. The penetration of RF fields used to excite nuclear transitions in NMR is severely limited through metal samples, an effect known as skin depth. Because the skin depth (ca. $10-20 \mu \mathrm{m}$ ) is usually an order of magnitude larger than the dendrite thickness, the RF signal fully penetrates any mossy, dendritic structures whereas the signal of the bulk metal appears constant and depends on the area of the anode. Thus, it is possible to correlate changes in the intensity of the $\mathrm{Li}$ metal peak during cycling to the growth of mossy/dendritic microstructures vs. smoothly deposited metal. In situ NMR was able to determine that up to $90 \%$ of lithium deposited 


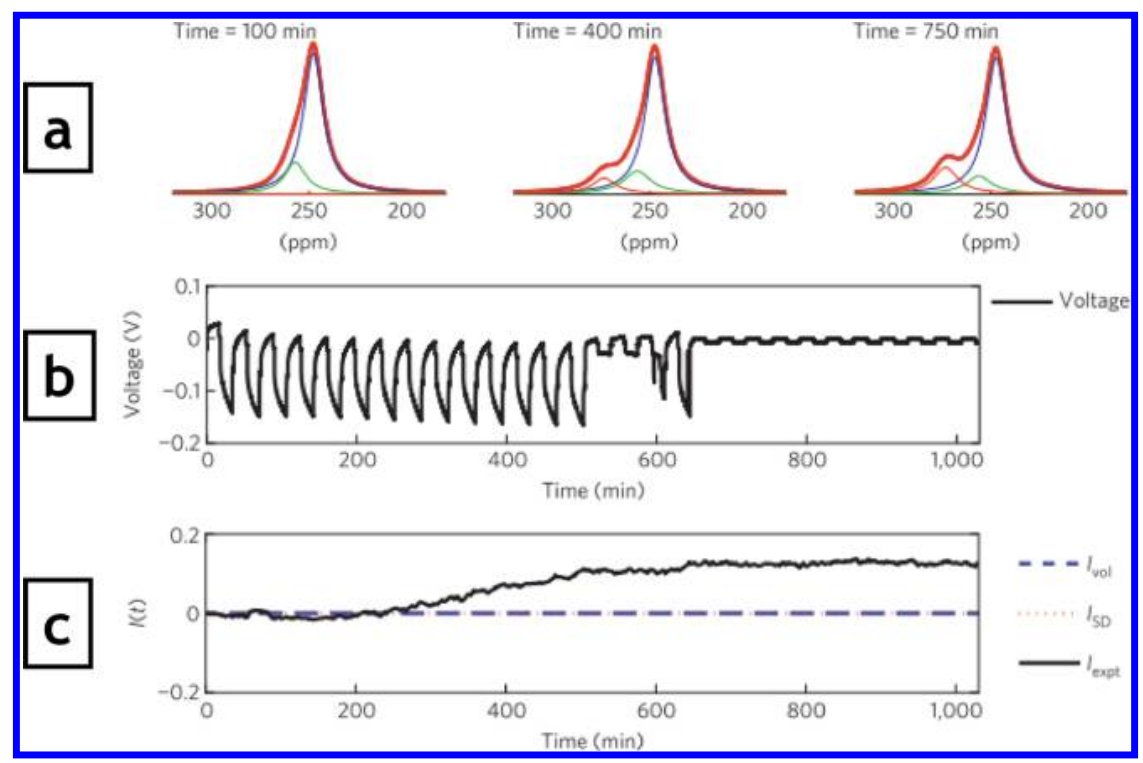

Figure 12. (a) Deconvoluted in situ ${ }^{7} \mathrm{Li}$ NMR spectra of the lithium metal peak from a $\mathrm{Li} / \mathrm{LiCoO}_{2}$ cell as a function of time. The deconvoluted peaks used to fit the NMR data are indicated with thin red, blue and green lines. The thick red line and blue line show the fit and the experimental spectra, respectively (further details of the fit to be found in ref 161). (b) Voltage curve of a $\mathrm{Li} / \mathrm{Li}$ symmetric cell under galvanostatic cycling during an in situ ${ }^{7} \mathrm{Li}$ NMR measurement. (c) Li metal intensity as measured by ${ }^{7} \mathrm{Li}$ NMR from the cycling experiments in panel b. Li metal intensity increases as a function of surface area with the increase in intensity indicating the formation of mossy/dendritic lithium. Lithium microstructures form (increased intensity in panel c) prior to the short-circuiting of the cell (anomalous features in electrochemistry (b)). Reprinted with permission from R. Bhattacharyya et al. Nat. Mater. 2010, 9 (6), 504 (ref 161). Copyright 2010 Macmillan Publishers Limited.

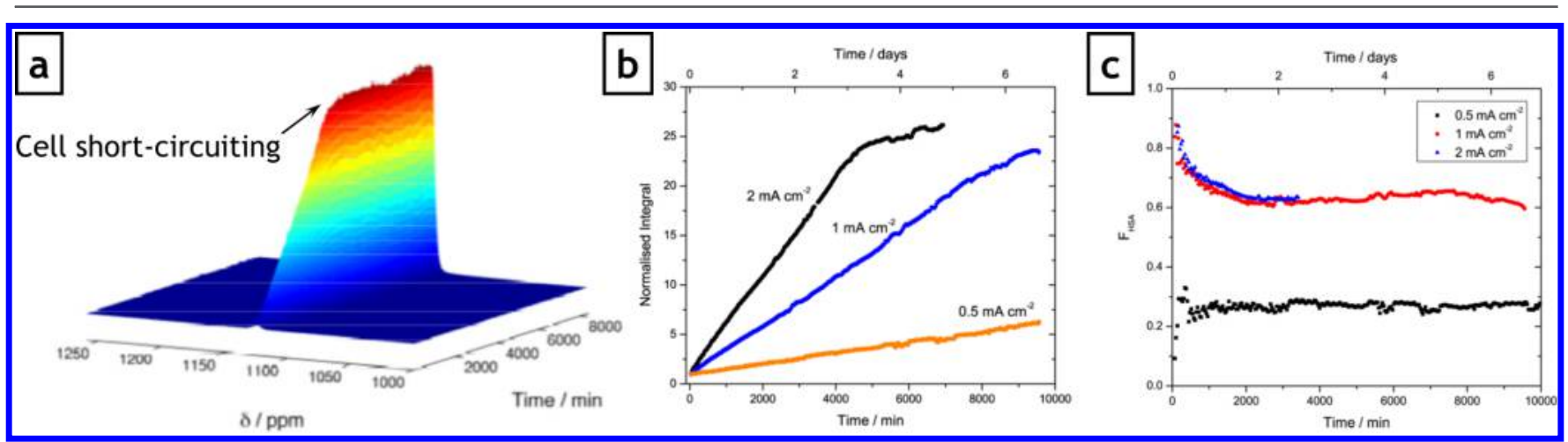

Figure 13. (a) In situ ${ }^{23} \mathrm{Na} \mathrm{NMR}$ signal of the Na metal peak grows until the cell short circuits. (b) Integral of the normalized ${ }^{23} \mathrm{Na}$ metal resonance for galvanostatic cycling at three different current densities. (c) Fraction of HSA Na during galvanostatic cycling at various current densities; a ratio of 1 indicates completely rough deposition whereas 0 indicates smooth deposition. Reprinted with permission from P. M. Bayley et al. J. Am. Chem. Soc. 2016, 138, 1955 (ref 158). Copyright 2016 American Chemical Society.

during slow charge of a $\mathrm{Li} / \mathrm{LiCoO}_{2}$ cell was dendritic and to quantify the effects of rate and electrolyte-solvent on microstructure formation and cell failure during plating and stripping in symmetric $\mathrm{Li} / \mathrm{Li}$ cells (Figure 12). This technique can be employed to test strategies for dendrite suppression systematically, e.g., electrolyte additives, advanced separators, cell pressure, temperature, and electrochemical cycling conditions.

4.2.2. Na Microstructures. Ex.: Insights into Sodium Metal Deposition as Probed with in Situ ${ }^{23} \mathrm{Na} N \mathrm{NMR} .{ }^{158}$ Analogously to the case of dendritic $\mathrm{Li}$ growth, $\mathrm{Na}$ anodes form high surface area (HSA) microstructures upon cycling. An in situ (here, operando) ${ }^{23} \mathrm{Na} \mathrm{NMR}$ study of $\mathrm{Na}-\mathrm{Na}$ symmetric cells revealed that electrochemical $\mathrm{Na}$ metal deposition (under the conditions used) continually formed HSA microstructures, even when the current was reversed (Figure 13a,b). Additionally, a comparison of the fraction of HSA Na detected by the NMR experiment $\left(m_{\mathrm{NMR}}\right)$ and the total accumulated mass derived from Faraday's law $\left(m_{\mathrm{eChem}}\right)$-denoted as $F_{\mathrm{HSA}}=m_{\mathrm{NMR}} / m_{\mathrm{eChem}}$ - enabled two types of HSA Na formation (Figure 13c) to be distinguished: smooth deposition and stripping (reversed current) regime with $F_{\mathrm{HSA}} \sim 0$ for low current densities $\left(0.5 \mathrm{~mA} \mathrm{~cm}{ }^{-2}\right)$ and a rough deposition regime $\left(F_{\mathrm{HSA}} \sim 1\right.$ for current densities $>0.5$ $\mathrm{mA} \mathrm{cm}^{-2}$ ) with minimal removal of HSA Na upon current reversal (Figure 13c). With this information, it may be possible to mitigate the prevalence of microstructures and the risk of short circuiting a cell through management of the operating parameters.

4.3. Electrolytes and Interfaces. In addition to the active electrode materials, battery operation is fundamentally dictated by ion transport through interfaces and the electrolyte. Can NMR help to understand the influence of electrolytes and interfaces, e.g., SEI formation?

4.3.1. SEl Formation. Ex.: Voltage Dependent Solid Electrolyte Interphase Formation in Si Electrodes: Monitoring the Formation of Organic Decomposition Products. ${ }^{17}$ It 
is the formation of a stable, ion-conducting, electron-resistive SEI that enables the use of all secondary batteries with electrode potentials outside the electrolyte stability window (Section 1.1, Figure 1b). For commonly employed carbonate solvents, low voltage anodes (e.g., lithium metal, graphite, silicon) and high voltage cathodes (e.g., $\mathrm{LiNi}_{0.5} \mathrm{Mn}_{1.5} \mathrm{O}_{4}$ and nickel-rich NMCs) are unstable and undergo electron transfer reactions with the electrolyte. In addition, many oxide cathodes are known to evolve $\mathrm{O}_{2}$ above $4.3 \mathrm{~V}$ vs $\mathrm{Li}^{+} / \mathrm{Li}$. A satisfactory understanding of the SEI is obstructed by a myriad of complications: organic and inorganic components; amorphous phases; nanometer thickness; and dependence on particle size, current density, electrolyte-solvent, additives, water content, voltage, cycle, temperature, and pressure. Despite these challenges, the nuclei-specificity and localized nature of NMR enables the separation and (quantitative) identification of many aspects of the SEI. For alloying electrodes such as $\mathrm{Si}$, it still remains a significant challenge to form a stable SEI. A combined investigation of ${ }^{1} \mathrm{H},{ }^{7} \mathrm{Li},{ }^{19} \mathrm{~F}$, and (selectively enriched) ${ }^{13} \mathrm{C}$ identified the voltage-dependent decomposition products of carbonate solvents and $\mathrm{LiPF}_{6}$ salt on $\mathrm{Si}$ electrodes (Figure 14). Inorganic $\mathrm{LiF}$ and $\mathrm{Li}_{2} \mathrm{CO}_{3}$ were observed directly. Although the lithium NMR alone was too broad to distinguish individual components (Figure 14a), two-dimensional NMR techniques were able to determine connectivity and identify organic components such as $\mathrm{ROCO}_{2} \mathrm{Li}(\mathrm{R}=\mathrm{H}$, hydrocarbon group) and short poly(ethylene oxide)-type (PEO) oligomers (Figure 14c,d). Ethylene carbonate (EC) decomposition primarily yielded the PEO oligomers whereas the major breakdown product of dimethyl carbonate (DMC) was lithium methyl carbonate.

4.3.2. Solid Electrolytes. Ex.: Insights into Fast Li-lon Conduction in $\mathrm{Li}_{4} \mathrm{SiO}_{4}-\mathrm{Li}_{3} \mathrm{PO}_{4}$ Solid Electrolytes. ${ }^{141}$ The transition from liquid to solid electrolytes would improve battery safety by removing the flammable liquid component and creating a mechanical barrier to dendrite formation and short circuits. The main challenge for solid electrolytes is inherently slower diffusion in the solid state. In this area, NMR can be applied as both a structural probe and a measure of ion dynamics; ${ }^{6} \mathrm{Li}$ (at N.A.) offers narrow NMR signal line widths in the (generally) highly crystalline solid electrolytes whereas the improved signal-to-noise of ${ }^{7} \mathrm{Li}$ allows multiple variable temperature spectra to be collected in a time-efficient manner (Sections 3.3.5 and 3.4).

In the solid electrolyte material $\mathrm{Li}_{3+x}\left(\mathrm{Si}_{x} \mathrm{P}_{1-x}\right) \mathrm{O}_{4}$, lithium conductivity depends strongly on the value of $x$. Structurally, ${ }^{6} \mathrm{Li}$ MAS NMR revealed lithium coordinated to 3-6 oxygen atoms. Dynamics, as measured with VT ${ }^{7} \mathrm{Li} \mathrm{NMR}$ relaxometry to derive activation energies (Figure 15) and correlated with theory, indicated an activation barrier for lithium hopping of around $200 \mathrm{meV}$ for the relatively high conducting intermediate composition phases. Understanding the mechanism of conductivity improvements, in this case via disorder in the polyanionic network, can lead to new solid electrolytes with improved performance.

4.3.3. Interfaces. Ex.: Monitoring Electrochemical Processes in the $\mathrm{Li}_{-} \mathrm{O}_{2}$ Battery by NMR. ${ }^{162,163}$ The development of the $\mathrm{Li}$-air battery is still at an early stage with operating cells still far from achieving their theoretical capabilities. As such, essentially all parts of the battery have been studied, from the metal anode to the electrolyte and the cathode accommodating the reaction between lithium and oxygen, for both the discharge and charge mechanisms. Monitoring the formation and

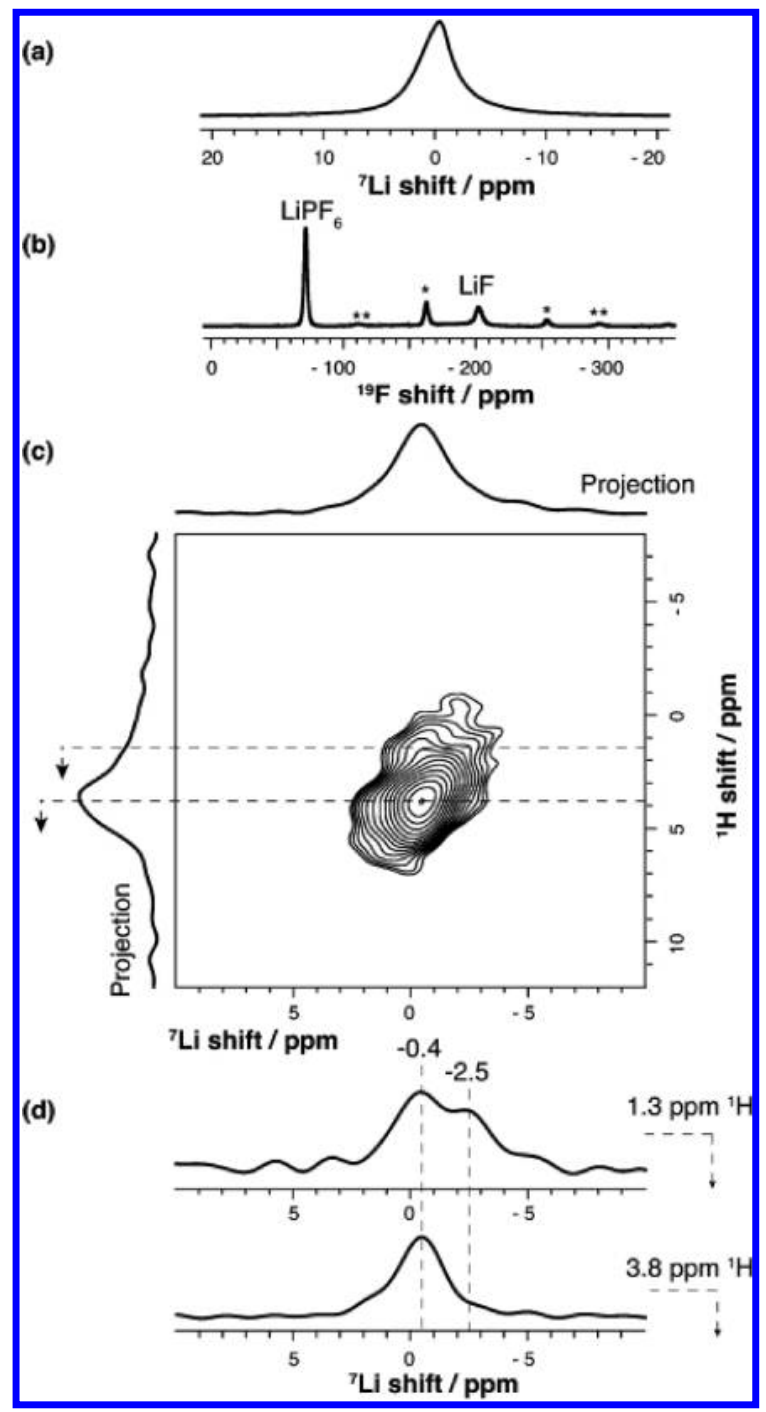

Figure 14. Unrinsed $\mathrm{C} / \mathrm{Si}$ electrode sample discharged to a $1 \mathrm{mV}$ limit, investigated by (a) ${ }^{7} \mathrm{Li}$, (b) ${ }^{19} \mathrm{~F}$, and (c) ${ }^{1} \mathrm{H}-{ }^{7} \mathrm{Li}$ heteronuclear dipolar correlation solid-state NMR experiments. Slices of the $2 \mathrm{D}$ spectrum are shown in panel $\mathrm{d}$ corresponding to ${ }^{1} \mathrm{H}$ chemical shifts of 1.3 and $3.8 \mathrm{ppm}$. MAS sidebands of $\mathrm{LiPF}_{6}$ and $\mathrm{LiF}$ are indicated by $(*)$ and $(* *)$, respectively. Reprinted with permission from A. L. Michan et al. Chem. Mater. 2016, 28, 385 (ref 17). Copyright 2016 American Chemical Society.

decomposition of electrochemical products is a crucial step in the design and optimization of a rechargeable $\mathrm{Li}-\mathrm{O}_{2}$ battery. Solid-state NMR measurements have been employed to investigate the $\mathrm{Li}-\mathrm{O}_{2}$ battery, to monitor the evolution of the electrochemical products formed during cycling, and to gain insight into processes affecting capacity fading. NMR has advantages over many other spectroscopic techniques in that it can be quantitative and sensitive to the entirety of the sample, and is not limited by the size and degree of crystallinity of the particles formed during cycling.

Among the main insights, we highlight the identification-by ${ }^{17} \mathrm{O}$ NMR - of (i) lithium peroxide as the predominant product in the first discharge in 1,2-dimethoxyethane (DME) based electrolytes and (ii) the reaction of $\mathrm{Li}_{2} \mathrm{O}_{2}$ with the carbon cathode surface to form carbonates during the charging process (Figure 16). Moreover, ${ }^{13} \mathrm{C}$ NMR provides evidence for carbonate formation on the surface of the carbon cathode, 


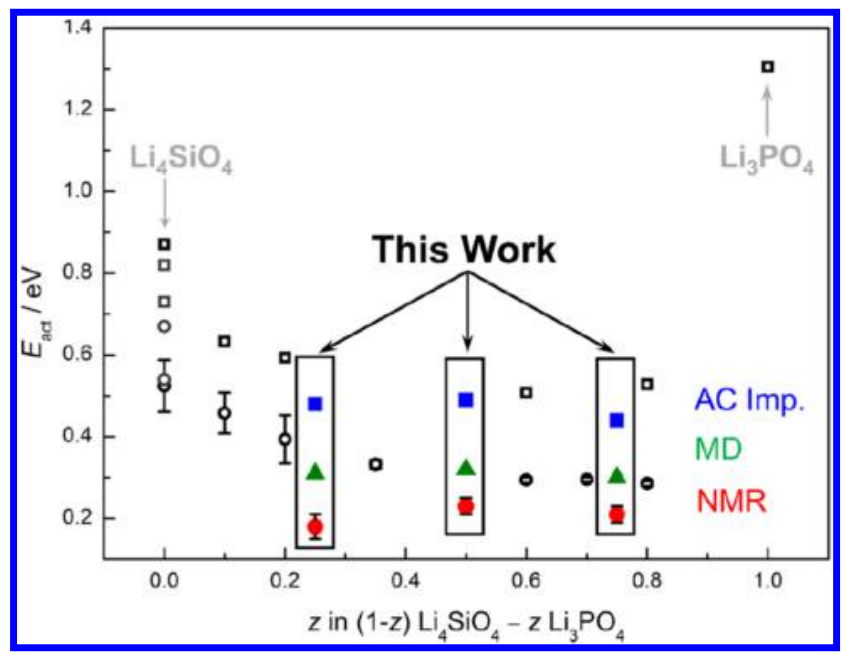

Figure 15. Activation energies $E_{\mathrm{a}}$ derived from conductivity (squares), NMR (circles) measurements, and $\mathrm{MD}$ modeling (triangles) for $\mathrm{Li}_{4} \mathrm{SiO}_{4}-\mathrm{Li}_{3} \mathrm{PO}_{4}$ samples. Data from previous studies is depicted in black and the values derived by the study in blue, green, and red. Reprinted with permission from Y. Deng et al. J. Am. Chem. Soc. 2015, 137, 9136 (ref 141). Copyright 2015 American Chemical Society.

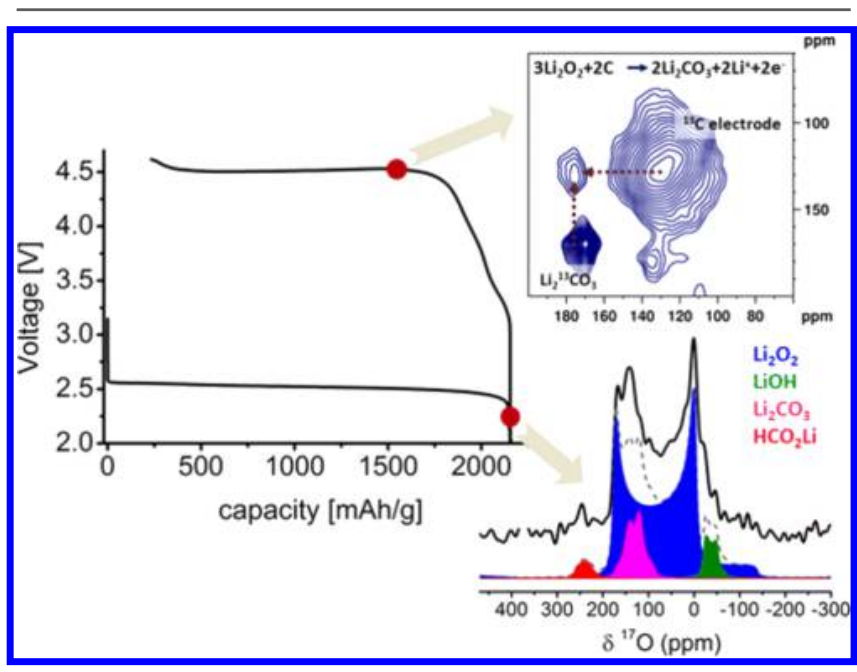

Figure 16. Solid-state NMR indicates that rechargeability of the $\mathrm{Li}-\mathrm{O}_{2}$ cell (left) is limited by electrolyte and electrode stability during cycling. ${ }^{13} \mathrm{C}-{ }^{13} \mathrm{C} 2 \mathrm{D}$ homonuclear dipolar correlation NMR experiments (top right) of the charged electrode material showing the reaction between the discharge products such as $\mathrm{Li}_{2} \mathrm{O}_{2}$ and the ${ }^{13} \mathrm{C}$ enriched cathode support. Static ${ }^{17} \mathrm{O}$ NMR experiments with signals of the products formed after discharge of the $\mathrm{Li}-\mathrm{O}_{2}$ battery (bottom right). Reprinted with permission from M. Leskes et al. J. Phys. Chem. C 2013, 117, 26929 (ref 163). Copyright 2013 American Chemical Society.

the carbonate being removed at high charging voltages in the first cycle but accumulating in later cycles. Small amounts of lithium hydroxide and formate are also detected in discharged cathodes, and although the hydroxide formation is reversible on charging to greater than $4 \mathrm{~V}$, the formate persists and accumulates in the cathode upon further cycling. These results indicate that the rechargeability of the battery is limited by both the electrolyte and the carbon cathode stability. The utility of NMR spectroscopy in directly detecting product formation and decomposition within the battery is demonstrated and is a necessary step in the assessment of new electrolytes, catalysts, and cathode materials for the development of a viable $\mathrm{Li}-\mathrm{O}_{2}$ battery.

\section{HOW TO GET STARTED}

Electrochemical energy storage and the characterization of batteries are huge fields with many suppliers for materials and devices as well as numerous approaches to combine ideas, knowledge, and practical skills. In the following, we will illustrate some of our hands-on experience on material synthesis, cell assembly and, in particular, solid-state NMR investigations focusing on the setup of in situ NMR experiments.

5.1. Synthesis, Casting Films, Electrochemical Cycling, and ex Situ NMR. Solid-state synthesis, one of many routes (Section 1) to obtain battery material powders, starts with weighing the precursor phases and often grinding or ball milling followed by thermal treatment of (a pellet pressed from) the mixed powders (Figure 17a). After reaction, the pellet is ground and should be checked for phase purity, e.g., by XRD (Section 1.2, Figure 2, Table 1). Next, the powder (active material) is mixed with carbon to increase conductivity and a polymer binder to increase mechanical stability (Figure 17a). Often, a film is now cast from this mixture to ensure a homogeneous distribution, equal thickness, and easy handling for the next step: punching out electrode discs for cell assembly (Figure 17b). Electrochemical cycling can be used for both achieving a distinct state of charge of the materials under investigation and for testing the electrochemical performance of the material under various conditions (Section 2). The use of coin cells is a very common approach to perform these experiments and consist of a cathode film (or powder), porous separator soaked with electrolyte, and anode film (Figure 17c). Other cell designs, e.g., Swagelok cells, are of course also reasonable and sometimes preferable due to a lower amount of waste produced (the casing, gasket, spacer disc, and spring of each coin cell are not generally reusable) and, hence, lower cost. In practice, electrode testing, both for cathodes and anodes, is usually carried out against the alkali metal (e.g., Li, $\mathrm{Na}$ ) directly. Such "half-cells" employ an excess of the metal, which is assumed to maintain a constant potential; this alleviates the need for electrode balancing, enables the counter electrode to serve also as the reference electrode, and decreases the number of variables in the system. Theoretical capacity $\left(Q_{\text {theoretical }}\right.$ in $\left.\mathrm{mA} \cdot \mathrm{h} \cdot \mathrm{g}^{-1}\right)$ may be calculated from $Q_{\text {theoretical }}=(n$. $\mathrm{F}) /(3.6 \cdot m)$ using the number of electrons transferred $(n)$, Faraday's constant $\left(F=96485.3 \mathrm{C} \cdot \mathrm{mol}^{-1}\right)$, the molecular mass of the active material $\left(m\right.$ in $\left.\mathrm{g} \cdot \mathrm{mol}^{-1}\right)$, and the scaling factor 3.6 to convert Coulombs to the conventional unit $\mathrm{mA} \cdot \mathrm{h}$. Once the desired battery material powder (or film) has been synthesized, the application of ex situ XRD and NMR can be useful to gain structural and electronic insights into the material as well as for optimization of in situ parameters (Section 4). Because NMR is a comparably expensive, time-consuming and non-phasediscriminating experimental technique, the choice of the right sample (e.g. single phase) is a crucial step. Otherwise, the NMR signals of both the majority and minority, i.e., impurity, phases will be detected during the measurement and the line shape analysis/interpretation might become more challenging.

In particular, the packing of an NMR rotor for ex situ MAS NMR experiments can be challenging, depending on the size of the rotor and material stability (Figure 18). NMR rotors are generally made from a highly precise $\mathrm{ZrO}_{2}$ cylinder in which the powder sample is packed and afterward tightly enclosed 


\section{a Solid-State Synthesis of Battery Material Powders}

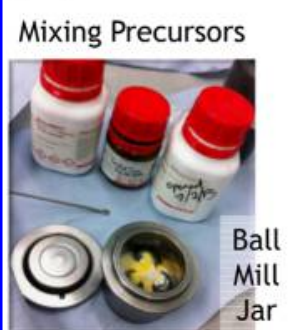

Thermal Treatment

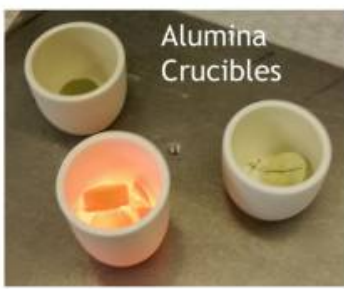

Various $\left(\mathrm{Nb}_{2} \mathrm{O}_{5}\right)$ Powders

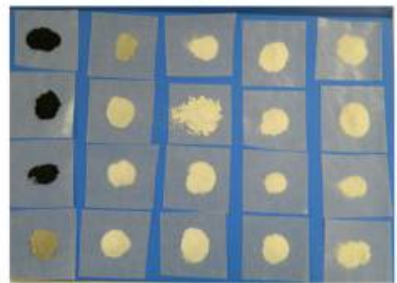

Active Material About to Be Ground with Carbon

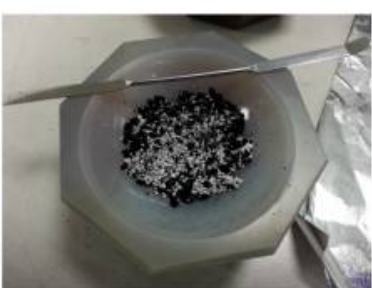

\section{b Cast Electrode Films}

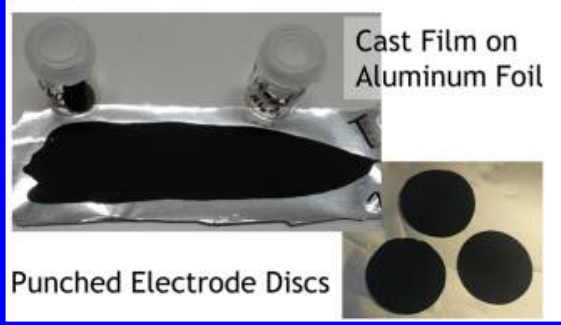

c Coin Cell Preparation

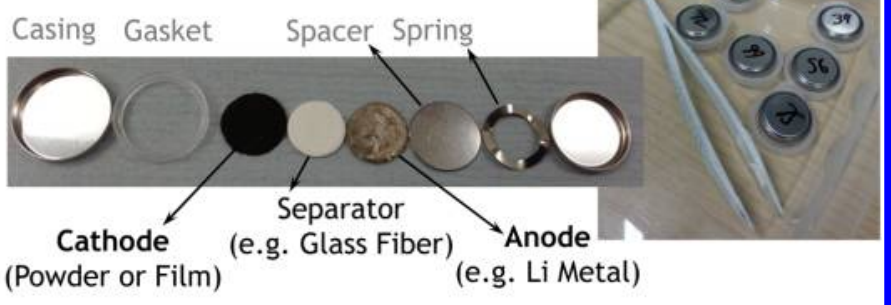

Figure 17. (a) One solid-state synthesis route for battery material powders involves weighing the precursor phases and ball milling. Next steps might involve thermal treatment and to check on phase purity using, e.g., XRD. Mixing the active material (powder sample) with graphitic carbon is a crucial step to increase the conductivity. (b) The mixture is now used to cast an electrode film, e.g., on an Al foil substrate, from which electrode discs are punched for further electrochemical experiments, e.g., using coin cells. (c) Coin cells are a common way to synthesize a battery material to a certain state of charge (for further investigations) as well as to explore the electrochemical performance of a material. The various components of the coin cell as well as assembled coin cells are depicted and labeled.

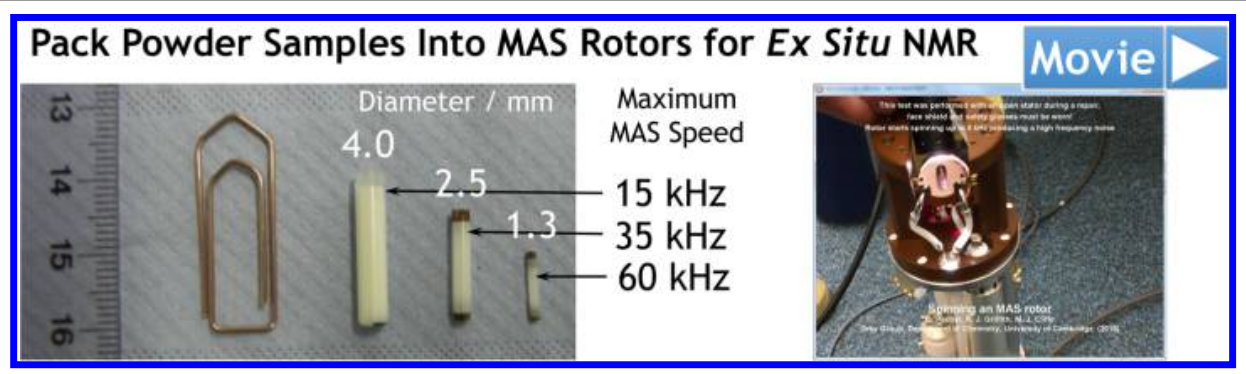

Figure 18. Packing a powder sample into $\mathrm{ZrO}_{2}$ rotors for ex situ MAS NMR investigations is a common strategy. The smaller the rotor diameter, the higher the maximum MAS spinning speed, which improves the experimental resolution in many cases. Furthermore, the weight of the powder sample might also influence (reduce) the maximum MAS spinning speed. See the Supporting Information to watch a movie of a spinning rotor (for a tutorial on rotor packing: http://www.theresonance.com/nmr-tutorial-mas-rotor-filling/).

with special plastic or ceramic caps, depending on the temperature regime of the desired NMR experiment; a tutorial on packing a MAS rotor is available online (http://www. theresonance.com/nmr-tutorial-mas-rotor-filling/). Spinning of the rotor is then enabled via slowly increasing gas flows (dry air or nitrogen), which keep the rotor floating within the coil of the NMR probehead (bearing gas) and spinning via specially designed top caps with wings (drive gas) (Figure 18); a short movie of a $4.0 \mathrm{~mm}$ rotor starting to spin is provided in the Supporting Information. The smaller the diameter of the rotor, the higher the MAS speeds that can be achieved, which is useful to increase the experimental resolution (Section 3.3). However, the smaller the rotor the more difficult it is to pack (especially inside a glovebox under inert gas, as required for air-sensitive samples). Furthermore, spinning of conductive samples (e.g., metallic and carbon species) might be challenging due to intrinsic heating by eddy currents. Similar problems might occur for paramagnetic materials at high magnetic fields due to their intrinsic magnetic moment. Reducing the particle size and/or dilution of the powder sample with unreactive, diamagnetic materials, e.g., $\mathrm{NaCl}, \mathrm{KBr}, \mathrm{GeO}_{2}, \mathrm{Y}_{2} \mathrm{O}_{3}$, or $\mathrm{TiO}_{2}$, can be helpful in these cases. In particular for the oxides, it is crucial that no reactions between the diluting oxide and sample occur, which might be the case for highly reduced samples.

5.2. Preparation of Self-Standing Cathode Films and Metal Anode Films. The type of electrochemical in situ cell design used (Section 3.5) defines the optimal way to prepare the cell component; e.g., Bellcore's plastic rechargeable LIB is composed of plasticized polymer laminates with a carbon based negative electrode, a plastic electrolyte separator, and a positive electrode laminate; the cell assembly is done in three laminating steps. ${ }^{138,150}$ In contrast, we will report on the straightforward use of self-standing cathode films, glass fiber separators, and metal anodes in both bag cells and our new plastic cell capsule design (Sections 5.3 and 5.4). The use of the plastic cell capsule design is potentially easier than other cell assemblies (Section 3.5) and shows a great potential to balance lab scale in situ NMR sample preparation with experimental efforts. 


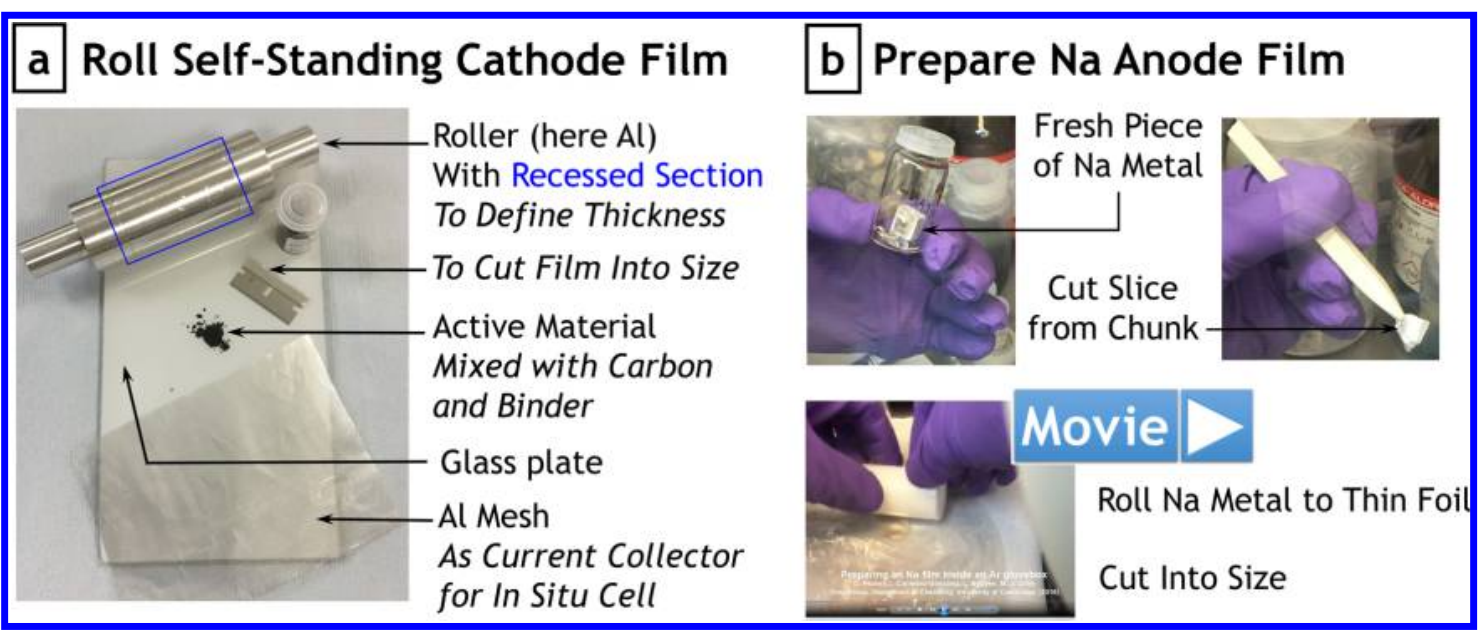

Figure 19. (a) Equipment to prepare an electrode film for use in a cell for in situ NMR experiments. Rollers (here, made of aluminum) with a recessed section (blue rectangle) can be machined by mechanical workshops using a lathe. (b) Preparation of thin Na metal films (as a metal anode) is more difficult than handling $\mathrm{Li}$ metal. See the Supporting Information for a movie on the preparation of a thin Na metal foil.

In particular, we will address one straightforward method that was successfully applied to produce self-standing $\mathrm{LiFePO}_{4}$ cathode films (Figure 19a). ${ }^{137}$ Here, the active material (e.g., carbon-coated $\mathrm{LiFePO}_{4}$ powder) is mixed with polytetrafluoroethylene (PTFE) binder and carbon in the desired mass ratio (with approximately $10 \mathrm{wt} \%$ binder usually being sufficient) and strongly ground in a mortar for 20 min until sticky layers of the composite result. Conductive carbon can also be added. These are now rolled on a glass plate until a homogeneous layer of the desired thickness (e.g., $1 \mathrm{~mm}$, defined by a roller with a recessed section; Figure 19a) results; during the rolling process the layers normally have to be cut and put on top of each other again to give a homogeneous layer. Finally, length and width of the film are determined by cutting it into size using a razor blade. Here, the cell design (see next subsection) defines the dimension of the film, typically $6 \times 9 \mathrm{~mm}$. After the film is weighed, it can be pressed onto a metal mesh, which works as the current collector (Figure 19a). Sometimes, the mesh needs to be hammered on the film (or a pellet press used) because a good connection between the mesh and the film is key for a good working electrochemistry. On the other hand, the connection between the metal anode with a wire or mesh is straightforward but the preparation of a thin metal film with clean and shiny surfaces can be tricky.

For Li metal, the use of commercially available Li foil, which is cleaned using a soft brush and then cut to size using scissors or a razor blade (n.b. sometimes ceramic cutting tools should be used so as not to contaminate the material), makes the task relatively straightforward; the handling of $\mathrm{Na}$ can be more nerve-racking because $\mathrm{Na}$ is stickier and more reactive. Starting with freshly prepared $\mathrm{Na}$ from commercially available cubes (washed with hexane and dried with paper inside the glovebox), we found that rolling the pieces on a polypropylene plastic surface with a PTFE roller is a very straightforward method to give thin and shiny (clean) surfaces (Figure 19b). After the rolling step, the $\mathrm{Na}$ sheet is cut to size with a razor blade and used in the assembly of the cell.

5.3. Preparation of Electrochemical Cells for in Situ NMR Experiments. A common way to create a working device inside of a NMR coil is the use of plastic bag cells (Figure 20a). The basis for its assembly is commercially available flexible polyester or polypropylene bags in which the cell components-current collector mesh, electrode, separator soaked with liquid electrolyte, electrode, and current collector mesh-are stacked, pressed together and hermetically sealed using a contact heat sealer. A binder is used to hold the electrode materials together (Section 5.2); other typical binders besides PTFE include polyvinylidene difluoride (PVDF) and CMC. Typically, $\mathrm{Cu}$ or $\mathrm{Al}$ meshes are used as current collectors (Figure 20a). The choice of each of these components affects the overall performance and longevity of the battery as well as the NMR experiment. ${ }^{138}$

In the case of symmetrical $(\mathrm{Li}-\mathrm{Li}$ or $\mathrm{Na}-\mathrm{Na})$ cells, the plastic bag, meshes, and separator are cut to size outside and transferred into an argon glovebox. The metal foil is prepared as previously described and pressed onto the meshes; both electrodes are kept separate within the cell by a glass fiber separator. In the case of a half (or full) cell, one of the electrodes might already be assembled and pressed onto the mesh before the final steps in the glovebox, which of course depends on the materials' sensitivity to moisture and air. Once all the components are aligned, the plastic bag is sealed through the current collector meshes, which holds the electrodes in place and prevents air from entering the cell. Before sealing all sides of the plastic bag cell, the separator is soaked with electrolyte using a pipette; most likely a small reservoir of electrolyte will result, which might even be beneficial during cycling so as not to run out of electrolyte as long as gas bubble formation is carefully prevented. Bubbles can cause inhomogeneity within the cell, which can influence the NMR signal. Finally, this side of the plastic bag is sealed, excess plastic foil cut away, and the overhanging tabs bent around and pressed on the cell from both sides (Figure 20a). The pressure can be increased by adding additional plastic sheets, e.g., Teflon, on both sides that are wrapped in Teflon tape or fixed with a strong but thin string (e.g., dental floss) string to keep everything in place (Figure 20a, front view steps 1-4). ${ }^{138}$

The plastic bag cell assembly procedure and design are highly adaptable regarding materials and sizes. Furthermore, the transparency of the plastic bag eases the battery assembly relative to other approaches, e.g., Bellcore's plastic or Swageloktype cells (Sections 5.3 and 3.5).$^{150-157}$ However, low pressure, long-term cycling stability, and difficulties with use in high temperature experiments can limit plastic bag cell applications 


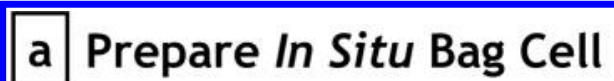

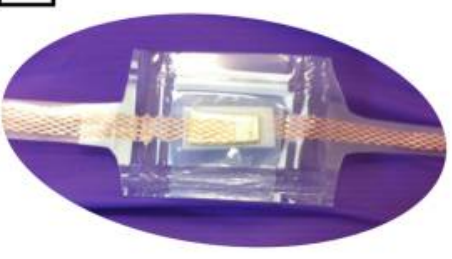

Top View

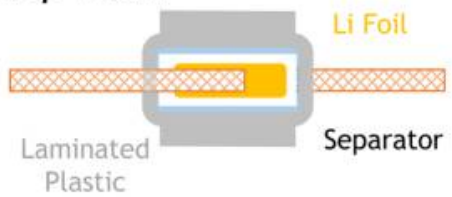

Side View

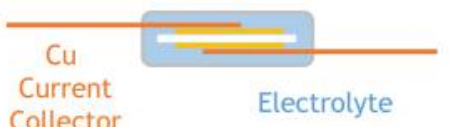

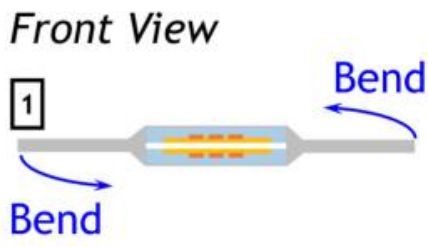

2

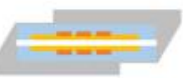

Pressure

3
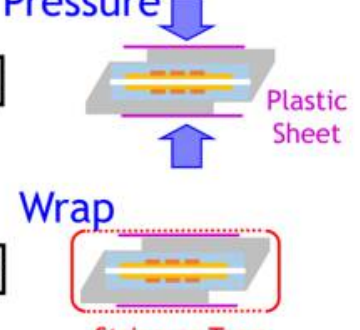

String or Tape

\section{b Prepare In Situ Plastic Cell Capsule}

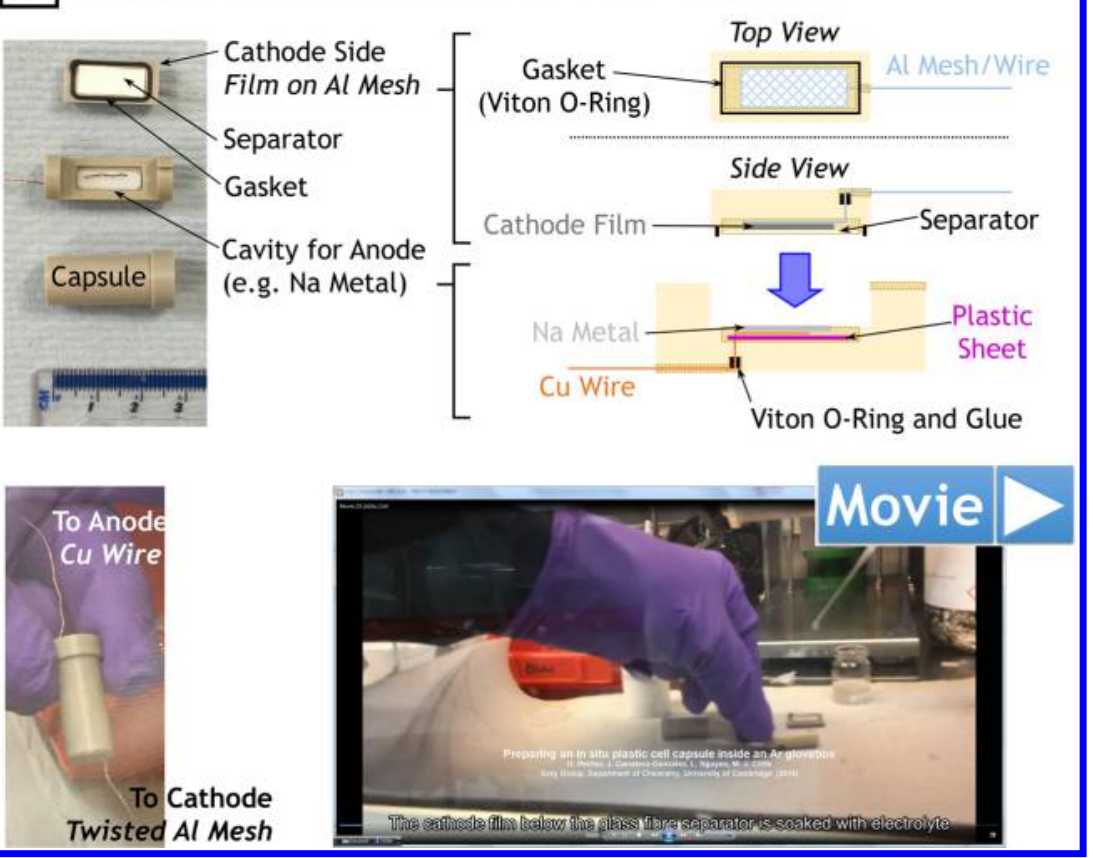

Figure 20. (a) Photograph and schematics (in top, side, and front view) of a symmetrical $\mathrm{Li}-\mathrm{LiPF}_{6}-\mathrm{Li}$ in situ plastic bag cell comprising $\mathrm{Li}$ metal foil pressed on $\mathrm{Cu}$ mesh current collectors and a glass fiber separator soaked with $\mathrm{LiPF}_{6}$ in $\mathrm{EC} / \mathrm{DMC}(50 / 50, \mathrm{v} / \mathrm{v})$ electrolyte. The final steps of cell preparation include (1) bending the overhanging tabs, (2) pressing them on the cell, (3) increasing the pressure by the application of a plastic sheet, and (4) wrapping the cell with a strong thin string (in practice we use dental floss) or a tape (although stretchable, in practice Teflon tape is the easiest to use). (b) Photographs of the cathode and anode cavity parts as well as the capsule and an assembled $\mathrm{FePO}_{4}-\mathrm{NaPF}_{6}-\mathrm{Na}$ in situ plastic cell capsule. The components of the anode and cathode side are shown schematically in the top right figure. See the Supporting Information for a movie of the assembly inside of an argon glovebox. Figure in part (picture and scheme of bag cell) reprinted and adapted with permission from $\mathrm{O}$. Pecher et al. J. Magn. Reson. 2016, 265, 200 (ref 137). Copyright 2016 Elsevier.

(Section 3.5). The use of Al-coated plastic bags (e.g., $3 \mathrm{M}$ Scotchpak MB285, heat sealable polyester film laminate) can increase the stability against moisture and air, which is particularly needed for highly sensitive samples; Al coated bags are much less permeable to air, but are opaque making assembly difficult. ${ }^{138,156}$ Even more problematic is the fact that the $\mathrm{Al}$ coating shields the materials inside the bag cell from the
RF pulses of the NMR experiment. This so-called skin depth penetration into the metal decreases the overall signal intensity. $^{138,161}$

We recently developed a new type of in situ cell, which consists of two halves of a plastic cylinder (fabricated from polyether ether ketone, PEEK) with cavities for the cathode, separator, and anode as well as holes for connecting the current 


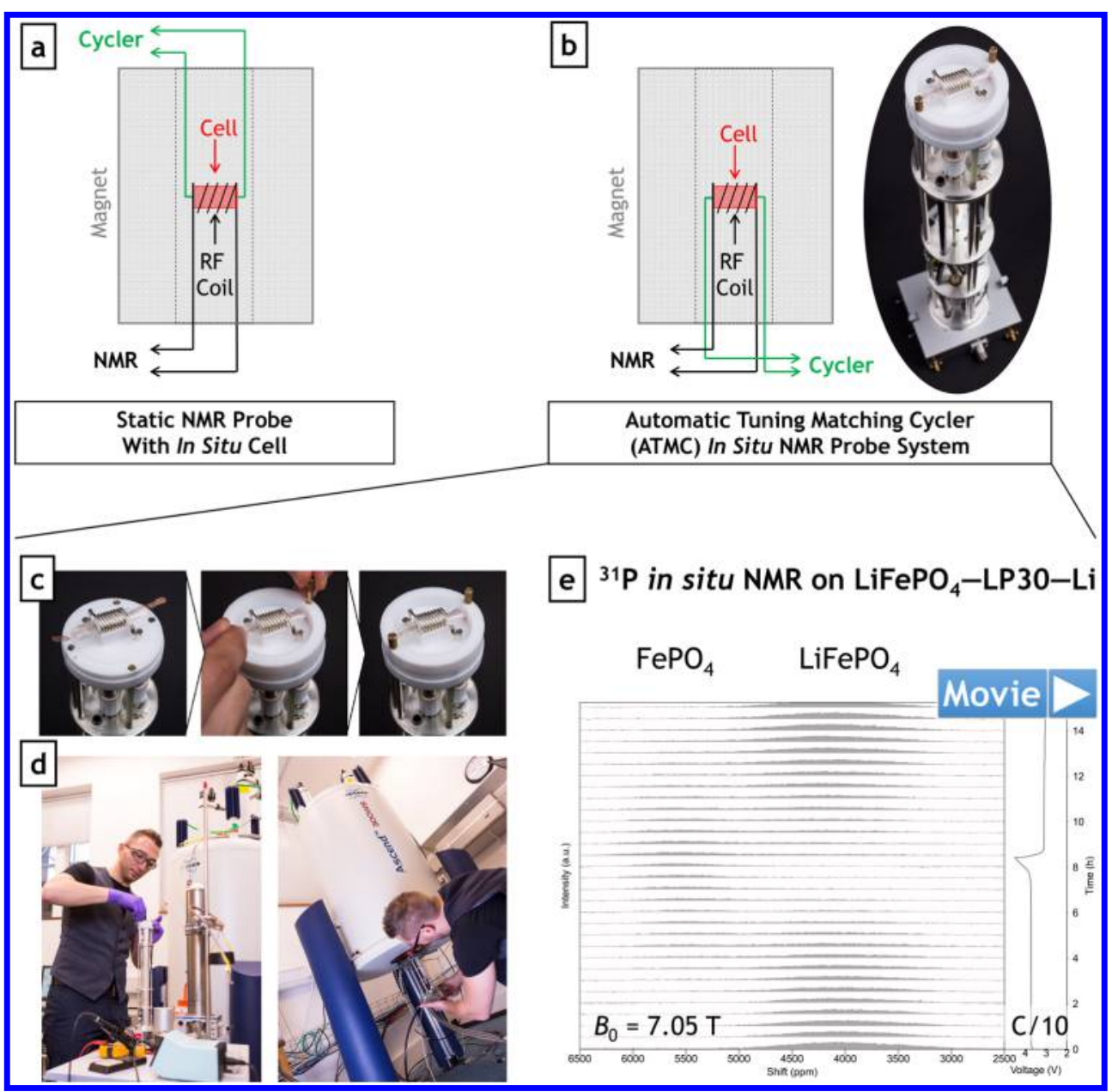

Figure 21. (a) Scheme of an in situ NMR setup using a static NMR probe. (b) Scheme of the ATMC in situ NMR system and a top view photo of the probehead. (c) Mounting an electrochemical cell inside the coil of the ATMC in situ probehead and connecting the current collectors with the leads. (d) Finalizing the setup and insertion of the probehead into the magnet. (e) ${ }^{31} \mathrm{P}$ in situ $\mathrm{NMR}$ signals of a $\mathrm{LiFePO}-\mathrm{LiPF}_{6}-\mathrm{Li}_{4}$ cell during $\mathrm{C} / 10$ charge and discharge. See the Supporting Information for a movie of the ${ }^{31} \mathrm{P}$ NMR signal line shape development and fit of the respective $\mathrm{LiFePO}_{4}$ and $\mathrm{FePO}_{4}$ signal contributions. Figure in part (picture of probehead in panel b and mounting of an in situ cell in panel c) reprinted and adapted with permission from O. Pecher et al. J. Magn. Reson. 2016, 265, 200 (ref 137). Copyright 2016 Elsevier.

collectors that are pressed together and encapsulated afterward to ensure sealing and constant pressure (Figure 20b). This plastic cell capsule (PCC) was made in house by standard machine shop techniques and addresses many of the challenges related to plastic bag cells and in situ NMR (Section 3.5). In the following, we will describe the assembly of a $\mathrm{FePO}_{4}-\mathrm{NaPF}_{6}-$ $\mathrm{Na}$ cell using this setup, which is generally applicable to any other chemical system (Figure 20b). The cathode, pressed onto the $\mathrm{Al} \mathrm{mesh}$, is placed into the cavity with the rest of the mesh twisted to a thin wire, which is then placed through the hole and outside the cell. A small drop of fast hardening epoxy holds and seals the outgoing side of the $\mathrm{Al}$ wire. A sheet of separator is cut into the right size for the cavity and pressed onto the cathode film (Figure 20b). The anode side holds a thin $\mathrm{Cu}$ wire that is glued into a Viton O-ring, which seals the hole through which the $\mathrm{Cu}$ wires exit the chamber, and pressed into the backside of this cavity. The $\mathrm{Cu}$ wire is placed inside the cavity with a thin Teflon sheet (cut to size) depending on the amount of pressure one would like to achieve inside the cell. The $\mathrm{Na}$ metal anode is now gently pressed onto the $\mathrm{Cu}$ wire. Finally, the separator is soaked with approximately $0.5 \mathrm{~mL}$ of electrolyte and both cavities are pushed together and fixed by the capsule (Figure 20b).
N.b., the choice of material of the current collector $(\mathrm{Cu}$ or $\mathrm{Al}$ mesh), is strongly dependent on the material under investigation and the voltage window of the desired electrochemical experiment. Li metal anodes must not be used with $\mathrm{Al}$ current collectors since alloys form which influence the connection and $\mathrm{Cu}$ current collectors must not be used with, e.g., $\mathrm{LiFePO}_{4}$ cathodes beyond approximately $3 \mathrm{~V}$ because $\mathrm{Cu}$ is then oxidized $\left(\mathrm{Cu}^{2+} / \mathrm{Cu}\right.$ with $0.34 \mathrm{~V}$ and $\mathrm{Li}^{+} / \mathrm{Li}$ with $-3.05 \mathrm{~V}$ vs SHE) and irreversible connection losses result.

5.4. How To Set up an in Situ NMR Experiment. In situ NMR experiments are principally possible with any static NMR probehead by connecting an electrochemical cell, which is placed inside the NMR coil, to an electrochemical cycler (Figure 21, Section 3.5). However, this can cause significant interferences between the NMR and cycler circuit because basically a new antenna is attached to the otherwise wellshielded and grounded NMR probehead. These interferences can impair in situ NMR experiments and we recently investigated the use of a new automatic tuning matching cycler (ATMC) in situ NMR system (Figure 21b). ${ }^{137}$ The two major benefits of the ATMC in situ NMR probehead system are (a) a straightforward connection of the electrochemical cell to leads in very close proximity to the NMR coil, which is highly 
shielded inside the probehead's torso, ending in two ports to connect the electrochemical it is not Figure $21 \mathrm{c}, \mathrm{b}$ an internal system that allows automatic recalibration of the resonance NMR circuit during the experiment. Details on the automatic tuning/matching can be found elsewhere. ${ }^{137}$ In the following, we will share some hands-on experience and practical considerations on how an in situ NMR experiment is set up, which is generally similar for any other probehead used.

5.4.1. Choose the NMR Coil Material. The number of turns of the NMR coil (in combination with the tuning and matching capacitors and/or coil) defines the frequency range accessible. Hence, on the basis of the desired nuclei and frequency range, one has to ensure that the coil is capable of tuning and matching the whole range of the NMR experiment. Furthermore, in experiments with broad excitation, it is important to ensure that no signal due to the coil material overlaps with any signals of the cell. N.b., the $\mathrm{Cu}$ signal from $\mathrm{Ag}$-coated $\mathrm{Cu}$ or $\mathrm{Cu}$ wire can appear in ${ }^{23} \mathrm{Na} \mathrm{NMR}$ spectra. The use of coils made of pure Ag wire is an alternative to overcome this issue. Furthermore, the use of Ag coils increases the quality factor of the probe and thus the signal/noise ratio for an experiment.

5.4.2. Reference and Shim. Once the right RF setting is found, the probe should be shift referenced by measuring a salt solution, e.g., $\mathrm{LiCl}$ or $\mathrm{NaCl}$ for ${ }^{6 ; 7} \mathrm{Li}$ and ${ }^{23} \mathrm{Na} \mathrm{NMR}$ experiments, respectively. ${ }^{145,146,164}$ The reference salt solution should also be used for shimming the probe. It is not advised to use the sample cell for shimming because the signals are influenced by the large susceptibility differences between all components, creating small magnetic field gradients that can broaden and/or shift the resonance.

5.4.3. Obtain Static NMR Spectra of Pristine Materials. Especially in the case of very broad frequency ranges, e.g., of paramagnetic cathode materials, it is useful to gain information on the expected frequency ranges through ex situ studies prior to the in situ NMR experiment. Therefore, the following measurements should be performed: (i) the pristine cathode powder, (ii) the pristine, e.g., self-standing, cathode film (Figure 19a) because this can affect the BMS shift (Section 3.2, Figure $6 \mathrm{~b})$, (iii) the cathode material in different stages of charge (e.g., electrochemically prepared using coin cells, Figure 17c), and finally (iv) the electrochemical cell at OCV. During these steps, the NMR experimental parameters are optimized, i.e., carrier frequency, pulse length and power level, recycle delay, tuning/ matching range, and respective capacitor positions (in the case of automatic recalibrations of the NMR circuit) as well as the choice for the right pulse program (broadband or selective excitation using frequency-sweep NMR). ${ }^{133,134,137}$

5.4.4. Mount the Electrochemical Cell. The assembled electrochemical cell needs to be mounted carefully inside the NMR coil (Figure 21c). One has to be very careful not to shortcircuit the cell during this procedure, and gloves should be worn to prevent skin contact with residual liquid electrolyte and short-circuiting. A preferred cell orientation with respect to the magnetic field (e.g., parallel, perpendicular, at the magic angle) needs to be chosen since this will likely influence the shift and line shape of the NMR signal and cause better or worse experimental resolution (Sections 3.3 .1 and 3.5.3, Figure 6b). ${ }^{138,139}$ In practice, it is useful to measure the signal of the pristine cell in all three orientations mentioned above and, based on these findings, decide on the cell orientation during the in situ experiment. Furthermore, if sufficient time is available, in situ measurements in all three orientations are useful because they provide valuable complementary information on BMS effects of the different cell components, which might be helpful for NMR signal line shape analysis and interpretation (Sections 3.3.1 and 3.5.3, Figure 6b). The cell orientation is fixed by pressing down the current collectors to the leads on the probehead's top using a Teflon ring (Figure 21c). Finally, the OCV should be checked at the electrochemistry connector ports at the probehead's bottom; the connection to the electrochemical cycler closed and then the OCV monitored and compared with the prior measurements. In some cases low pass filters need to be included into the cycler-NMR connections to block interferences between these circuits. $^{137}$

5.4.5. Adjust the NMR Circuit and Synchronize CyclerNMR Timing. With the cell attached inside the coil and the electrochemical circuit closed, the NMR (RF) circuit needs to be adjusted to the resonance frequency of the nucleus under investigation (Table 2) and, in cases of automatic recalibration, the tuning and matching capacitor positions need to be checked. Finally, the timing of the cycler and NMR experiment need to be synchronized, i.e., how much time is required for each NMR measurement during the electrochemical experiment. This depends on both the minimum number of scans required to obtain good $\mathrm{S} / \mathrm{N}$ for the NMR as well as the type for electrochemical experiment, e.g., galvanostatic cycling, galvanostatic or potentiostatic intermittent titration technique (GITT or PITT, respectively).

5.5. Applications and Opportunities of ATMC in situ NMR Spectroscopy. We recently applied the ATMC in situ NMR approach to enable ${ }^{31} \mathrm{P}$ NMR measurements on a $\mathrm{LiFePO}_{4}-\mathrm{LiPF}_{6}-\mathrm{Li}$ cell during $\mathrm{C} / 10$ charge (delithiation) and discharge (lithiation), which was one of the first in situ NMR experiments on significantly paramagnetic broadened NMR signals (Figure 21e). ${ }^{137,165}$ In this case, ${ }^{31} \mathrm{P}$ NMR is beneficial since there is no overlap of the solvent or electrolyte signals with the NMR signals of the active material and/or anode, as is the case for ${ }^{7} \mathrm{Li}^{137}$ The significant $\mathrm{LiFePO}_{4}$ and $\mathrm{FePO}_{4}$ shift difference of 4000 vs. 5700 ppm make on-resonance conditions during the experiment challenging but have been overcome by the automatic recalibration capabilities of the ATMC in situ NMR system. The intensities of the well separated ${ }^{31} \mathrm{P}$ NMR signals continuously vary as the battery undergoes charge and discharge (Figure 21e). A movie showing the real-time analysis and fit of the lineshapes can be found in the Supporting Information. ${ }^{31} \mathrm{P}$ NMR on this system is a promising source of information to gain insights into the changes of the local atomic environments during cycling as ongoing attempts are made to increase the cell's cycling rate and temperature range (Sections 3.3 and 5.3).

The ATMC in situ NMR approach was also successfully applied to investigate NIB materials, e.g., in ${ }^{31} \mathrm{P}$ NMR of $\mathrm{Na}_{3} \mathrm{~V}_{2}\left(\mathrm{PO}_{4}\right)_{2} \mathrm{~F}_{3}$ as a cathode in a NIB as well as ${ }^{23} \mathrm{Na} \mathrm{NMR}$ of $\mathrm{Na}$ metal anodes allowing observation of the formation of different $\mathrm{Na}$ metal species and $\mathrm{Na}$ electrolyte consumption. ${ }^{137,158,159}$ Furthermore, our ongoing ${ }^{23} \mathrm{Na}$ ATMC in situ NMR studies of $\mathrm{Na}$ storage into hard carbons ${ }^{166}$ and the formation of amorphous and crystalline $\mathrm{Na}_{x} \mathrm{Sn}$ species during sodiation of $\mathrm{Sn}$ metal anodes are challenging because the materials under investigation change conductivity, which influences the NMR resonance conditions. Details on the $\mathrm{Na}_{x} \mathrm{Sn}$ study will be reported shortly. 


\section{CONCLUSIONS AND OUTLOOK}

The application of solid-state NMR spectroscopy is a very suitable tool to gain insights into the multiple processes involved during electrochemical cycling. Because of high chemical specificity and sensitivity to crystalline and amorphous phases, comprehensive information on structural and electronic changes of the materials involved are accessible. Combined with other experimental techniques, e.g., diffraction methods and $a b$ initio calculations, this approach shows considerable promise, allowing a deeper understanding of the chemical reactions involving the multiple cell components to be obtained. Furthermore, the application of in situ NMR as a non-invasive analysis tool offers insights into kinetically vs. thermodynamically driven processes as well as into metastable and short-lived phases forming during electrochemical cycling. This real-time monitoring of the electrochemical processes is not without its challenges due to the multicomponent nature of the cell including, at least a subset of, air sensitive, metallic, organic, inorganic, liquid, and solid components. Furthermore, interference of the electrochemical circuit with the radio frequency circuit can impair the experiments. Recent applications of the ATMC in situ NMR methodology show promise to overcome many of the challenges and open these measurements to cathode and anode materials with huge spectral ranges and variable conductivity during cycling.

The lack of an in situ geometry compatible with MAS and the (sometimes) relatively slow time scale of NMR measurements compared with electrochemistry constrain chemical and temporal resolution, respectively. Future in situ NMR hardware developments might aim to tackle this challenge and overcome mechanical issues in the design of an electrochemical cell for in situ MAS NMR, which would benefit both in situ sensitivity as well as experimental resolution. In addition, in situ NMR experiments will focus on gaining more quantitative information on dynamic processes through operando spin-lattice and spin-spin relaxometry, which was recently demonstrated for $\mathrm{Li}_{1.08} \mathrm{Mn}_{1.92} \mathrm{O}_{4}$ electrodes. ${ }^{167}$ These approaches will become even more powerful when combined with in situ MAS NMR. Another promising approach to study batteries is the application of magnetic resonance imaging (MRI), which allows spatial identification of different ions and chemical species. ${ }^{105}$ Limitations and difficulties of pushing the resolution below $100 \mu \mathrm{m}$ (particularly for solids and high conductivity liquids) still hinder the application of MRI to a wider range of battery studies.

The bottom line of "NMR in battery research" might be not to start with an in situ NMR experiment immediately but to break down the complex problem into smaller pieces, i.e., start with ex situ characterization and tests on electrochemical performance by "conventional" methods. This will enable, the right in situ cell setup to be found, which shows an electrochemical performance comparable to, e.g., coin cells. Finally, in situ studies can complement and expand on the ex situ characterization data. Applications of NMR in battery research will surely aid the understanding and prevention of battery failures and, furthermore, improve technologies to realize the demand for higher efficiency, longer lifetime, and lower cost in the future.

\section{ASSOCIATED CONTENT}

\section{Supporting Information}

The Supporting Information is available free of charge on the ACS Publications website at DOI: 10.1021/acs.chemmater.6b03183.

Movie of a $4.0 \mathrm{~mm}$ rotor starting to spin; movie on the preparation of a thin $\mathrm{Na}$ metal foil; movie on the assembly of an in situ cell inside of an argon glovebox; movie of the ${ }^{31} \mathrm{P}$ NMR signal line shape development and fit of the respective $\mathrm{LiFePO}_{4}$ and $\mathrm{FePO}_{4}$ signal contributions (ZIP)

\section{AUTHOR INFORMATION}

\section{Corresponding Authors}

*Email: op261@cam.ac.uk (Dr. Oliver Pecher).

*Email: cpg27@cam.ac.uk (Prof. Clare P. Grey).

\section{Notes}

The authors declare no competing financial interest.

\section{ACKNOWLEDGMENTS}

We gratefully acknowledge the generous support of all members of the Grey research group in Cambridge (UK). In particular, we would like to thank Dr. Matthew J. Cliffe, Joshua M. Stratford, H. B. Long Nguyen, Dr. Paul M. Bayley, Dr. Nicole M. Trease, Dr. Michael W. Gaultois, and Wei Meng for their help with videos and photos as well as fruitful discussions. Dr. Rachel N. Kerber, Dr. Céline Merlet, Dr. Ieuan Seymour, Dr. Matthew T. Dunstan, David M. Halat, Dr. Elizabeth Castillo-Martínez, Dr. Zigeng Liu, Dr. Sylvia Britto, Dr. Lauren E. Marbella, and Dr. Pieter C. M. M. Magusin are thanked for fruitful discussions. We thank Prof. Andrew J. Pell (Stockholm University, Sweden) for fruitful discussions on paramagnetic NMR spectroscopy and Dr. Frank Haarmann (Aachen, Germany) for preliminary drawings used in the NMR interactions figure. We thank Michael A. Hope for thoroughly proofreading the manuscript. We gratefully acknowledge Nathan Pitt, Gabriella Bocchetti, and Lloyd Mann (University of Cambridge, UK) for technical assistance. This project has received funding from the European Union's Horizon 2020 research and innovation program under the Marie SkłodowskaCurie grant agreement No 655444 (O.P.). K.J.G. thanks the Winston Churchill Foundation of the United States and the Herchel Smith Scholarship for financial support.

\section{REFERENCES}

(1) EUROPEAN COMMISSION Climate Action. Annual Conference of Parties (COP) at COP21 at Stade de France (Gate E) in Paris (7-8 December 2015) http://ec.europa.eu/clima/policies/ international/negotiations/paris/index_en.htm.

(2) Gholam-Abbas, N.; Pistoia, G. Lithium Batteries Science and Technology; Springer: New York, 2003.

(3) Tarascon, J.-M.; Armand, M. Issues and Challenges Facing Rechargeable Lithium Batteries. Nature 2001, 414, 359-367.

(4) Palacín, M. R. Recent Advances in Rechargeable Battery Materials: A Chemist's Perspective. Chem. Soc. Rev. 2009, 38, 25652575.

(5) Palacín, M. R.; de Guibert, A. Why Do Batteries Fail? Science 2016, 351, 1253292.

(6) Hammami, A.; Raymond, N.; Armand, M. Lithium-Ion Batteries: Runaway Risk of Forming Toxic Compounds. Nature 2003, 424, 635636.

(7) Armand, M.; Tarascon, J. Building Better Batteries. Nature 2008, 451, 652-657. 
(8) Goodenough, J. B.; Kim, Y. Challenges for Rechargeable Li Batteries. Chem. Mater. 2010, 22, 587-603.

(9) Dunn, B.; Kamath, H.; Tarascon, J.-M. Electrical Energy Storage for the Grid: A Battery of Choices. Science 2011, 334, 928-935.

(10) Goodenough, J. B. Electrochemical Energy Storage in a Sustainable Modern Society. Enerov Environ. Sci. 2014, 7, 14-18.

(11) Larcher, D.; Tarascon, J.-M. Towards Greener and More Sustainable Batteries for Electrical Energy Storage. Nat. Chem. 2014, 7, 19-29.

(12) Steele, B. C. H. Fast Ion Transport in Solids; Van Gool, W., Ed.; North-Holland: Amsterdam, 1973.

(13) Armand, M. B. North-Holland Amsterdam; Van Gool, W., Ed.; North-Holland: Amsterdam, 1973.

(14) Nagara, T.; Tozawa, K. Lithium Ion Rechargeable Battery. Prog. Batter. Sol. Cells 1990, 9, 209.

(15) CRC Handbook of Chemistry and Physics, 97th ed.; Haynes, W. M., Lide, D. R., Bruno, T. J., Eds.; CRC Press Taylor \& Francis Group: Boca Raton, FL, 2016.

(16) Key, B.; Bhattacharyya, R.; Morcrette, M.; Seznéc, V.; Tarascon, J.-M.; Grey, C. Real-Time NMR Investigations of Structural Changes in Silicon Electrodes for Lithium-Ion Batteries. I. Am. Chem. Soc. 2009, 131, 9239-9249.

(17) Michan, A. L.; Leskes, M.; Grey, C. P. Voltage Dependent Solid Electrolyte Interphase Formation in Silicon Electrodes: Monitoring the Formation of Organic Decomposition Products. Chem. Mater. 2016, 28, 385-398.

(18) Park, C.-M.; Sohn, H.-J. Black Phosphorus and Its Composite for Lithium Rechargeable Batteries. Adv. Mater. 2007, 19, 2465-2468.

(19) Mayo, M.; Griffith, K. J.; Pickard, C. J.; Morris, A. J. Ab Initio Study of Phosphorus Anodes for Lithium- and Sodium-Ion Batteries. Chem. Mater. 2016, 28, 2011-2021.

(20) Poli, F.; Wong, A.; Kshetrimayum, J. S.; Monconduit, L.; Letellier, M. In Situ NMR Insights into the Electrochemical Reaction of $\mathrm{Cu}_{3} \mathrm{P}$ Electrodes in Lithium Batteries. Chem. Mater. 2016, 28, 1787-1793.

(21) Courtney, I. A.; Dahn, J. R. Electrochemical and In Situ X-Ray Diffraction Studies of the Reaction of Lithium with Tin Oxide Composites. I. Electrochem. Soc. 1997, 144, 2045-2052.

(22) Allan, P. K.; Griffin, J. M.; Darwiche, A.; Borkiewicz, O. J.; Wiaderek, K. M.; Chapman, K. W.; Morris, A. J.; Chupas, P. J.; Monconduit, L.; Grey, C. P. Tracking Sodium-Antimonide Phase Transformations in Sodium-Ion Anodes: Insights from Operando Pair Distribution Function Analysis and Solid-State NMR Spectroscopy. $I$. Am. Chem. Soc. 2016, 138, 2352-2365.

(23) Kepler, K. D.; Vaughey, J. T.; Thackeray, M. M. $\mathrm{Li}_{\mathrm{x}} \mathrm{Cu}_{6} \mathrm{Sn}_{5}(0<$ $x<13)$ : An Intermetallic Insertion Electrode for Rechargeable Lithium Batteries. Electrochem. Solid-State Lett. 1999, 2, 307-309.

(24) Hu, X.; Deng, Z.; Suo, J.; Pan, Z. A High Rate, High Capacity and Long Life $\left(\mathrm{LiMn}_{2} \mathrm{O}_{4}+\mathrm{AC}\right) / \mathrm{Li}_{4} \mathrm{Ti}_{5} \mathrm{O}_{12}$ Hybrid Battery-supercapacitor. I. Power Sources 2009, 187, 635-639.

(25) Ren, Y.; Liu, Z.; Pourpoint, F.; Armstrong, A. R.; Grey, C. P.; Bruce, P. G. Nanoparticulate $\mathrm{TiO}_{2}(\mathrm{~B})$ : An Anode for Lithium-Ion Batteries. Angew. Chem. Int. Ed. 2012, 51, 2164-2167.

(26) Griffith, K. J.; Forse, A. C.; Griffin, J. M.; Grey, C. P. High-Rate Intercalation without Nanostructuring in Metastable $\mathrm{Nb}_{2} \mathrm{O}_{5}$ Bronze Phases. I. Am. Chem. Soc. 2016, 138, 8888-8899.

(27) Han, J.-T.; Huang, Y.-H.; Goodenough, J. B. New Anode Framework for Rechargeable Lithium Batteries. Chem. Mater. 2011, 23, 2027-2029.

(28) Thackeray, M. M.; Johnson, P. J.; de Picciotto, L. A.; Bruce, P. G.; Goodenough, J. G. Electrochemical Extraction of Lithium from $\mathrm{LiMn}_{2} \mathrm{O}_{4}$. Mater. Res. Bull. 1984, 19, 179-187.

(29) Lu, J.; Zhan, C.; Wu, T.; Wen, J.; Lei, Y.; Kropf, A. J.; Wu, H.; Miller, D. J.; Elam, J. W.; Sun, Y.-K.; Qiu, X.; Amine, K. Effectively Suppressing Dissolution of Manganese from Spinel Lithium Manganate via a Nanoscale Surface-Doping Approach. Nat. Commun. 2014, 5, 5693.

(30) Thackeray, M. M.; Johnson, C. S.; Kim, J.-S.; Lauzze, K. C.; Vaughey, J. T.; Dietz, N.; Abraham, D.; Hackney, S. A.; Zeltner, W.;
Anderson, $\mathrm{M} . \mathrm{ZrO}_{2^{-}}$and $\mathrm{Li}_{2} \mathrm{ZrO}_{3}$-Stabilized Spinel and Layered Electrodes for Lithium Batteries. Electrochem. Commun. 2003, 5, 752758.

(31) Padhi, A. K.; Nanjundaswamy, K. S.; Goodenough, J. B. Phospho-Olivines as Positive-Electrode Materials for Rechargeable Lithium Batteries. I. Electrochem. Soc. 1997, 144, 1188-1194.

(32) Goodenough, J. B. Oxide Engineering for Advanced Power Sources. Electrochem. Soc. Proc. 1999, 99-24, 1-14.

(33) Rousse, G.; Tarascon, J. M. Sulfate-Based Polyanionic Compounds for Li-Ion Batteries: Synthesis, Crystal Chemistry, and Electrochemistry Aspects. Chem. Mater. 2014, 26, 394-406.

(34) Ma, J.; Hu, P.; Cui, G.; Chen, L. Surface and Interface Issues in Spinel $\mathrm{LiNi}_{0.5} \mathrm{Mn}_{1.5} \mathrm{O}_{4}$ : Insights into a Potential Cathode Material for High Energy Density Lithium Ion Batteries. Chem. Mater. 2016, 28, $3578-3606$

(35) Wang, F.; Robert, R.; Chernova, N. A.; Pereira, N.; Omenya, F.; Badway, F.; Hua, X.; Ruotolo, M.; Zhang, R.; Wu, L.; Volkov, V.; Su, D.; Key, B.; Whittingham, M. S.; Grey, C. P.; Amatucci, G. G.; Zhu, Y.; Graetz, J. Conversion Reaction Mechanisms in Lithium Ion Batteries: Study of the Binary Metal Fluoride Electrodes. I. Am. Chem. Soc. 2011, 133, 18828-18836

(36) Tarascon, J.-M.; Poizot, P.; Laruelle, S.; Grugeon, S.; Dupont, L. Nano-Sized Transition-Metal Oxides as Negative-Electrode Materials forLithium-Ion Batteries. Nature 2000, 407, 496-499.

(37) Cabana, J.; Monconduit, L.; Larcher, D.; Palacín, M. R. Beyond Intercalation-Based Li-Ion Batteries: The State of the Art and Challenges of Electrode Materials Reacting Through Conversion Reactions. Adv. Mater. 2010, 22, E170-E192.

(38) Lin, Y.-C.; Wen, B.; Wiaderek, K. M.; Sallis, S.; Liu, H.; Lapidus, S. H.; Borkiewicz, O. J.; Quackenbush, N. F.; Chernova, N. A.; Karki, K.; Omenya, F.; Chupas, P. J.; Piper, L. F. J.; Whittingham, M. S.; Chapman, K. W.; Ong, S. P. Thermodynamics, Kinetics and Structural Evolution of $\varepsilon$-LiVOPO ${ }_{4}$ over Multiple Lithium Intercalation. Chem. Mater. 2016, 28, 1794-1805.

(39) Sloop, S. E.; Pugh, J. K.; Wang, S.; Kerr, J. B.; Kinoshita, K. Chemical Reactivity of $\mathrm{PF}_{5}$ and $\mathrm{LiPF}_{6}$ in Ethylene Carbonate/ Dimethyl Carbonate Solutions. Electrochem. Solid-State Lett. 2001, 4, A42-A44.

(40) Fergus, J. W. Ceramic and Polymeric Solid Electrolytes for Lithium-Ion Batteries. L. Power Sources 2010, 195, 4554-4569.

(41) Belloré Group. Electric vehicles, Solutions: Mobile applications from Blue Applications BLUECAR® (accessed 01/08/2016). http:// www.bollore.com/en-us/activities/electricity-storage-and-solutions/ electric-vehicles-solutions.

(42) Martin Jolicoeur (lesaffaires.com). Bolloré Group to invest $\$ 120$ million in Boucherville (accessed 27/10/2009). http://www. international.gouv.qc.ca/en/bruxelles/actualites/7066.

(43) Palomares, V.; Serras, P.; Villaluenga, I.; Hueso, K. B.; Carretero-González, J.; Rojo, T. Na-Ion Batteries, Recent Advances and Present Challenges to Become Low Cost Energy Storage Systems. Eneroy Environ. Sci. 2012, 5, 5884-5901.

(44) Palomares, V.; Casas-Cabanas, M.; Castillo-Martínez, E.; Han, M. H.; Rojo, T. Update on Na-Based Battery Materials. A Growing Research Path. Energy Environ. Sci. 2013, 6, 2312-2337.

(45) Abraham, K. M.; Jiang, Z. A Polymer Electrolyte-Based Rechargeable Lithium/Oxygen Battery. I. Electrochem. Soc. 1996, 143, 1-5.

(46) Peng, Z.; Freunberger, S. A.; Chen, Y.; Bruce, P. G. A Reversible and Higher-Rate $\mathrm{Li}_{-} \mathrm{O}_{2}$ Battery. Science 2012, 337, 563-566.

(47) Liu, T.; Leskes, M.; Yu, W.; Moore, A. J.; Zhou, L.; Bayley, P. M.; Kim, G.; Grey, C. P. Cycling $\mathrm{Li}_{-} \mathrm{O}_{2}$ Batteries via $\mathrm{LiOH}$ Formation and Decomposition. Science 2015, 350, 530-533.

(48) See, K. A.; Jun, Y.-S.; Gerbec, J. A.; Sprafke, J. K.; Wudl, F.; Stucky, G. D.; Seshadri, R. Sulfur-Functionalized Mesoporous Carbons as Sulfur Hosts in Li-S Batteries: Increasing the Affinity of Polysulfide Intermediates to Enhance Performance. ACS Appl. Mater. Interfaces 2014, 6, 10908-10916.

(49) See, K. A.; Leskes, M.; Griffin, J. M.; Britto, S.; Matthews, P. D.; Emly, A.; Van der Ven, A.; Wright, D. S.; Morris, A. J.; Grey, C. P.; 
Seshadri, R. Ab Initio Structure Search and In Situ ${ }^{7} \mathrm{Li}$ NMR Studies of Discharge Products in the Li-S Battery System. I. Am. Chem. Soc. 2014, 136, 16368-16377.

(50) Wild, M.; O’Neill, L.; Zhang, T.; Purkayastha, R.; Minton, G.; Marinescu, M.; Offer, G. J. Lithium Sulfur Batteries, a Mechanistic Review. Energy Environ. Sci. 2015, 8, 3477-3494.

(51) Manthiram, A.; Fu, Y.; Chung, S.; Zu, C.; Su, Y. Rechargeable Lithium - Sulfur Batteries. Chem. Rev. 2014, 114, 11751-11787.

(52) Bruce, P. G.; Freunberger, S. A.; Hardwick, L. J.; Tarascon, J.-M. $\mathrm{Li}-\mathrm{O}_{2}$ and $\mathrm{Li}-\mathrm{S}$ Batteries with High Energy Storage. Nat. Mater. 2011, 11, 19-29.

(53) Aurbach, D.; Lu, Z.; Schechter, A.; Gofer, Y.; Gizbar, H.; Turgeman, R.; Cohen, Y.; Moshkovich, M.; Levi, E. Prototype Systems for Rechargeable Magnesium Batteries. Nature 2000, 407, 724-727.

(54) Aurbach, D.; Gofer, Y.; Lu, Z.; Schechter, A.; Chusid, O.; Gizbar, H.; Cohen, Y.; Ashkenazi, V.; Moshkovich, M.; Turgeman, R.; Levi, E. A Short Review on the Comparison between Li Battery Systems and Rechargeable Magnesium Battery Technology. I. Power Sources 2001, 97, 28-32.

(55) Levi, E.; Levi, M. D.; Chasid, O.; Aurbach, D. A Review on the Problems of the Solid State Ions Diffusion in Cathodes for Rechargeable Mg Batteries. I. Electroceram. 2009, 22, 13-19.

(56) Levi, E.; Gofer, Y.; Aurbach, D. On the Way to Rechargeable Mg Batteries: The Challenge of New Cathode Materials. Chem. Mater. 2010, 22, 860-868.

(57) Yoo, H. D.; Shterenberg, I.; Gofer, Y.; Gershinsky, G.; Pour, N.; Aurbach, D. Mg Rechargeable Batteries: An on-Going Challenge. Energy Environ. Sci. 2013, 6, 2265-2279.

(58) Muldoon, J.; Bucur, C. B.; Oliver, A. G.; Sugimoto, T.; Matsui, M.; Kim, H. S.; Allred, G. D.; Zajicek, J.; Kotani, Y. Electrolyte Roadblocks to a Magnesium Rechargeable Battery. Energv Environ. Sci. 2012, 5, 5941-5950.

(59) Ponrouch, A.; Frontera, C.; Bardé, F.; Palacín, M. R. Towards a Calcium-Based Rechargeable Battery. Nat. Mater. 2015, 15, 169-172.

(60) Noack, J.; Roznyatovskaya, N.; Herr, T.; Fischer, P. The Chemistry of Redox-Flow Batteries. Angew. Chem. Int. Ed. 2015, 54, 9776-9809.

(61) Dunn, B.; Kamath, H.; Tarascon, J.-M. Electrical Energy Storage for the Grid: A Battery of Choices. Science 2011, 334, 928-935.

(62) Ashbrook, S. E.; McKay, D. Combining Solid-State NMR Spectroscopy with First-Principles Calculations - A Guide to NMR Crystallography. Chem. Commun. 2016, 52, 7186-7204.

(63) Islam, M. S.; Fisher, C. A. J.; Islam, S. M.; Fisher, C. A. J. Lithium and Sodium Battery Cathode Materials: Computational Insights into Voltage, Diffusion and Nanostructural Properties. Chem. Soc. Rev. 2014, 43, 185-204.

(64) Pickard, C. J.; Needs, R. J. Ab Initio Random Structure Searching. I. Phvs.: Condens. Matter 2011, 23, 053201.

(65) Clément, R.; Pell, A.; Middlemiss, D.; Strobridge, F.; Miller, J.; Whittingham, M.; Emsley, L.; Grey, C.; Pintacuda, G. Spin-Transfer Pathways in Paramagnetic Lithium Transition-Metal Phosphates from Combined Broadband Isotropic Solid-State MAS NMR Spectroscopy and DFT Calculations. I. Am. Chem. Soc. 2012, 134, 17178-17185.

(66) Middlemiss, D. S.; Ilott, A. J.; Clément, R. J.; Strobridge, F. C.; Grey, C. P. Density Functional Theory-Based Bond Pathway Decompositions of Hyperfine Shifts: Equipping Solid-State NMR to Characterize Atomic Environments in Paramagnetic Materials. Chem. Mater. 2013, 25, 1723-1734.

(67) Kim, J.; Middlemiss, D. S.; Chernova, N. A.; Zhu, B. Y. X.; Masquelier, C.; Grey, C. P. Linking Local Environments and Hyperfine Shifts: A Combined Experimental and Theoretical ${ }^{31} \mathrm{P}$ and ${ }^{7} \mathrm{Li}$ Solid-State NMR Study of Paramagnetic Fe(III) Phosphates. I. Am. Chem. Soc. 2010, 132, 16825-16840.

(68) Carlier, D.; Ménétrier, M.; Grey, C.; Delmas, C.; Ceder, G. Understanding the NMR Shifts in Paramagnetic Transition Metal Oxides Using Density Functional Theory Calculations. Phys. Rev. B: Condens. Matter Mater. Phvs. 2003, 67, 1-14.

(69) Urban, A.; Seo, D.-H.; Ceder, G. Computational Understanding of Li-Ion Batteries. npj Comput. Mater. 2016, 2, 16002.
(70) Harks, P.; Mulder, F. M.; Notten, P. H. L. In Situ Methods for Li-Ion Battery Research: A Review of Recent Developments. J. Power Sources 2015, 288, 92-105.

(71) Blanc, F.; Leskes, M.; Grey, C. P. In Situ Solid-State NMR Spectroscopy of Electrochemical Cells: Batteries, Supercapacitors, and Fuel Cells. Acc. Chem. Res. 2013, 46, 1952-1963.

(72) Itkis, D.; Velasco-Velez, J.; Knop-Gericke, A.; Vyalikh, A.; Avdeev, M.; Yashina, L. Probing Operating Electrochemical Interfaces by Photons and Neutrons. ChemElectroChem 2015, 2, 1427-1445.

(73) Uthayakumar, S.; Pandiyan, M. S.; Porter, D. G.; Gutmann, M. J.; Fan, R.; Goff, J. P. Crystal Growth and Neutron Diffraction Studies of $\mathrm{Li}_{\mathrm{x}} \mathrm{CoO}_{2}$ Bulk Single Crystals. I. Cryst. Growth 2014, 401, 169-172.

(74) Morcrette, M.; Chabre, Y.; Vaughan, G.; Amatucci, G.; Leriche, J.-B.; Patoux, S.; Masquelier, C.; Tarascon, J.-M. In Situ X-Ray Diffraction Techniques as a Powerful Tool to Study Battery Electrode Materials. Electrochim. Acta 2002, 47, 3137-3149.

(75) Liu, H.; Strobridge, F. C.; Borkiewicz, O. J.; Wiaderek, K. M.; Chapman, K. W.; Chupas, P. J.; Grey, C. P. Capturing Metastable Structures during High-Rate Cycling of $\mathrm{LiFePO}_{4}$ Nanoparticle Electrodes. Science 2014, 344, 1252817.

(76) Senyshyn, A.; Mühlbauer, M. J.; Nikolowski, K.; Pirling, T.; Ehrenberg, H. In-Operando" Neutron Scattering Studies on Li-Ion Batteries. I. Power Sources 2012, 203, 126-129.

(77) Schuster, J.; Köhn, R.; Döblinger, M.; Keilbach, A.; Amenitsch, H.; Bein, T. In Situ SAXS Study on a New Mechanism for Mesostructure Formation of Ordered Mesoporous Carbons: Thermally Induced Self-Assembly. I. Am. Chem. Soc. 2012, 134, 1113611145 .

(78) Li, T.; Senesi, A. J.; Lee, B. Small Angle X-Ray Scattering for Nanoparticle Research. Chem. Rev. 2016, 116, 11128-11180.

(79) Seidlmayer, S.; Hattendorff, J.; Buchberger, I.; Karge, L.; Gasteiger, H. A.; Gilles, R. In Operando Small-Angle Neutron Scattering (SANS) on Li-Ion Batteries. I. Electrochem. Soc. 2015, 162, A3116-A3125.

(80) Day, R. P.; Xia, J.; Petibon, R.; Rucska, J.; Wang, H.; Wright, A. T. B.; Dahn, J. R. Differential Thermal Analysis of Li-Ion Cells as an Effective Probe of Liquid Electrolyte Evolution during Aging. I. Electrochem. Soc. 2015, 162, A2577-A2581.

(81) Balke, N.; Jesse, S.; Morozovska, A. N.; Eliseev, E.; Chung, D. W.; Kim, Y.; Adamczyk, L.; García, R. E.; Dudney, N.; Kalinin, S. V. Nanoscale Mapping of Ion Diffusion in a Lithium-Ion Battery Cathode. Nat. Nanotechnol. 2010, 5, 749-754.

(82) Zheng, H.; Meng, Y. S.; Zhu, Y. Frontiers of In Situ Electron Microscopy. MRS Bull. 2015, 40, 12-18.

(83) Huang, J. Y.; Zhong, L.; Wang, C. M.; Sullivan, J. P.; Xu, W.; Zhang, L. Q.; Mao, S. X.; Hudak, N. S.; Liu, X. H.; Subramanian, A.; Fan, H.; Qi, L.; Kushima, A.; Li, J. In Situ Observation of the Electrochemical Lithiation of a Single $\mathrm{SnO}_{2}$ Nanowire Electrode. Science 2010, 330, 1515-1520.

(84) Wang, Z.; Santhanagopalan, D.; Zhang, W.; Wang, F.; Xin, H. L.; He, K.; Li, J.; Dudney, N.; Meng, Y. S. In Situ STEM-EELS Observation of Nanoscale Interfacial Phenomena in All-Solid-State Batteries. Nano Lett. 2016, 16, 3760-3767.

(85) Inaba, M.; Kawatate, Y.; Funabiki, A.; Jeong, S.-K.; Abe, T.; Ogumi, Z. STM Study on Graphite/Electrolyte Interface in LithiumIon Batteries: Solid Electrolyte Interface Formation in Trifluoropropylene Carbonate Solution. Electrochim. Acta 1999, 45, 99-105.

(86) Paz-Garcia, J. M.; Taiwo, O. O.; Tudisco, E.; Finegan, D. P.; Shearing, P. R.; Brett, D. J. L.; Hall, S. A. 4D Analysis of the Microstructural Evolution of Si-Based Electrodes during Lithiation: Time-Lapse X-Ray Imaging and Digital Volume Correlation. L. Power Sources 2016, 320, 196-203.

(87) Wang, H.; Downing, R. G.; Dura, J. A.; Hussey, D. S. In Situ Neutron Techniques for Studving Lithium Ion Batteries. In Polvmers for Eneroy Storage and Deliverv: Polvelectrolvtes for Batteries and Fuel Cells; American Chemical Society: Washington, DC, 2012; pp 91106.

(88) Finegan, D. P.; Scheel, M.; Robinson, J. B.; Tjaden, B.; Hunt, I.; Mason, T. J.; Millichamp, J.; Di Michiel, M.; Offer, G. J.; Hinds, G.; 
Brett, D. J. L.; Shearing, P. R. In-Operando High-Speed Tomography of Lithium-Ion Batteries during Thermal Runaway. Nat. Commun. 2015, 6, 6924.

(89) Peng, H.-G.; Tyagi, M.; Page, K. A.; Soles, C. L. Inelastic Neutron Scattering on Polymer Electrolytes for Lithium-Ion Batteries. In Polvmers for Energy Storage and Deliverv: Polvelectrolvtes for Batteries and Fuel Cells; American Chemical Society: Washington, DC, 2012; pp $67-90$.

(90) Russina, O.; Triolo, A.; Aihara, Y.; Telling, M. T. F.; Grimm, H. Quasi-Elastic Neutron Scattering Investigation of Dynamics in Polymer Electrolytes. Macromolecules 2004, 37, 8653-8660.

(91) Sugiyama, J.; Nozaki, H.; Umegaki, I.; Mukai, K.; Miwa, K.; Shiraki, S.; Hitosugi, T.; Suter, A.; Prokscha, T.; Salman, Z.; Lord, J. S.; Månsson, M. Li-Ion Diffusion in $\mathrm{Li}_{4} \mathrm{Ti}_{5} \mathrm{O}_{12}$ and $\mathrm{LiTi}_{2} \mathrm{O}_{4}$ Battery Materials Detected by Muon Spin Spectroscopy. Phvs. Rev. B: Condens. Matter Mater. Phvs. 2015, 92, 14417.

(92) Amores, M.; Ashton, T. E.; Baker, P. J.; Cussen, E. J.; Corr, S. A. Fast Microwave-Assisted Synthesis of Li-Stuffed Garnets and Insights into Li Diffusion from Muon Spin Spectroscopy. I. Mater. Chem. A 2016, 4, 1729-1736.

(93) Britto, S.; Leskes, M.; Hua, X.; Hébert, C.-A.; Shin, H. S.; Clarke, S.; Borkiewicz, O.; Chapman, K. W.; Seshadri, R.; Cho, J.; Grey, C. P. Multiple Redox Modes in the Reversible Lithiation of High-Capacity, Peierls-Distorted Vanadium Sulfide. I. Am. Chem. Soc. 2015, 137, 8499-8508.

(94) Luo, K.; Roberts, M. R.; Hao, R.; Guerrini, N.; Pickup, D. M.; Liu, Y.-S.; Edström, K.; Guo, J.; Chadwick, A. V.; Duda, L. C.; Bruce, P. G. Charge-Compensation in 3d-Transition-Metal-Oxide Intercalation Cathodes through the Generation of Localized Electron Holes on Oxygen. Nat. Chem. 2016, 8, 684-691.

(95) Islam, M. S.; Ammundsen, B.; Jones, D. J.; Roziere, J. EXAFS: A Structural Probe for Cathode Materials in Lithium Ion Batteries. In Materials for Lithium-Ion Batteries; Springer: Dordrecht, The Netherlands, 2000; pp 279-292.

(96) Dedryvère, R.; Laruelle, S.; Grugeon, S.; Poizot, P.; Gonbeau, D.; Tarascon, J.-M. Contribution of X-Ray Photoelectron Spectroscopy to the Study of the Electrochemical Reactivity of $\mathrm{CoO}$ toward Lithium. Chem. Mater. 2004, 16, 1056-1061.

(97) Schroder, K.; Alvarado, J.; Yersak, T. A.; Li, J.; Dudney, N.; Webb, L. J.; Meng, Y. S.; Stevenson, K. J. The Effect of Fluoroethylene Carbonate as an Additive on the Solid Electrolyte Interphase on Silicon Lithium-Ion Electrodes. Chem. Mater. 2015, 27, 5531-5542.

(98) Téllez, H.; Aguadero, A.; Druce, J.; Burriel, M.; Fearn, S.; Ishihara, T.; McPhail, D. S.; Kilner, J. A. New Perspectives in the Surface Analysis of Energy Materials by Combined Time-of-Flight Secondary Ion Mass Spectrometry (ToF-SIMS) and High Sensitivity Low-Energy Ion Scattering (HS-LEIS). I. Anal. At. Spectrom. 2014, 29, 1361-1370.

(99) Kitta, M.; Matsuda, T.; Maeda, Y.; Akita, T.; Tanaka, S.; Kido, Y.; Kohyama, M. Atomistic Structure of a Spinel $\mathrm{Li}_{4} \mathrm{Ti}_{5} \mathrm{O}_{12}(111)$ Surface Elucidated by Scanning Tunneling Microscopy and Medium Energy Ion Scattering Spectrometry. Surf. Sci. 2014, 619, 5-9.

(100) Akita, T.; Taguchi, N. Practical Analysis of Li Distribution by EELS. Surf. Interface Anal. 2016, 48, 1226.

(101) Mauchamp, V.; Boucher, F.; Moreau, P. Electron Energy-Loss Spectroscopy in the Low-Loss Region as a Characterization Tool of Electrode Materials. Ionics 2008, 14, 191-195.

(102) Danet, J.; Brousse, T.; Rasim, K.; Guyomard, D.; Moreau, P. Valence Electron Energy-Loss Spectroscopy of Silicon Negative Electrodes for Lithium Batteries. Phvs. Chem. Chem. Phvs. 2010, 12, 220-226.

(103) Vidal-Abarca, C.; Lavela, P.; Tirado, J. L. The Origin of Capacity Fading in $\mathrm{NiFe}_{2} \mathrm{O}_{4}$ Conversion Electrodes for Lithium Ion Batteries Unfolded by ${ }^{57} \mathrm{Fe}$ Mössbauer Spectroscopy. I. Phvs. Chem. C 2010, 114, 12828-12832.

(104) Sathiya, M.; Leriche, J.-B.; Salager, E.; Gourier, D.; Tarascon, J.-M.; Vezin, H. Electron Paramagnetic Resonance Imaging for RealTime Monitoring of Li-Ion Batteries. Nat. Commun. 2015, 6, 6276.
(105) Chandrashekar, S.; Trease, N. M.; Chang, H. J.; Du, L.-S.; Grey, C. P.; Jerschow, A. ${ }^{7} \mathrm{Li}$ MRI of Li Batteries Reveals Location of Microstructural Lithium. Nat. Mater. 2012, 11, 311-315.

(106) Wu, H.-L.; Huff, L. A.; Esbenshade, J. L.; Gewirth, A. A. In Situ EQCM Study Examining Irreversible Changes the Sulfur-Carbon Cathode in Lithium-Sulfur Batteries. ACS Appl. Mater. Interfaces 2015, 7, 20820-20828.

(107) Sharon, D.; Etacheri, V.; Garsuch, A.; Afri, M.; Frimer, A. A.; Aurbach, D. On the Challenge of Electrolyte Solutions for Li-Air Batteries: Monitoring Oxygen Reduction and Related Reactions in Polyether Solutions by Spectroscopy and EQCM. I.Phys. Chem. Lett. 2013, 4, 127-131.

(108) Chung, S.-Y.; Bloking, J. T.; Chiang, Y.-M. Electronically Conductive Phospho-Olivines as Lithium Storage Electrodes. Nat. Mater. 2002, 1, 123-128.

(109) Hardwick, L. J.; Holzapfel, M.; Wokaun, A.; Novák, P. Raman Study of Lithium Coordination in EMI-TFSI Additive Systems as Lithium-Ion Battery Ionic Liquid Electrolytes. I. Raman Spectrosc. 2007, 38, 110-112.

(110) Chakrabarti, S.; Thakur, A. K.; Biswas, K. Raman and FTIR Spectroscopy Study of $\mathrm{LiFeTiO}_{4}$ and $\mathrm{Li}_{2} \mathrm{FeTiO}_{4}$. Ionics 2016, 22, 2045-2057.

(111) Wang, B.; Bates, J. B.; Hart, F. X.; Sales, B. C.; Zuhr, R. A.; Robertson, J. D. Characterization of Thin-Film Rechargeable Lithium Batteries with Lithium Cobalt Oxide Cathodes. I. Electrochem. Soc. 1996, 143, 3203-3213.

(112) Berg, H. Batteries for Electric Vehicles Materials and Electrochemistry; Cambridge University Press: Cambridge, England, 2015.

(113) Berndt, D. Maintenance-Free Batteries; Wiley: New York, 1997.

(114) Armstrong, A. R.; Armstrong, G.; Canales, J.; Bruce, P. G. $\mathrm{TiO}_{2}$-B Nanowires. Angew. Chem. Int. Ed. 2004, 43, 2286-2288.

(115) Dalton, A. S.; Belak, A. A.; Van der Ven, A. Van der. Thermodynamics of Lithium in $\mathrm{TiO}_{2}(\mathrm{~B})$ from First Principles. Chem. Mater. 2012, 24, 1568-1574.

(116) Delacourt, C.; Poizot, P.; Tarascon, J.-M.; Masquelier, C. The Existence of a Temperature-Driven Solid Solution in $\mathrm{Li}_{\mathrm{x}} \mathrm{FePO}_{4}$ for $0 \leq$ $x \leq 1$. Nat. Mater. 2005, 4, 254-260.

(117) Zhang, X.; van Hulzen, M.; Singh, D.; Brownrigg, A.; Wright, J.; van Dijk, N.; Wagemaker, M. Rate-Induced Solubility and Suppression of the First-Order Phase Transition in Olivine $\mathrm{LiFePO}_{4}$. Nano Lett. 2014, 14, 2279-2285.

(118) Strobridge, F. C.; Liu, H.; Leskes, M.; Borkiewicz, O. J.; Wiaderek, K. M.; Chupas, P. J.; Chapman, K. W.; Grey, C. P. Unraveling the Complex Delithiation Mechanisms of Olivine-Type Cathode Materials, $\mathrm{LiFe}_{\mathrm{x}} \mathrm{Co}_{1-\mathrm{x}} \mathrm{PO}_{4}$. Chem. Mater. 2016, 28, 36763690.

(119) Malik, R.; Zhou, F.; Ceder, G. Kinetics of Non-Equilibrium Lithium Incorporation in $\mathrm{LiFePO}_{4}$. Nat. Mater. 2011, 10, 587-590.

(120) Tang, M.; Carter, W. C.; Chiang, Y.-M. Electrochemically Driven Phase Transitions in Insertion Electrodes for Lithium-Ion Batteries: Examples in Lithium Metal Phosphate Olivines. Annu. Rev. Mater. Res. 2010, 40, 501-529.

(121) Hu, Y.-Y.; Liu, Z.; Nam, K.-W.; Borkiewicz, O. J.; Cheng, J.; Hua, X.; Dunstan, M. T.; Yu, X.; Wiaderek, K. M.; Du, L.-S.; Chapman, K. W.; Chupas, P. J.; Yang, X.-Q.; Grey, C. P. Origin of Additional Capacities in Metal Oxide Lithium-Ion Battery Electrodes. Nat. Mater. 2013, 12, 1130-1136.

(122) Laws, D.; Bitter, H.-M.; Jerschow, A. Solid-State NMR Spectroscopic Methods in Chemistry. Angew. Chem. Int. Ed. 2002, 41, 3096-3129.

(123) Levitt, M. H. The Signs of Frequencies and Phases in NMR. I. Magn. Reson. 1997, 126, 164-182.

(124) Apperley, D. C.; Harris, R. K.; Hodgkinson, P. Solid-State NMR: Basic Principles \& Practice; Momentum Press, LLC: New York, 2012.

(125) Levitt, M. H. Spin Dynamics - Basics of Nuclear Magnetic Resonance; John Wiley \& Sons, Ltd.: Chichester, England, 2008; free download at http://www.southampton.ac.uk/ mhl/publications/ books/SpinDynamics/SD1/index.html. 
(126) Haarmann, F. Ouadrupolar NMR of Intermetallic Compounds: Harris, R. K., Wasylishen, R. E., Eds.; John Wiley \& Sons, Ltd: Chichester, England, 2011.

(127) Knight, W. D.; Kobayashi, S.-I. Knight Shift. In Enzyclopedia of Magnetic Resonance; Harris, R. K., Wasylishen, R. E., Eds.; John Wiley: Chichester, England.

(128) Grey, C. P.; Dupré, N. NMR Studies of Cathode Materials for Lithium-Ion Rechargeable Batteries. Chem. Rev. 2004, 104, 44934512.

(129) Man, P. P. Quadrupolar Interactions. In Enzyclopedia of Magnetic Resonance; Harris, R. K., Wasylishen, R. E., Eds.; John Wiley: Chichester, England.

(130) Ashbrook, S.-E.; Wimperis, S. Quadrupolar Coupling: An Introduction and Crystallographic Aspects. In Enzyclopedia of Magnetic Resonance; Harris, R. K., Wasylishen, R. E., Eds.; John Wiley: Chichester, England.

(131) Vega, A. J. Quadrupolar Nuclei in Solids. In Enzyclopedia of Magnetic Resonance; Harris, R. K., Wasylishen, R. E., Eds.; John Wiley: Chichester, England.

(132) Bräuniger, T.; Jansen, M. Solid-State NMR Spectroscopy of Quadrupolar Nuclei in Inorganic Chemistry. Z. Anorg. Allg. Chem. 2013, 639, 857-879.

(133) Schurko, R. W. Acquisition of Wideline Solid-State NMR Spectra of Quadrupolar Nuclei. In eMagRes.; Harris, R. K., Wasylishen, R. E., Eds.; John Wiley \& Sons, Ltd: Chichester, England, 2011.

(134) Schurko, R. W. Ultra-Wideline Solid-State NMR Spectroscopy. Acc. Chem. Res. 2013, 46, 1985-1995.

(135) Pell, A. J.; Pintacuda, G. Broadband Solid-State MAS NMR of Paramagnetic Systems. Prog. Nucl. Magn. Reson. Spectrosc. 2015, 84, $33-72$.

(136) Clément, R. J.; Pell, A. J.; Middlemiss, D. S.; Strobridge, F. C.; Miller, J. K.; Whittingham, M. S.; Emsley, L.; Grey, C. P.; Pintacuda, G. Spin-Transfer Pathways in Paramagnetic Lithium Transition-Metal Phosphates from Combined Broadband Isotropic Solid-State MAS NMR Spectroscopy and DFT Calculations. I. Am. Chem. Soc. 2012, 134, 17178-17185.

(137) Pecher, O.; Bayley, P. M.; Liu, H.; Liu, Z.; Trease, N. M.; Grey, C. P. Automatic Tuning Matching Cycler (ATMC) In Situ NMR Spectroscopy as a Novel Approach for Real-Time Investigations of Liand Na-Ion Batteries. I. Magn. Reson. 2016, 265, 200-209.

(138) Trease, N. M.; Zhou, L.; Chang, H. J.; Zhu, B. Y.; Grey, C. P. In Situ NMR of Lithium Ion Batteries: Bulk Susceptibility Effects and Practical Considerations. Solid State Nucl. Magn. Reson. 2012, 42, 6270 .

(139) Zhou, L.; Leskes, M.; Ilott, A. J.; Trease, N. M.; Grey, C. P. Paramagnetic Electrodes and Bulk Magnetic Susceptibility Effects in the In Situ NMR Studies of Batteries: Application to $\mathrm{Li}_{1.08} \mathrm{Mn}_{1.92} \mathrm{O}_{4}$ Spinels. I. Magn. Reson. 2013, 234, 44-57.

(140) Chang, H. J.; Trease, N. M.; Ilott, A. J.; Zeng, D.; Du, L.-S.; Jerschow, A.; Grey, C. P. Investigating Li Microstructure Formation on Li Anodes for Lithium Batteries by In Situ ${ }^{6} \mathrm{Li} /{ }^{7} \mathrm{Li}$ NMR and SEM. I. Phvs. Chem. C 2015, 119, 16443-16451.

(141) Deng, Y.; Eames, C.; Chotard, J.-N.; Lalère, F.; Seznec, V.; Emge, S.; Pecher, O.; Grey, C. P.; Masquelier, C.; Islam, M. S. Structural and Mechanistic Insights into Fast Lithium-Ion Conduction

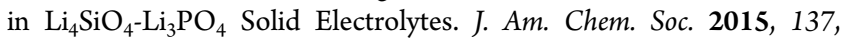
9136-9145.

(142) Kuhn, A.; Dupke, S.; Kunze, M.; Puravankara, S.; Langer, T.; Winter, M.; Eckert, H.; Heitjans, P. Insight into the Li Ion Dynamics in $\mathrm{Li}_{12} \mathrm{Si}_{7}$ : Combining Field Gradient Nuclear Magnetic Resonance, One- and Two-Dimensional Magic- Angle Spinning Nuclear Magnetic Resonance, and Nuclear Magnetic Resonance Relaxometry. I. Phvs. Chem. C 2014, 118, 28350-28360.

(143) Indris, S.; Heitjans, P.; Uecker, R.; Roling, B. Li Ion Dynamics in a $\mathrm{LiAlO}_{2}$ Single Crystal Studied by Li NMR Spectroscopy and Conductivity Measurements. I. Phys. Chem. C 2012, 116, 1424314247.
(144) Dunstan, M. T.; Griffin, J. M.; Blanc, F.; Leskes, M.; Grey, C. P. Ion Dynamics in $\mathrm{Li}_{2} \mathrm{CO}_{3}$ Studied by Solid-State NMR and FirstPrinciples Calculations. I. Phvs. Chem. C 2015, 119, 24255-24264.

(145) Harris, R. K.; Becker, E. D.; De Cabral Menezes, S. M.; Granger, P.; Hoffman, R. E.; Zilm, K. W. Further Conventions for NMR Shielding and Chemical Shifts (IUPAC Recommendations 2008). Magn. Reson. Chem. 2008, 46, 582-598.

(146) Harris, R. K.; Becker, E. D.; Cabral de Menezes, S. M.; Goodfellow, R.; Granger, P. NMR Nomenclature: Nuclear Spin Properties and Conventions for Chemical Shifts. IUPAC Recommendations 2001. International Union of Pure and Applied Chemistry. Physical Chemistry Division. Commission on Molecular Structure and Spectroscopy. Magn. Reson. Chem. 2002, 40, 489-505.

(147) Gerald, R. E.; Klingler, R. J.; Sandi, G.; Johnson, C. S.; Scanlon, L. G.; Rathke, J. W. ${ }^{7} \mathrm{Li}$ NMR Study of Intercalated Lithium in Curved Carbon Lattices. I. Power Sources 2000, 89, 237-243.

(148) Gerald, R. E.; Sanchez, J.; Johnson, C. S.; Klingler, R. J.; Rathke, J. W. In Situ Nuclear Magnetic Resonance Investigations of Lithium Ions in Carbon Electrode Materials Using a Novel Detector. $I$. Phvs.: Condens. Matter 2001, 13, 8269-8285.

(149) Rathke, J. W.; Klingler, R. J.; Gerald, R. E.; Kramarz, K. W.; Woelk, K. Toroids in NMR Spectroscopy. Prog. Nucl. Magn. Reson. Spectrosc. 1997, 30, 209-253.

(150) Tarascon, J. M.; Gozdz, A. S.; Schmutz, C.; Shokoohi, F.; Warren, P. C. Performance of Bellcore's Plastic Rechargeable Li-Ion Batteries. Solid State Ionics 1996, 86-88, 49-54.

(151) Letellier, M.; Chevallier, F.; Clinard, C.; Frackowiak, E.; Rouzaud, J.-N.; Béguin, F.; Morcrette, M.; Tarascon, J.-M. The First In Situ ${ }^{7} \mathrm{Li}$ Nuclear Magnetic Resonance Study of Lithium Insertion in Hard-Carbon Anode Materials for Li-Ion Batteries. I. Chem. Phys. 2003, 118, 6038-6045.

(152) Chevallier, F.; Letellier, M.; Morcrette, M.; Tarascon, J.-M.; Frackowiak, E.; Rouzaud, J.-N.; Béguin, F. In Situ ${ }^{7}$ Li-Nuclear Magnetic Resonance Observation of Reversible Lithium Insertion into Disordered Carbons. Electrochem. Solid-State Lett. 2003, 6, A225A228.

(153) Letellier, M.; Chevallier, F.; Béguin, F.; Frackowiak, E.; Rouzaud, J. N. The First In Situ ${ }^{7} \mathrm{Li}$ NMR Study of the Reversible Lithium Insertion Mechanism in Disorganised Carbons. I. Phvs. Chem. Solids 2004, 65, 245-251.

(154) Letellier, M.; Chevallier, F.; Béguin, F. In Situ ${ }^{7}$ Li NMR during Lithium Electrochemical Insertion into Graphite and a Carbon/ Carbon Composite. I. Phvs. Chem. Solids 2006, 67, 1228-1232.

(155) Letellier, M.; Chevallier, F.; Morcrette, M. In Situ ${ }^{7}$ Li Nuclear Magnetic Resonance Observation of the Electrochemical Intercalation of Lithium in Graphite; 1st Cycle. Carbon 2007, 45, 1025-1034.

(156) Arai, J.; Okada, Y.; Sugiyama, T.; Izuka, M.; Gotoh, K.; Takeda, K. In Situ Solid State ${ }^{7} \mathrm{Li}$ NMR Observations of Lithium Metal Deposition during Overcharge in Lithium Ion Batteries. L. Electrochem. Soc. 2015, 162, A952-A958.

(157) Poli, F.; Kshetrimayum, J. S.; Monconduit, L.; Letellier, M. New Cell Design for In-Situ NMR Studies of Lithium-Ion Batteries. Electrochem. Commun. 2011, 13, 1293-1295.

(158) Bayley, P. M.; Trease, N. M.; Grey, C. P. Insights into Electrochemical Sodium Metal Deposition as Probed with In Situ ${ }^{23} \mathrm{Na}$ NMR. I. Am. Chem. Soc. 2016, 138, 1955-1961.

(159) Liu, Z.; Hu, Y.-Y.; Dunstan, M. T.; Huo, H.; Hao, X.; Zou, H.; Zhong, G.; Yang, Y.; Grey, C. P. Local Structure and Dynamics in the $\mathrm{Na}$ Ion Battery Positive Electrode Material $\mathrm{Na}_{3} \mathrm{~V}_{2}\left(\mathrm{PO}_{4}\right)_{2} \mathrm{~F}_{3}$. Chem. Mater. 2014, 26, 2513-2521.

(160) Broux, T.; Bamine, T.; Fauth, F.; Simonelli, L.; Olszewski, W.; Marini, C.; Ménétrier, M.; Carlier, D.; Masquelier, C.; Croguennec, L. Strong Impact of the Oxygen Content in $\mathrm{Na}_{2} \mathrm{~V}_{2}\left(\mathrm{PO}_{4}\right)_{2} \mathrm{~F}_{2}, \mathrm{O}_{4}(0<v$ $\leq 0.5)$ on Their Structural and Electrochemical Properties. Chem. Mater. 2016, in press, DOI: 10.1021/acs.chemmater.6b02659.

(161) Bhattacharyya, R.; Key, B.; Chen, H.; Best, A. S.; Hollenkamp, A. F.; Grey, C. P. In Situ NMR Observation of the Formation of Metallic Lithium Microstructures in Lithium Batteries. Nat. Mater. 2010, 9, 504-510. 
(162) Leskes, M.; Drewett, N. E.; Hardwick, L. J.; Bruce, P. G.; Goward, G. R.; Grey, C. P. Direct Detection of Discharge Products in Lithium-Oxygen Batteries by Solid-State NMR Spectroscopy. Angew. Chem. Int. Ed. 2012, 51, 8560-8563.

(163) Leskes, M.; Moore, A. J.; Goward, G. R.; Grey, C. P. Monitoring the Electrochemical Processes in the Lithium-Air Battery by Solid State NMR Spectroscopy. L. Phvs. Chem. C 2013, 117, 26929-26939.

(164) Harris, R. K.; Becker, E. D. NMR Nomenclature: Nuclear Spin Properties and Conventions for Chemical Shifts-IUPAC Recommendations. J. Magn. Reson. 2002, 156, 323-326.

(165) Pecher, O.; Vyalikh, A.; Grey, C. P. Challenges and New Opportunities of In Situ NMR Characterization of Electrochemical Processes. AIP Conf. Proc. 2015, 1765, 020011.

(166) Stratford, J. M.; Allan, P. K.; Pecher, O.; Chater, P. A.; Grey, C. P. Mechanistic Insights into Sodium Storage in Hard Carbon Anodes Using Local Structure Probes. Chem. Commun. 2016, 52, 1243012433.

(167) Zhou, L.; Leskes, M.; Liu, T.; Grey, C. P. Probing Dynamic Processes in Lithium-Ion Batteries by In Situ NMR Spectroscopy: Application to $\mathrm{Li}_{1.08} \mathrm{Mn}_{1.92} \mathrm{O}_{4}$ Electrodes. Angew. Chem. Int. Ed. 2015, $54,14782-14786$. 